Jihane Romanos

\title{
ESTUDO DE MUTAÇÕES DO GENE OTOF EM PACIENTES COM DEFICIÊNCIA AUDITIVA E SUA RELAÇÃO COM A NEUROPATIA AUDITIVA
}




\section{Jihane Romanos}

\section{ESTUDO DE MUTAÇÕES DO GENE OTOF EM PACIENTES COM DEFICIÊNCIA AUDITIVA E SUA RELAÇÃO COM A NEUROPATIA AUDITIVA}

Dissertação apresentada ao Instituto de Biociências da Universidade de São Paulo para obtenção de Título de Mestre em Ciências na Área de Biologia/Genética.

Orientador: Profa. Dra. Regina Célia Mingroni Netto 


\section{Romanos, J.}

ESTUDO DE MUTAÇÕES DO GENE OTOF EM PACIENTES COM DEFICIÊNCIA AUDITIVA E SUA RELAÇÃO COM A NEUROPATIA AUDITIVA 98p.

Dissertação de Mestrado - Instituto de Biociências da Universidade de São Paulo. Departamento de Genética e Biologia Evolutiva.

1. Deficiência auditiva,

2. Neuropatia auditiva,

3. Gene OTOF.

Comissão Julgadora:

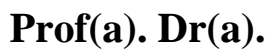

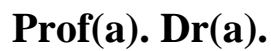

Profa. Dra. Regina Célia Mingroni Netto

Orientadora 
Aos meus pais, Joseph e Gracia. 
Quando o vosso amigo fala livremente, vós não receais o "não", nem retendes o "não".

E quando ele está calado o vosso coração não deixa de ouvir o coração dele; Pois na amizade, todos os pensamentos, todos os desejos, todas as esperanças nascem e são partilhadas sem palavras, com alegria. Quando vos separais de um amigo não fiqueis em dor, pois aquilo que mais nele tornar-se-á mais claro com a sua ausência, tal como a montanha, para quem a escala, é mais nítida vista da planície.

Gibran Khalil Gibran 


\section{AGRADECIMENTOS}

À minha orientadora Regina Célia Mingroni Netto, por viabilizar o sonho de realizar pesquisa em genética humana, bem como pela dedicação com que orientou esse trabalho.

Aos pacientes e familiares, sem os quais esse trabalho não poderia ser realizado.

Ao Dr. Alfredo Tabith Júnior, por ter permitido que parte da pesquisa se desenvolvesse na DERDIC (Divisão de Educação e Reabilitação de Distúrbios da Comunicação da Pontifícia Universidade Católica de São Paulo).

Às médicas, Dra. Mariana Lopes Fávero e Dra. Sulene Pirana, pelo auxílio nas análises dos exames audiológicos e a todos os profissionais da DERDIC. Agradecemos também ao Dr. Décio Brunoni pelo encaminhamento de pacientes.

Ao Dr. Ignácio del Castillo e Dra. Montserrat Rodríguez-Ballesteros da Unidad de Genética Molecular, Hospital Ramon y Cajal, Madrid, Espanha, por terem me recebido em visita ao seu laboratório, pelas sugestões e trocas de informações.

Ao Departamento de Genética e Biologia Evolutiva do IB-USP, pelo uso das dependências.

À Dra. Angela M.V. Morgante, Dra. Luciana Amaral Haddad, Dra Carla Rosenberg e Dr. Paulo Otto pelo apoio e sugestões.

Ao Dr. Peter Pearson, pela revisão do "abstract".

Aos amigos, Ronaldo, Karina e Ana Carla, cujo apoio intelectual e científico foi essencial para a concretização desse projeto.

Aos colegas de bancada e parceiros nos sucessos e insucessos da pesquisa: Claudia, Daniel, e principalmente Lílian, a nossa animadora, sem esquecer também da amiga Teresa, pela ajuda laboratorial e pessoal.

Aos amigos Jacaré, Rafaella, Luis, Nathália, Larissa, Ana Cristina, Silvia, Maraísa, Fátima, Paulo, Mara, Lígia, Andréa Manchester, Juliana, Vivi, Simone, Fernando, Andréa, Samaris, Beto, Raquel, Joana e Ana Maria, pela alegria, amizade e companhia de todos os momentos.

À amiga Eliete, pela amizade, longas conversas e conselhos. 
À minha irmã adotiva Carola, pela ótima convivência, incluindo vários finais de semana no laboratório.

À estagiária e grande amiga Fernanda pelo auxílio no laboratório e pela sua amizade sempre presente, sem esquecer da nossa pequena Sofia.

Aos meus amigos, André, Georges e Rita, por terem sido meu apoio nos momentos mais difíceis, em especial ao Helvio, pelo companheirismo e grande ajuda para finalizar esse trabalho.

Às minhas amigas de infância, Cherine e Leah, que sempre estão presentes na minha vida, e que me incentivaram e me apoiaram a viajar e realizar meu sonho.

Aos meus familiares, tio Johad, tia Nair, Jany, Jorge e Alexandre, pela acolhida. Além, é claro, do primo Lucas, por ser um irmão que nunca tive e que me ajudou muito nessa grande cidade.

Às minhas irmãs, Julie e Kristy, pelo carinho, apoio e incentivo, mesmo à distância.

Aos meus pais, Joseph e Gracia, meus maiores exemplos e incentivadores de dedicação e pelo amor e segurança, nos quais sempre pude me apoiar durante toda esta jornada.

À FAPESP, pelo auxílio financeiro.

Ao CNPq, pela bolsa de mestrado.

À CAPES, pela bolsa emergencial. 


\section{ÍNDICE GERAL}

RESUMO 1

ABSTRACT 3

I. INTRODUÇÃO 6

I.1. A deficiência auditiva 6

I.2. Surdez hereditária não-sindrômica 8

I.2. Fisiologia da audição 12

$\begin{array}{ll}\text { I.3. Exames clínicos para estudar a deficiência auditiva } & 18\end{array}$

$\begin{array}{ll}\text { I.4. Neuropatia Auditiva } & 20\end{array}$

I.5. Genética da Neuropatia Auditiva 22

I.5.1. Neuropatia auditiva com herança autossômica dominante:

O loco AUNA1 23

I.5.2. Neuropatia auditiva com herança recessiva ligada ao cromossomo $\mathrm{X}$ :

O loco AUNX1 23

I.5.3. Neuropatia auditiva com herança mitocondrial 23

I.5.4. Neuropatia auditiva com herança autossômica recessiva 24

$\begin{array}{ll}\text { I.5.4.a. O gene OTOF } & 24\end{array}$

I.5.4.b. Neuropatia auditiva ou patologia endococlear? 30

$\begin{array}{ll}\text { I.5.4.c. O gene DFNB59 (PJVK) } & 30\end{array}$

II. OBJETIVOS 33

III. CASUÍSTICA E MÉTODOS 35

III.1. Casuística 35

III.2. Métodos 37

III.2.1. Extração de DNA e estimativa de concentração 37

III.2.2. Triagem da mutação Q829X no exon 22 do gene OTOF 37

III.2.3. Análise de microssatélites $\quad 39$

III.2.4. Pesquisa de outras mutações no gene OTOF por SSCP 39

III.2. 5. Seqüenciamento do gene OTOF 41

III.2.6. Clonagem 43

III.2.7. Programas computacionais utilizados para avaliação do efeito das mutações 43

III.2.8. Estudos Complementares $\quad 43$

IV. RESULTADOS E DISCUSSÃO 46

IV.1. Triagem da mutação Q829X no exon 22 do gene OTOF 46 
IV.2. Análise de microssatélites

IV.3. Análise de SSCP seguida de seqüenciamento dos exons com alteração

IV.4. Seqüenciamento completo do gene $O T O F$

IV.4.1. Discussão do significado das alterações identificadas

IV.4.2. Conclusões do estudo das famílias selecionadas para seqüenciamento completo do gene $O T O F$

IV.4.2.a. Família 1 56

IV.4.2.b. Família 6 57

IV.4.2.c. Família 20 58

IV.4.2.d. Família 26 59

IV.4.2.e. Família 39 60

IV.4.2.f. Família 52 61

IV.4.2.g. Família 63 62

V. CONCLUSÕES 65

\section{REFERÊNCIAS BIBLIGRÁFICAS} 67

VIII.ANEXOS 78

Anexo I. Ficha de anamnese genético clínica 78

Anexo II. Heredogramas das 64 famílias selecionadas 82 


\section{ÍNDICE DE FIGURAS}

Figura 1. Esquema representando o aparelho auditivo humano. 12

$\begin{array}{ll}\text { Figura 2. Detalhe da orelha média e da orelha interna. } & 13\end{array}$

$\begin{array}{lll}\text { Figura 3. Secção transversal de um dos giros da cóclea, mostrando sua } & 14\end{array}$ divisão em três compartimentos longitudinais.

Figura 4. Secção do órgão de Corti mostrando as células ciliadas internas e 15 as células ciliadas externas.

$\begin{array}{lll}\text { Figura 5. Esquema representando a cóclea e as vias auditivas centrais. } & 17\end{array}$

Figura 6. Resultado da audiometria de paciente com perda auditiva 18 moderada.

Figura 7. Resultado de um teste de BERA. 19

Figura 8. O teste das EOAs e os registros de um indivíduo com audição 20 normal.

Figura 9. Comparação entre a otoferlina humana, a mioferlina, a disferlina 25 e proteína fer-1 descrita em C.elegans.

Figura 10. Esquema representativo dos introns e exons do gene OTOF mostrando os diferentes padrões de splicing alternativo nessas regiões.

Figura 11. Exemplo de resultado da digestão com a enzima de restrição $B f a I$ dos produtos amplificados do exon 22 do gene $O T O F$.

Figura 12. Gráficos indicando os picos de fluorescência dos alelos de microssatélites.

Figura 13. Resultado do seqüenciamento apresentando a mutação 2905-2923 58 del19ins11.

Figura 14. Resultado do seqüenciamento apresentando a mutação 15521567del16.

Figura 15. Resultado do seqüenciamento apresentando a mutação $3400 \mathrm{C}>\mathrm{T} . \quad 60$

Figura 16. Resultado do seqüenciamento apresentando a mutação 2348delG. 61

Figura 17. Resultado do seqüenciamento apresentando a mutação 5431A>T. 62 


\section{ÍNDICE DE TABELAS}

Tabela I. Locos responsáveis por surdez hereditária não-sindrômica autossômica recessiva.

Tabela II. Famílias já descritas com mutações patogênicas no gene 29 OTOF (DFNB9).

Tabela III. Primers utilizados na amplificação dos exons 5, 15, 16, 19, 40 22, 36, 37 e 48.

Tabela IV. Primers utilizados na amplificação dos demais exons do 42 gene $O T O F$.

Tabela V. Mutações encontradas nos exons dos pacientes que 47 mostraram alteração no SSCP.

$\begin{array}{llllllllll}\text { Tabela VI. } & \text { Resultado do } & \text { seqüenciamento dos } & 48 & \text { exons } & \text { em } & 18 & 51\end{array}$ propósitos.

Tabela VII. Resumo das variantes exônicas identificadas pelo 52 sequienciamento completo do gene $O T O F$ e pela análise de SSCP seguida de sequenciamento.

Tabela VIII. Resumo das variantes intrônicas identificadas pelo seqüenciamento completo do gene OTOF e pela análise de SSCP seguida de sequenciamento.

Tabela IX. Resumo dos resultados das análises do PolyPhen, Blast, ProDom e das características dos aminoácidos envolvidos nas onze não-sinônimas mutações não descritas. 


\section{RESUMO}

A herança autossômica recessiva pode ser responsável por aproximadamente $77 \%$ dos casos de surdez hereditária. Em 1996, Chaib e col. mapearam o loco responsável por surdez profunda neurossensorial de herança recessiva na região cromossômica 2p22-23 (DFNB9). Em 1999, Yasunaga e col. identificaram esse gene como o que codifica a proteína otoferlina $(O T O F)$ nessa região. Até hoje, já foram descritas 31 mutações patogênicas diferentes no gene $O T O F$ em populações de várias origens, com destaque a mutação Q829X que foi encontrada em $\sim 3 \%$ dos casos de surdez na Espanha (Migliosi e col., 2002; Rodríguez-Ballesteros e col., 2003).

Alguns pacientes com mutações no gene OTOF apresentavam neuropatia auditiva, um tipo de deficiência auditiva neurossensorial caracterizada pela ausência ou anomalia das ondas no exame dos Potenciais Evocados Auditivos do Tronco Encefálico ou BERA com a presença das emissões otoacústicas e/ou microfonismo coclear.

O objetivo desse projeto foi investigar a contribuição relativa das mutações no gene $O T O F$ ao casos de neuropatia auditiva e de outros tipos surdez em famílias brasileiras.

Uma amostra de 343 propósitos portadores de deficiência auditiva foi submetida ao estudo da mutação Q829X. Não foi identificada em nenhum caso. Dessa casuística foram selecionados 48 propósitos de famílias com consangüinidade ou com 2 ou mais afetados na irmandade e quatro pacientes com neuropatia auditiva e com consangüinidade parental ou com dois ou mais afetados na irmandade. Além disso, foram também selecionados 7 casos isolados com neuropatia auditiva e 5 casos de portadores de alterações no tronco encefálico. Essa amostra totalizou 64 propósitos.

Propósitos dessas 64 famílias foram genotipados em relação a cinco marcadores de microssatélites ligados ao gene $O T O F$. A análise dos haplótipos excluiu ligação ao gene $O T O F$ em 34 casos, 19 não eram conclusivos e 11 indicaram possibilidade de ligação ao gene $O T O F$ (incluindo uma família com pais consangüíneos e neuropatia auditiva e três propósitos com neuropatia auditiva).

Simultaneamente, os 64 propósitos foram triados para mutações em oito exons do gene $O T O F$, nos quais mutações já haviam sido descritas, por meio de SSCP seguido de seqüenciamento. 
Os 11 casos com resultados compatíveis com ligação ao gene OTOF (4 com neuropatia auditiva) e os sete casos de neuropatia auditiva foram selecionados para o seqüenciamento de todos os exons (total de 18 propósitos).

Identificamos no total 58 alterações diferentes. Onze variantes eram potencialmentes patogênicas, encontradas em sete dos propósitos, todos pertencentes ao grupo dos 18 selecionados. Quatro casos eram heterozigotos compostos [98G>A (R33Q) e 2401G $>$ T e 2402A $>$ T (E801L)]; [1841G $>$ A (G614E) e 3239G $>C$ (R1080P)], [3751T > G (C1251G) e 5431A>T (K1811X)] e [2348delG (G783fs) e 5800-5801insC (L1934fs)], dois eram heterozigotos [1552-1567del16 (R518fs); 29052923del19ins11 (A969fs)] sem que uma segunda mutação fosse detectada e um apresentava a mutação em homozigose [3400C>T (R1134X)]. Desses sete propósitos com mutações patogênicas, somente um paciente com mutação em heterozigose não apresentava neuropatia auditiva.

Dentre os 11 casos com neuropatia auditiva, seis tinham pelo menos uma mutação no gene $O T O F$ que poderia ser a causa de surdez. Esse achado reforça a associação entre o fenótipo da neuropatia auditiva e mutações no gene OTOF.

A variante Q829X não foi encontrada nenhuma vez em nossa amostra, portanto, não deve ser causa importante de surdez na nossa população. Porém, nosso estudo mostra que mutações no gene $O T O F$ são causas freqüentes de neuropatia auditiva no Brasil (mais de $50 \%$ dos casos).

Nossos resultados reforçam a hipótese que pacientes com neuropatia auditiva devem ser selecionados para pesquisa de mutações no gene OTOF e que talvez mais de $50 \%$ dos casos de neuropatia auditiva tenham causa genética. 


\begin{abstract}
$77 \%$ of nonsyndromic prelingual deafness have an autosomal recessive inheritance. In 1996, Chaib et al. mapped a locus associated with sensorineural nonsyndromic recessive deafness to chromosome region 2p22-23 (DFNB9) by linkage studies. In 1999, Yasunaga et al. identified the OTOF gene encoding otoferlin, in this region. To date, there are 31 different pathogenic mutations described in the OTOF gene, from populations of variable origins. A Q829X mutation was found at a frequency of $\sim 3 \%$ of deafness in Spain (Migliosi e col., 2002; Rodríguez-Ballesteros e col., 2003).

Some affected individuals with mutations in the $O T O F$ gene were reported to present auditory neuropathy, a type of deafness characterized by an absent or severely abnormal auditory brainstem response, with preservation of otoacoustic emissions and/or cochlear microphonics.

The main purpose of this project was to investigate the relative contribution of OTOF mutations to auditory neuropathy and other type of deafness, amongst Brazilian families.

We enrolled 343 Brazilian unrelated subjects with nonsyndromic hearing loss. A specific test for the Q829X mutation was performed first. We failed to find any subjects carrying this mutation. From this group, we selected 48 probands from families with consanguinity or with two or more affected sibs and four probands with diagnosis of auditory neuropathy and from consanguineous unions or with two or more affected sibs. In addition, we selected 7 isolated subjects with auditory neuropathy and 5 cases with diagnosis of brainstem alteration. This gave a total of 64 probands.

Subjects from the 64 families were genotyped for five microsatellites markers, linked to the OTOF gene. The analysis of the haplotype excluded linkage to the OTOF gene in 34 families, it was inconclusive in 19 families and it showed compatibility with linkage in the remaining 11 families (including one with consanguineous parents and auditory neuropathy and three with diagnosis of auditory neuropathy).
\end{abstract}


Simultaneously, the 64 subjects were screened for mutations in 8 exons previously identified to other mutations using the SSCP technique. In positive cases, DNA sequencing was carried out.

In the 11 subjects consistent with putative linkage to OTOF gene and the 7 isolated cases of auditory neuropathy, an exon by exon screening for mutations in the OTOF gene was performed using DNA sequencing (Total of 18 subjects).

We found a total of 58 different variants. Eleven were possibly causative mutations and were found in seven of the 18 subjects. Amongst them, four cases were compound heterozygotes R33Q with E801L, G614E with E1080P, 2348delG with 5800-5801insC and K1811X with C1251G, two cases were heterozygotes [15521567del16 and 2905-2923del19in11] without a second mutation and one presented a mutation in homozygous form [3400C $>\mathrm{T}$ (R1134X)]. Among these seven probands, only one patient with a heterozygote mutation did not have a diagnosis of auditory neuropathy.

In the 11 cases of auditory neuropathy, six had at least one mutation in the OTOF gene that is the probable cause of their deafness. These findings support the association between auditory neuropathy and mutations in the OTOF gene.

While we failed to confirm the high frequency of Q829X mutation found in Spain, our study shows that mutations in the OTOF gene are frequent causes of auditory neuropathy in Brazil (more than 50\%).

Our results reinforced that patients with auditory neuropathy must be selected for mutation detection in the OTOF gene and that more than $50 \%$ of cases of auditory neuropathy have a defined genetic etiology. 


\section{INTRODUÇÃO}




\section{INTRODUÇÃO}

\section{I.1. A deficiência auditiva}

A audição é um dos sentidos mais importantes para o desenvolvimento de um indivíduo. Ela é essencial para o desenvolvimento da fala, da linguagem, da socialização e de outras formas de comportamento. Sem a audição, o indivíduo tem limitações graves para a aquisição da linguagem falada. A perda de audição pode causar isolamento social e depressão. Por isso, a detecção precoce é importante para terapias e educação especial. Além disso, o diagnóstico etiológico e o aconselhamento genético são muito importantes na prevenção de novos casos.

A surdez é uma das deficiências hereditárias mais freqüentes nos seres humanos (Morton, 1991). Sua incidência é muito heterogênea, variando de 1 a 7 em cada 1000 recém-nascidos, dependendo da amostra e da região estudada. No Brasil, essa freqüência foi estimada em 4: 1000 (Braga e col., 1999). Entre o total de casos, a deficiência auditiva pré-lingual não-sindrômica é a mais freqüente. Segundo dados da Organização Mundial de Saúde, 250 milhões de indivíduos da população mundial possuem deficiência auditiva moderada, severa ou profunda (www.who.int/pbd/deafness/facts/en/index.html). Esse número é ainda maior na população idosa. Mais de $60 \%$ das pessoas com mais de 70 anos apresentam perda auditiva em grau suficiente para que seja necessário algum tipo de intervenção para que continuem a se comunicar (Kalatzis e Petit, 1998).

A definição dos termos deficiência ou perda auditiva utilizados nesse estudo é a de qualquer déficit ou comprometimento auditivo independente do tipo ou grau. Dessa maneira, os termos surdez, perda ou deficiência auditiva serão usados como sinônimos, do mesmo modo que têm sido utilizados na maioria dos trabalhos de genética.

A surdez pode ser causada por fatores ambientais, genéticos ou por uma combinação de ambos. Numa população particular, a contribuição de cada causa depende de fatores sociais como a estrutura populacional e a consangüinidade, o controle de infecções e imunização e o acompanhamento médico neo e pós-natal (Morton, 1991). Os fatores ambientais, como exposição excessiva a ruídos, patógenos e drogas, atuam tanto no desenvolvimento do aparelho auditivo quanto no seu funcionamento. No Brasil, foi estimado que as causas hereditárias contribuem com cerca de 16\% dos casos de deficiência auditiva (Braga e col., 1999). A rubéola 
materna e a meningite eram as mais importantes causas de surdez no país até a década de noventa (Braga e col.,1999). Em função disso, estima-se que a freqüência da surdez no Brasil possa ser três a quatro vezes maior que nos países desenvolvidos, isso devido a uma maior contribuição dos fatores ambientais.

As perdas auditivas podem ser classificadas segundo a etiologia. As pesquisas epidemiológicas de surdez mostram, em vários estudos, que 50\% das deficiências auditivas infantis podem ser atribuidas às causas genéticas nos países desenvolvidos. O diagnóstico dos casos genéticos pode permitir melhor aconselhamento e o planejamento familial. Testes genéticos oferecidos aos familiares podem oferecer informações essenciais sobre fatores de risco genéticos e ambientais, como por exemplo, no caso dos indivíduos com a mutação mitocondrial A1555G que apresentam risco aumentado de perda de audição em função da utilização dos antibióticos aminoglicosídeos (Bitner-Glindzicz, 2002).

As perdas auditivas são classificadas também segundo a lateralidade, o grau da perda, a configuração da perda, a idade de manifestação, o tipo da perda, a manifestação clínica e a evolução.

Quanto à lateralidade, a surdez pode afetar um lado somente e ser chamada de surdez unilateral; se ambas as orelhas são afetadas, ela é chamada de surdez bilateral.

Há divergência sobre como classificar as perdas auditivas quanto ao grau. Utilizamos nesse estudo a classificação modificada de Davis e Silverman (1970) que considera a média dos limiares em dB obtidas no melhor ouvido em freqüências de 500, 1000, 2000 e $4000 \mathrm{~Hz}$ para determinar o limiar da perda. Dessa maneira, a audição é considerada normal se o limiar for até $20 \mathrm{~dB}$. Ocorre perda auditiva leve entre 21 e $40 \mathrm{~dB}$, perda auditiva moderada de 41 a $70 \mathrm{~dB}$, perda auditiva severa (ou grave) de 71 a $90 \mathrm{~dB}$ e perda auditiva profunda acima de $91 \mathrm{~dB}$.

Quanto à idade de manifestação, a surdez é considerada pré-lingual quando se manifesta antes ou durante o aprendizado da linguagem falada e pós-lingual quando a deficiência ocorre depois que a pessoa domina a linguagem.

Além disso, classifica-se a surdez, segundo o tipo da perda, como condutiva ou sensório-neural (neurossensorial). A deficiência auditiva pode ser definida como condutiva quando afeta o mecanismo de condução do som por um defeito no canal auditivo externo, na membrana timpânica ou nos ossículos da orelha média. As perdas que não são condutivas são chamadas de sensório-neurais, que podem ser melhor classificadas como sensoriais, centrais ou neurais. As perdas são definidas como 
sensoriais quando a lesão é coclear, afetando em particular as células ciliadas internas e externas; como neural quando afeta os nervos auditivos ou central quando afeta as vias auditivas em qualquer ponto do tronco ou do encéfalo. Utiliza-se o termo surdez mista quando coexistem componentes condutivos e sensório-neurais.

Considerando-se sua evolução, a deficiência auditiva pode ser chamada de estacionária ou progressiva. Uma perda é estacionária quando não se altera com o tempo. Quando se apresenta primeiramente leve, tornando-se progressivamente mais severa e evolui para outras frequiências, caracteriza-se como surdez progressiva.

A surdez hereditária pode ser classificada também em formas sindrômicas ou não-sindrômicas. Há, aproximadamente, 400 doenças hereditárias conhecidas com perda auditiva associada a várias anomalias como doenças oculares, músculoesqueléticas, renais, nervosas e pigmentárias. Essas formas sindrômicas correspondem a cerca de 30\% dos casos de surdez hereditária em crianças (Keats e Berlin, 1999; Bitner-Glindzicz, 2002). Na maioria dos casos, no entanto, a deficiência auditiva é geralmente o único sintoma, sendo referida como surdez isolada, ou seja, nãosindrômica.

\section{I.2. Surdez hereditária não-sindrômica}

A deficiência auditiva não-sindrômica é uma das doenças geneticamente mais heterogêneas que se tem conhecimento, apresentando vários padrões de herança.

Os diferentes locos ou regiões candidatas a conterem um ou mais genes responsáveis pelas formas de surdez não-sindrômica são chamados de DFN (do inglês DeaFNess). Os locos relacionados com surdez de herança autossômica dominante são denominados DFNA, os locos de surdez autossômica recessiva são chamados de DFNB e os locos que estão no cromossomo X, DFN. Além disso, há dois locos modificadores nomeados de DFNM1 e DFNM2 e um único loco mapeado no cromossomo Y designado com a sigla DFNY. Os locos são numerados segundo a ordem de descoberta, DFNA1 sendo o primeiro gene de surdez de herança autossômica dominante mapeado em 1992 (Van Camp e Smith, 2006).

Dos casos hereditários de surdez não-sindrômica, $75-80 \%$ têm transmissão autossômica recessiva (DFNB), 10-15\% mostram transmissão autossômica dominante e os restantes apresentam herança mitocondrial ou ligada ao cromossomo X (Van Camp e col., 1997; Bitner-Glindzicz, 2002). De acordo com Van Camp e Smith (2006), há 116 locos de deficiências auditivas não-sindrômicas conhecidos no seres 
humanos mas somente 50 genes nucleares e dois mitocondriais foram identificados até o momento. Através da identificação desses genes, descobriu-se que a deficiência auditiva hereditária pode resultar de diversas anomalias durante o desenvolvimento ou no funcionamento da orelha interna e das células formadoras da cóclea.

As deficiências auditivas não-sindrômicas de herança autossômica dominante se caracterizam por serem geralmente pós-linguais, progressivas e sensório-neurais (Petit, 1996; Van Camp e col., 1997; Van Laer e col., 1999; Bitner-Glindzicz, 2002). Quarenta e nove locos já foram mapeados, dos quais 24 genes já foram identificados (Van Camp e Smith, 2006). Até o momento, o DFNA9 é o loco com o maior número de famílias descritas (19), nele se localiza o gene $\mathrm{COCH}$ (do inglês coagulation factor C homology) (Robertson e col., 1998; Fransen e col., 1999; Kok e col., 1999).

As perdas auditivas não-sindrômicas de herança autossômica recessiva são sensório-neurais, estacionárias, geralmente de grau severo a profundo, de manifestação pré-lingual e geralmente atingem todas as freqüencias (Campbell e col., 1997; Keats e Berlin, 1999; Bitner-Glindzicz, 2002). Até o momento, já foram mapeados 57 locos autossômicos responsáveis por surdez recessiva (Tabela I). Dentre os 26 genes identificados, o gene GJB2 (DFNB1) é o mais importante por ser relacionado a mais de 50\% dos casos de surdez não-sindrômica autossômica recessiva (Gasparini e col., 1997; Bitner-Glindzicz, 2002). Ele foi mapeado na região cromossômica 13q12-13 e codifica a conexina 26, proteína dos canais de junção do tipo "gap". Outros genes se destacaram também como sendo os mais freqüentemente alterados em amostras de indivíduos surdos. Os genes MYO7 e o MYO15 codificam duas miosinas não-convencionais, a miosina VII A e a miosina XV (locos DFNB2 and DFNB3, respectivamente) que são expressas somente nas células ciliadas do órgão de Corti. O gene PDS (Pendred Syndrome Gene) codifica a pendrina, proteína transportadora de cloro ou iodo (DFNB4). O gene TECTA mapeado no cromossomo 11q23-25, codifica um componente da membrana tectorial, a alfa-tectorina (DFNB21) e o gene OTOF codifica a otoferlina (DFNB9) envolvida nas fusões de vesículas sinápticas (Sundstrom e col., 1999).

Já a deficiência auditiva ligada ao cromossomo $\mathrm{X}$ tem cinco locos mapeados e dois genes identificados. O loco mais freqüentemente associado aos casos de surdez ligada ao cromossomo $\mathrm{X}$ é o DFN3, onde reside o gene POU3F4 que codifica um fator de transcrição (Willems e col., 2000; Van Camp e Smith, 2006). 
A contribuição dos genes mitocondriais na etiologia da deficiência auditiva é estimada em pelo menos $2 \%$ dos casos (Abreu-Silva e col., 2006). A surdez pode ter grau e idade de manifestação variáveis mesmo dentro da mesma família. Até o momento dois genes e oito mutações já foram descritas no DNA mitocondrial, sendo a mutação A1555G, do gene que codifíca o RNA ribossômico $12 \mathrm{~S}$, a mais freqüente delas. Algumas das mutações mitocondriais foram relacionadas com susceptibilidade aumentada à ototoxicidade pelos aminoglicosídeos, como é o caso da mutação A1555G (Estivill e col., 1998). 
Tabela I. Locos responsáveis por surdez hereditária não-sindrômica autossômica recessiva (modificado de Van Camp e Smith, 2006).

\begin{tabular}{|c|c|c|c|c|}
\hline $\begin{array}{l}\text { Nome dos } \\
\text { Locos }\end{array}$ & $\begin{array}{l}\text { Localização } \\
\text { cromossômica }\end{array}$ & Gene & $\begin{array}{l}\text { Marcadores genéticos } \\
\text { próximos }\end{array}$ & Referências mais importantes \\
\hline DFNB1 & $13 \mathrm{q} 12$ & GJB2 & D13S175, D13S292 & Guilford e col., 1994a; Kelsell e col., 1997 \\
\hline DFNB2 & $11 \mathrm{q} 13.5$ & MYO7A & D11S4081, D11S906 & $\begin{array}{l}\text { Guilford e col., 1994b; Liu e col., 1997; } \\
\text { Weil e col., } 1997\end{array}$ \\
\hline DFNB3 & $17 \mathrm{p} 11.2$ & MYO15 & D17S2196,D17S2187 & Friedman e col., 1995; Wang e col., 1998 \\
\hline DFNB4 & $7 \mathrm{q} 31$ & $S L C 26 A 4$ & D7S496, D7S2459 & Baldwin e col., 1995; Li e col., 1998 \\
\hline DFNB5 & $14 \mathrm{q} 12$ & desconhecido & $\begin{array}{l}\text { D14S286, D14S579, } \\
\text { D14S301 }\end{array}$ & Fukushima e col., 1995a \\
\hline DFNB6 & 3p14-p21 & TMIE & D3S1767, D3S3647 & Fukushima e col., 1995b; Naz e col., 2002 \\
\hline DFNB7 & $9 q 13-q 21$ & $T M C 1$ & D9S301, D9S1876 & Jain e col., 1995; Kurima e col., 2002 \\
\hline DFNB8 & $21 \mathrm{q} 22$ & TMPRSS3 & D21S1260,D21S1259 & Veske e col., 1996; Scott e col., 2001 \\
\hline DFNB9 & $2 \mathrm{p} 22-\mathrm{p} 23$ & OTOF & D2S158, D2S174 & Chaib e col., 1996a; Yasunaga e col., 1999 \\
\hline DFNB10 & $21 \mathrm{q} 22.3$ & TMPRSS3 & ver DFNB8 & Bonné-Tamir e col., 1996; Scott e col., 2001 \\
\hline DFNB11 & $9 q 13-q 21$ & $T M C 1$ & ver DFNB7 & Scott e col., 1996; Kurima e col., 2002 \\
\hline DFNB12 & $10 \mathrm{q} 21-\mathrm{q} 22$ & $\mathrm{CDH} 23$ & D10S537, D10S1432 & Chaib e col., 1996b; Bork e col., 2001 \\
\hline DFNB13 & $7 q 34-36$ & desconhecido & D7S1824, D7S2513 & Mustapha e col., 1998a \\
\hline DFNB14 & $7 \mathrm{q} 31$ & desconhecido & $\begin{array}{l}\text { D7S554, D7S515; } \\
\text { D7S2459 }\end{array}$ & Mustapha e col., 1998b \\
\hline DFNB15 & $\begin{array}{l}3 q 21-q 25 \\
19 p 13\end{array}$ & desconhecido & $\begin{array}{l}\text { D3S1764, D3S1744, } \\
\text { D3S1605, D19S216, } \\
\text { D19S406, D19S221 }\end{array}$ & Chen e col., 1997 \\
\hline DFNB16 & $15 q 21-q 22$ & STRC & D15S994, D15S659 & Campbell e col., 1997; Verpy e col., 2001 \\
\hline DFNB17 & $7 \mathrm{q} 31$ & desconhecido & D7S501, D7S692 & Greinwald e col., 1998 \\
\hline DFNB18 & $11 \mathrm{p} 14-15.1$ & USHIC & D11S902, D11S2368 & $\begin{array}{l}\text { Jain e col., 1998; Ouyang e col., 2002; } \\
\text { Ahmed e col., } 2002\end{array}$ \\
\hline DFNB19 & $18 \mathrm{p} 11$ & desconhecido & D18S452, D18S843 & Green e col., 1998 \\
\hline DFNB20 & 11q25-qter & desconhecido & D11S968, D11S2359 & Moynihan e col., 1999 \\
\hline DFNB21 & $11 \mathrm{q}$ & TECTA & D11S925, D11S4464 & Mustapha e col., 1999 \\
\hline DFNB22 & $16 \mathrm{p} 12.2$ & OTOA & D16S3046, D16S403 & Zwaenepoel e col., 2002 \\
\hline DFNB23 & $10 \mathrm{p} 11.2-\mathrm{q} 21$ & PCDH15 & D10S1762,D10S1227 & Ahmed e col., 2003a \\
\hline DFNB24 & $11 \mathrm{q} 23$ & desconhecido & $\begin{array}{l}\text { D11S2017, D11S908, } \\
\text { D11S1992 }\end{array}$ & Richard Smith, não publicado \\
\hline DFNB25 & $4 p 15.3-q 12$ & desconhecido & $\begin{array}{l}\text { D4S2632, D4S405, } \\
\text { D4S428 }\end{array}$ & Richard Smith, não publicado \\
\hline DFNB26 & $4 \mathrm{q} 31$ & desconhecido & $\begin{array}{l}\text { D4S424, D4S1625, } \\
\text { D4S1604, D1S2815, } \\
\text { D1S1619, D1S1165 }\end{array}$ & Riazuddin e col., 2000 \\
\hline DFNB27 & $2 q 23-q 31$ & desconhecido & $\begin{array}{l}\text { D2S2307, D2S2314, } \\
\text { D2S148 }\end{array}$ & Pulleyn e col., 2000 \\
\hline DFNB28 & $22 \mathrm{q} 13$ & TRIOBP & $\begin{array}{l}\text { D22S1045, D22S423, } \\
\text { D22S282 }\end{array}$ & $\begin{array}{l}\text { Walsh e col., 2000; Shahin e col., 2006; } \\
\text { Riazuddin e col., } 2006\end{array}$ \\
\hline DFNB29 & $21 \mathrm{q} 22$ & CLDN14 & D21S1252,D21S168 & Wilcox e col., 2001 \\
\hline DFNB30 & $10 \mathrm{p} 12.1$ & MYO3A & D10S1749, D10S2481 & Walsh e col., 2002 \\
\hline DFNB31 & $9 q 32-q 34$ & WHRN & D9S302, D9S1776 & Mustapha e col., 2002; Mburu e col., 2003 \\
\hline DFNB32 & $1 \mathrm{p} 13.3-22.1$ & desconhecido & $\begin{array}{l}\text { D1S2819, D1S495, } \\
\text { D1S3723 }\end{array}$ & Masmoudi e col., 2003 \\
\hline DFNB33 & $9 \mathrm{q} 34.3$ & desconhecido & $\begin{array}{l}\text { D9S1826, D9S158, } \\
\text { D9S1838 }\end{array}$ & Medlej-Hashim e col., 2002 \\
\hline DFNB35 & $14 q 24.1-24.3$ & desconhecido & $\begin{array}{l}\text { D14S258, D14S77, } \\
\text { D14S53 }\end{array}$ & Ansar e col., 2003a \\
\hline
\end{tabular}


Tabela I. Continuação

\begin{tabular}{|c|c|c|c|c|}
\hline $\begin{array}{l}\text { Nome dos } \\
\text { Locos }\end{array}$ & $\begin{array}{l}\text { Localização } \\
\text { cromossômica }\end{array}$ & Gene & $\begin{array}{l}\text { Marcadores genéticos } \\
\text { próximos }\end{array}$ & Referências mais importantes \\
\hline DFNB36 & $1 \mathrm{p} 36.3$ & $E S P N$ & D1S2870, D1S214 & Naz e col., 2004 \\
\hline DFNB37 & $6 q 13$ & MYO6 & D6S1659, D6S1031 & Ahmed e col., 2003b \\
\hline DFNB38 & 6q26-q27 & desconhecido & D6S1599, D6S1277 & Ansar e col., 2003b \\
\hline DFNB39 & 7q11.22-q21.12 & desconhecido & $\begin{array}{l}\text { D7S2516, D7S2204, } \\
\text { D7S644 }\end{array}$ & Wajid e col., 2003 \\
\hline DFNB40 & $22 q$ & desconhecido & $\begin{array}{l}\text { D22S686, D22S1174, } \\
\text { D22S1144 }\end{array}$ & Delmaghani e col., 2003 \\
\hline DFNB42 & $3 q 13.31-q 22.3$ & desconhecido & & Aslam e col., 2005 \\
\hline DFNB44 & 7p14.1-q11.22 & desconhecido & & Ansar e col., 2004 \\
\hline DFNB46 & 18p11.32-p11.31 & desconhecido & & Mir e col., 2005 \\
\hline DFNB47 & $2 \mathrm{p} 25.1-\mathrm{p} 24.3$ & desconhecido & & Hassan e col., 2005 \\
\hline DFNB48 & $15 \mathrm{q} 23-\mathrm{q} 25.1$ & desconhecido & & Ahmad e col., 2005 \\
\hline DFNB49 & $5 q 12.3-q 14.1$. & desconhecido & & Ramzan e col., 2005 \\
\hline DFNB50 & $12 q 23$ & desconhecido & & \\
\hline DFNB51 & $11 \mathrm{p} 13-\mathrm{p} 12$ & desconhecido & & Shaikh e col., 2005 \\
\hline DFNB53 & $6 \mathrm{p} 21.3$ & desconhecido & & Chen e col., 2005 \\
\hline DFNB55 & $4 q 12-q 13.2$ & desconhecido & & Irshad e col., 2005 \\
\hline DFNB57 & $10 \mathrm{q} 23.1-\mathrm{q} 26.11$ & desconhecido & & \\
\hline DFNB58 & $2 q 14.1-q 21.2$ & & D2S2970, D2S112 & R. Smith, não publicado \\
\hline DFNB59 & 2q31.1-q31.3 & $P J V K$ & & Delmaghani e col., 2006 \\
\hline DFNB60 & $5 q 22-q 31$ & desconhecido & D5S404, D5S1979 & R. Smith, não publicado \\
\hline DFNB62 & 12p13.2-p11.23 & desconhecido & & Ali e col., 2006 \\
\hline DFNB65 & 20q13.2-q13.32 & desconhecido & & Tariq e col., 2006 \\
\hline DFNB66 & $6 \mathrm{p} 21.2-22.3$ & LHFPL4 & & Tlili e col., 2005 \\
\hline DFNB67 & $6 \mathrm{p} 21.1-\mathrm{p} 22.3$ & $T M H S$ & & Shabbir e col., 2006 \\
\hline
\end{tabular}

\section{I.2. Fisiologia da audição}

O órgão responsável pela audição é a orelha, o qual se divide em orelha externa, orelha média e orelha interna (Figura 1).

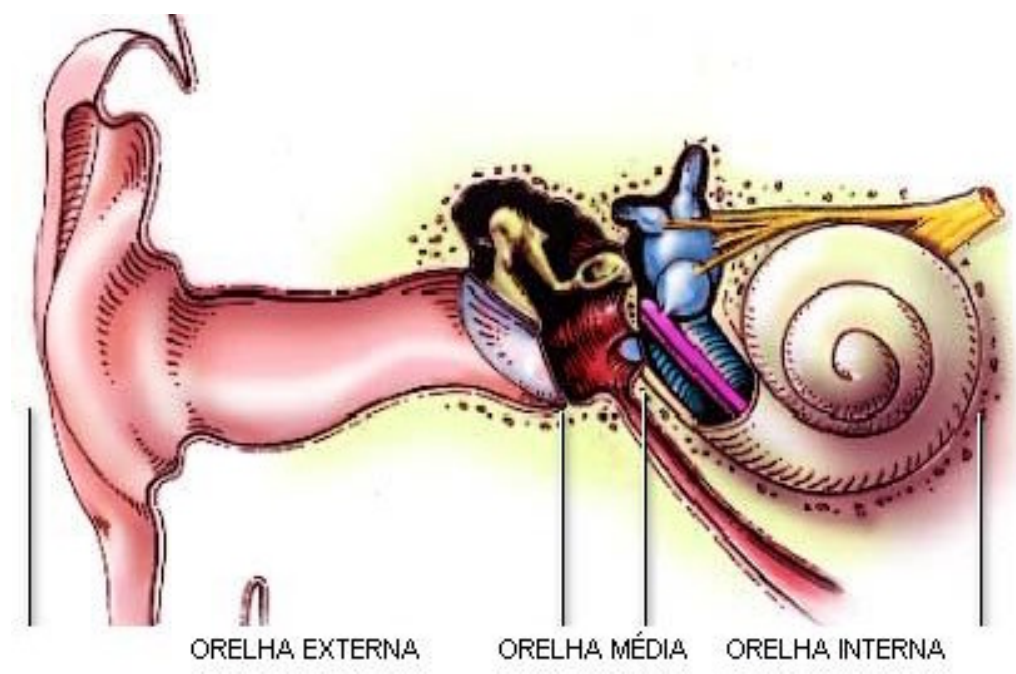

Figura 1. Esquema representando o aparelho auditivo humano (modificada da página Promenade round the cochlea Home Page). 
A orelha externa é formada pelo pavilhão e pelo conduto auditivo externo. Sua finalidade é coletar as ondas sonoras provenientes de uma grande área, concentrandoas no tímpano, que constitui a fronteira entre a orelha externa e a orelha média.

A orelha média é uma cavidade cheia de ar escavada no osso temporal na qual residem os ossículos martelo, bigorna e estribo (Figura 2). Os ossículos da orelha média coduzem o som do tímpano para a orelha interna através da janela oval. A diferença entre o tímpano, cuja area é maior, e a janela oval, cuja area é menor, acarreta aumento da pressão que é transmitida para o interior da cóclea. Esse mecanismo maximiza a transferência da energia sonora que será conduzida para os líquidos que preenchem a cóclea.

A orelha interna corresponde a uma cavidade óssea onde estão o aparelho vestibular, responsável pelo equilíbrio, e a cóclea, que converte os estímulos sonoros em sinais nervosos ou elétricos (Petit, 1996). A cóclea (Figuras 2 e 3) em forma de caracol, é um canal ósseo-membranoso. Ela é dividida em três dutos preenchidos por fluidos: a escala vestibular, a escala timpânica e a escala média ou duto coclear, que abriga o órgão de Corti (Willems, 2000; Pujol e col., 2006).

(a)

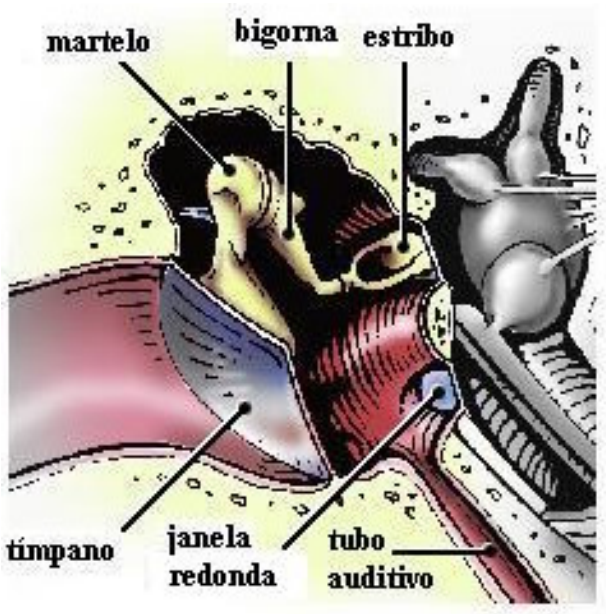

(b) aparelho

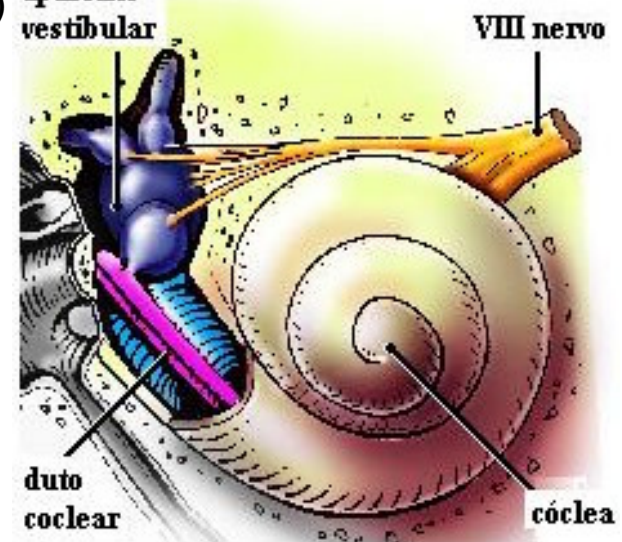

Figura 2. Em (a) detalhe da orelha média, mostrando os ossículos (martelo, bigorna e estribo), o tímpano, a janela redonda e o tubo auditivo. Em (b) detalhe da orelha interna mostrando vestíbulo ou aparelho vestibular, o VIII nervo craniano, cóclea e duto coclear (em rosa), que abriga o orgão de Corti (modificada da página Promenade round the cochlea Home Page). 


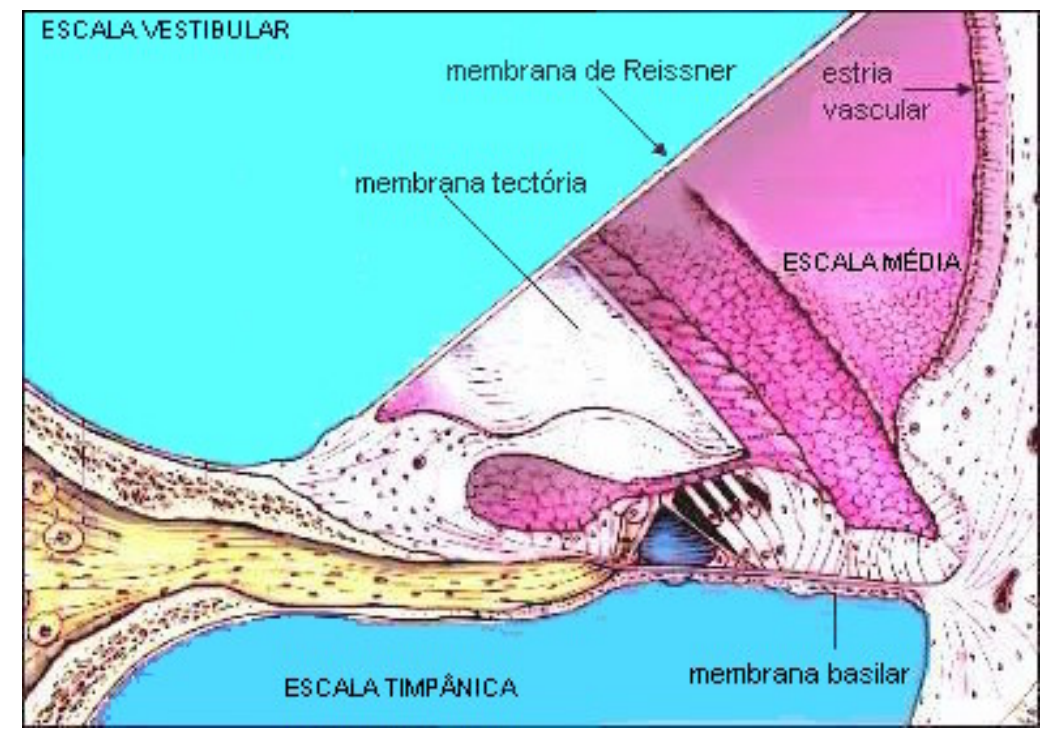

Figura 3. Secção transversal de um dos giros da cóclea, mostrando sua divisão em três compartimentos longitudinais: a escala vestibular e escala timpânica (em azul) e a escala média ou duto coclear (em rosa) (modificada da página Promenade round the cochlea Home Page).

A escala vestibular e a escala timpânica comunicam-se no ápice da cóclea e contêm perilinfa, fluido extracelular típico, com composição semelhante à do plasma. O principal componente desse fluido é o cátion sódio, além de conter ainda cloro, bicarbonato e baixa concentração do cátion potássio. Já a endolinfa presente no duto coclear é uma solução única no organismo. Apresenta alta concentração do cátion potássio e baixa concentração do cátion sódio, ou seja, com composição iônica distinta da perilinfa e semelhante à do citossol. A diferença de composição iônica entre os diferentes compartimentos da cóclea gera o potencial endococlear, que é de fundamental importância para a transdução do som. A manutenção do potencial endococlear é realizada pela estria vascular (Figura 3), um epitélio multiestratificado que participa na reciclagem de potássio dentro do órgão de Corti e que secreta a endolinfa (Petit, 1996; Pujol e col.,2006).

O orgão de Corti é a estrutura receptora auditiva, formada por células de sustentação e por células ciliadas sensoriais (Figuras 3 e 4). Essas células apresentam em suas superfícies apicais dezenas de estereocílios, que são microvilosidades dispostas em três fileiras, banhadas pela endolinfa e sustentadas por feixes de actina. Essas células, situadas em toda sua extensão sobre a membrana basilar que separa a escala timpânica do duto coclear, são divididas em dois tipos, as células ciliadas externas e as células ciliadas internas (Figura 4). Sobre as células ciliadas existe uma membrana chamada de tectória, onde ficam imersos os cílios das células ciliadas 
externas, enquanto os cílios das células ciliadas internas estão livres na endolinfa (Pujol e col.,2006).

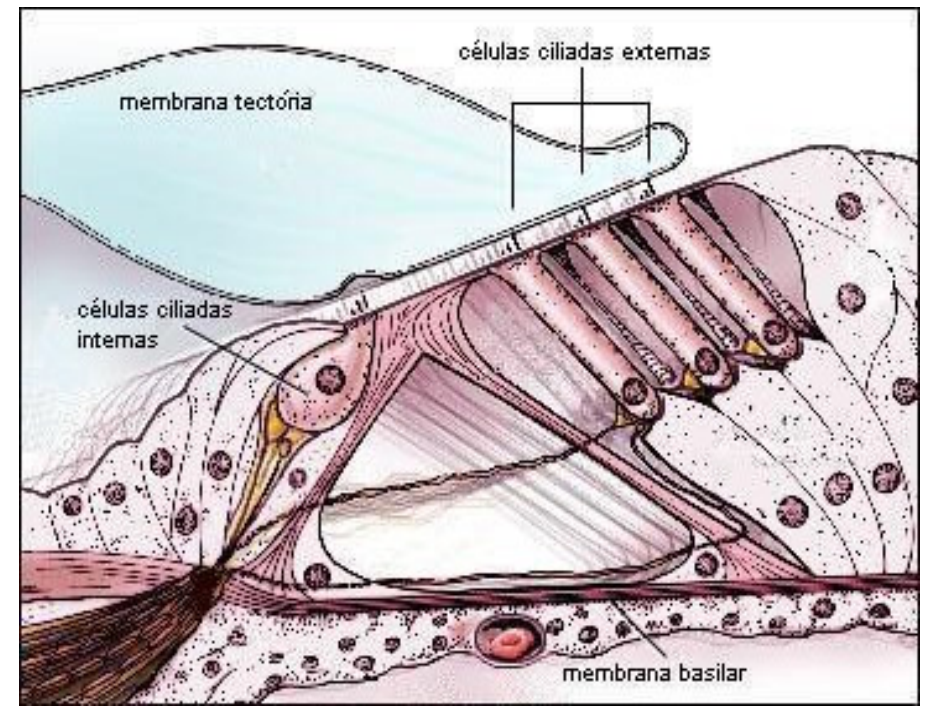

Figura 4. Secção do órgão de Corti mostrando as células ciliadas internas e as células ciliadas externas (modificada da página Promenade round the cochlea Home Page).

As células ciliadas externas são banhadas pela endolinfa no pólo apical e estão em contato com células de sustentação no pólo basal. Devido às suas propriedades eletrobiomecânicas, as células ciliadas externas têm grande importância na amplificação do estímulo e na capacidade de discriminação de freqüências (Nudelmann e col., 1997). Elas provocam aumento na amplitude da vibração da membrana tectória, amplificando assim a energia sonora, o que aumenta a estimulação das células ciliadas internas.

As células ciliadas internas estão dispostas em uma só fileira sobre a membrana basilar. São presas às células de suporte no pólo basal e banhadas pela endolinfa no pólo apical. São transdutores sensoriais, os verdadeiros receptores da mensagem sonora, produzindo codificação em mensagem elétrica, que é enviada pelas vias nervosas aos centros auditivos do lobo temporal (Nudelmann e col., 1997).

À medida que ocorre o deslocamento de ondas mecânicas dentro dos fluidos da cóclea, em função da estimulação externa, os estereocílios das células ciliadas são defletidos, levando à uma mudança de potencial químico endocelular que desencadeia movimentos de despolarização nas células ciliadas externas, ou seja, contração dessas células e hiperpolarização, ou alongamento das mesmas (Dallos, 1992). O movimento das células ciliadas externas é transmitido às células ciliadas internas que, ao serem estimuladas, desencadeiam potenciais de ação e liberam neurotransmissores para os 
receptores dos dendritos mielinizados dos neurônios do gânglio espiral, com os quais as células ciliadas internas fazem sinapse, provocando o disparo do impulso nervoso para os axônios que compõem o VIII par craniano (Kurc, 1999).

A transmissão de sinais no sistema nervoso se dá por meio de potenciais de ação, sendo a fibra nervosa, ou axônio, a linha de transmissão desses potenciais. Essa rede de fibras nervosas é denominada Sistema Nervoso Auditivo Central (SNAC). As fibras que transportam as informações até o córtex fazem parte das vias auditivas aferentes (Figura 5). As informações nervosas também são transmitidas do córtex para a cóclea por meio das fibras que compõem as vias auditivas eferentes (Bess e Humes, 1998).

Referindo-se à inervação aferente, por volta de $95 \%$ das fibras que constituem o gânglio espiral partem das células ciliadas internas e ascendem nesse sistema. Essa via leva a mensagem sonora para os centros auditivos. Isso se dá porque as células ciliadas internas recebem inervação de neurônios mielinizados e responsáveis por uma condução rápida e eficiente. Já as células ciliadas externas são inervadas por neurônios sem bainha de mielina, sendo que somente 5\% das fibras do sistema aferente partem dessas células (Pujol e col.,2006).

Assim, fica evidente a responsabilidade das células ciliadas internas na condução da informação auditiva ao cérebro, sendo as mesmas consideradas como principais receptores sensoriais auditivos. 


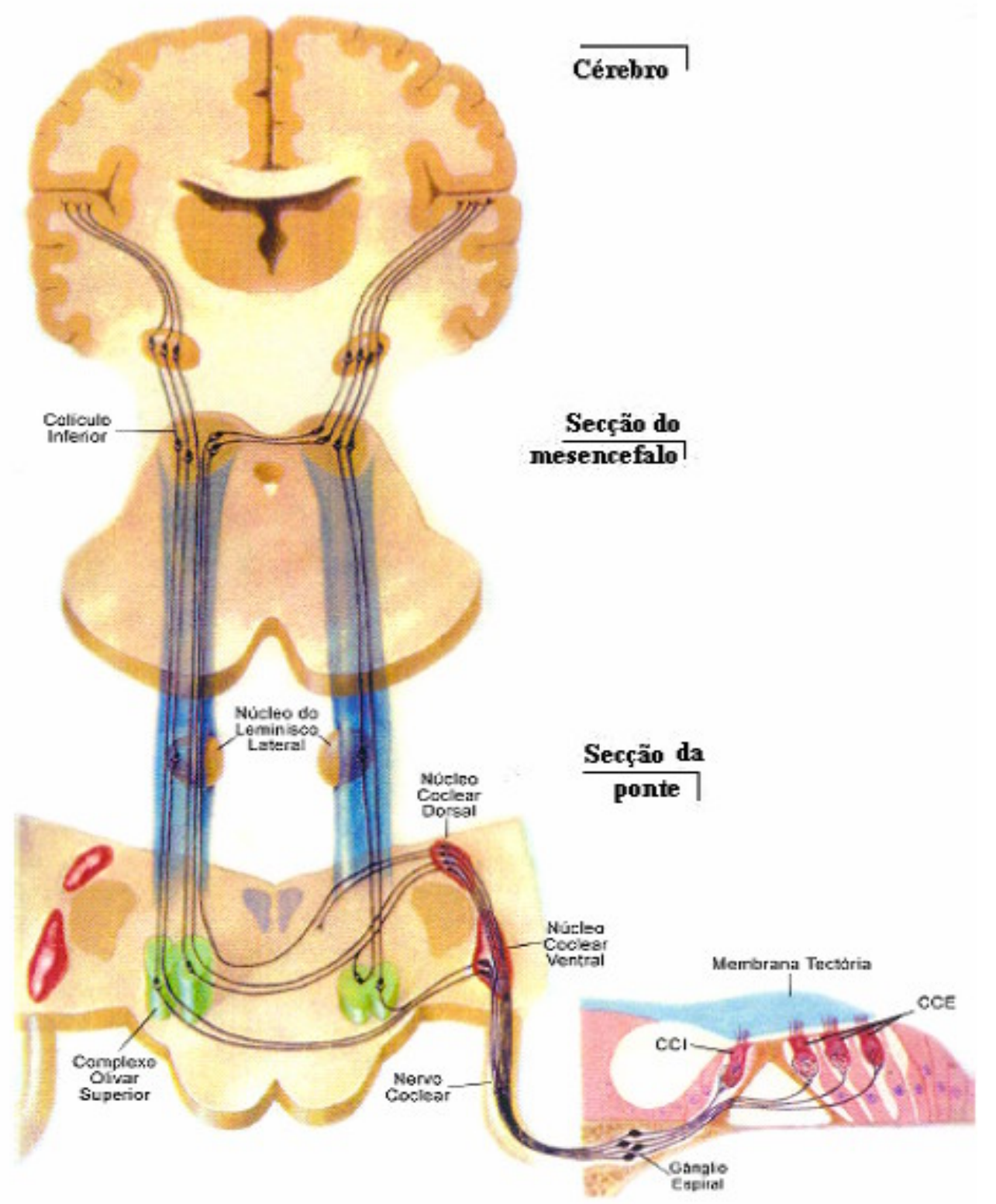

Figura 5. Esquema representando a cóclea e as vias auditivas centrais (modificado do Netter FH, 1958).

Não se sabe se a aferência das células ciliadas externas conduz algum tipo de informação. Há hipótese de que esse sistema captaria informações sobre o estado de contração das células ciliadas externas para o sistema nervoso central. Essas informações seriam importantes para regular o tônus das células ciliadas externas e suas contrações. Outra hipótese é a de que funcionariam como sistema de alerta na presença de ruído intenso (Nudelmann e col., 1997).

As vias auditivas eferentes parecem possuir um papel importante na função das células ciliadas externas, atuando como proteção contra a ação lesiva da exposição a altos níveis de pressão sonora. 


\section{I.3. Exames clínicos para estudar a deficiência auditiva}

Desde que um defeito auditivo pode ocorrer em qualquer lugar durante o trajeto de condução do estímulo sonoro, seria razoável esperar ser possível diferenciar os tipos de surdez com base no local onde o processo de condução está comprometido. Por isso, novas estratégias de testes audiológicos têm sido desenvolvidas com as quais se busca identificar onde tal defeito ocorreu exatamente.

Os principais testes utilizados na avaliação clínica da deficiência auditiva são: Audiometria tonal pura: foi o método padrão usado para medir limiares mínimos de audição por via aérea e via óssea. O teste avalia várias frequiências. Cada uma delas é testada separadamente com intensidades decrescentes até que se encontre o limiar de detecção daquela determinada freqüência (Figura 6). Para a realização deste teste são necessárias maturidade e coordenação, por isso é indicado principalmente após os 5 anos, idade a partir da qual as crianças são capazes de realizar os testes com melhor desempenho. A audiometria testa a integridade total do caminho auditivo, mas não dá informação exata sobre onde esse caminho está prejudicado.

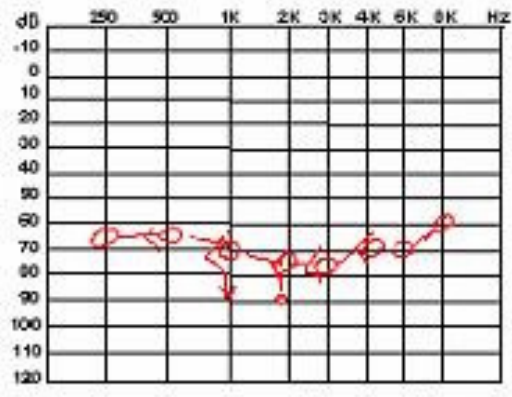

Orelha Direita

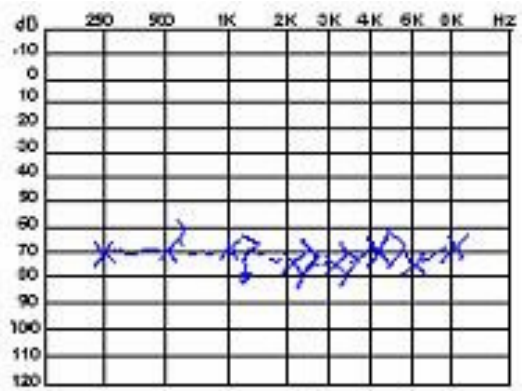

Orelha Esquerda

Figura 6. Resultado da audiometria de paciente com perda auditiva moderada mostrando as freqüências em $\mathrm{Hz}$ (no eixo horizontal) e a intensidade dos sons em dB (no eixo vertical). "O" na cor vermelha indica os limiares da via aérea na orelha direita, " $X$ " na cor azul limiares da via aérea na orelha esquerda, "<" na cor vermelha limiares da via óssea na orelha direita, ">”na cor azul limiares da via óssea na orelha esquerda.

\section{Potenciais Evocados Auditivos do Tronco Encefálico ou BERA: O BERA foi descrito} pela primeira vez por Jewett e Willinston (1971) e é considerado um método objetivo para avaliar a audição, pois possibilita a verificação do funcionamento da via auditiva, desde o nervo auditivo até o tronco encefálico, avaliando assim sua integridade nessa porção. Além de permitir inferir se existem anormalidades estruturais que possam interferir na transmissão do estímulo acústico ao longo da via auditiva, permite também avaliar a sincronia neural e identificar anormalidades funcionais, que interferem na maneira pela qual o estímulo acústico é codificado e conduzido (revisão 
em Matas e Rondina, 2004). Em resposta à estimulação acústica, espera-se que ocorra o disparo de estímulos de um grande grupo de neurônios de forma simultânea, o que resulta numa resposta neural sincronizada, que é registrada em forma de ondas, por meio de eletrodos fixados no couro cabeludo, na fronte e nos lóbulos das orelhas (Figura 7). As ondas encontradas no registro do BERA são geradas por uma ou mais estruturas ao longo da via auditiva no tronco encefálico. Uma das classificações mais utilizadas atualmente é a do Möller e col. (1981), na qual são descritos os seguintes geradores: onda I - porção distal ao tronco encefálico do nervo auditivo, onda II porção proximal, onda III - núcleo coclear, onda IV - complexo olivar superior e onda V - lemenisco lateral (revisão em Matas e Rondina, 2004).

No BERA pode ser observado também o microfonismo coclear, que dá informação sobre o funcionamento e a integridade das células ciliadas externas e internas. Pode ser estudado quando se inverte a polaridade do estímulo acústico. Dessa forma, a presença do microfonismo coclear evidencia a preservação da cóclea.

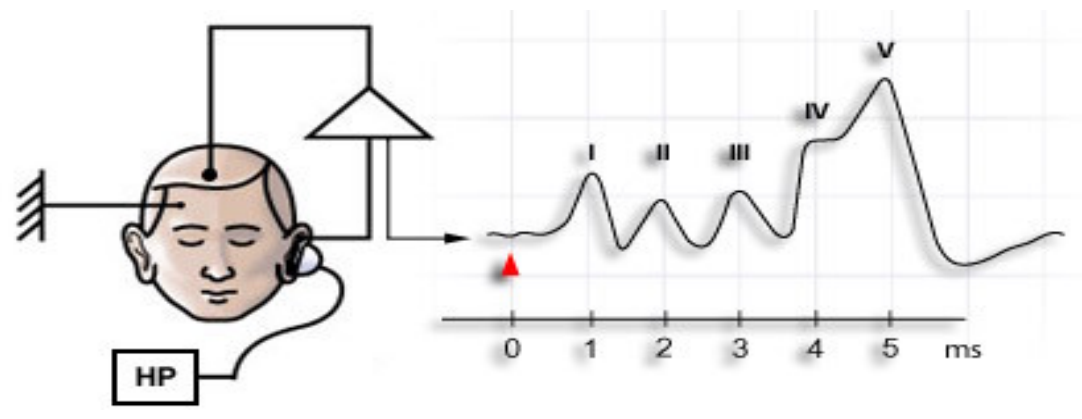

Figura 7. Resultado de um teste de BERA mostrando as ondas de I a V normais.

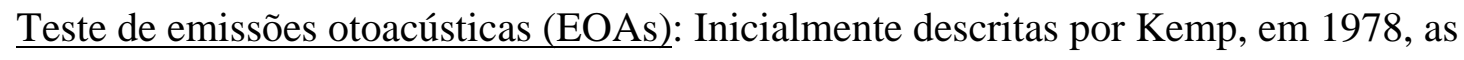
EOAs são sons que decorrem de uma atividade interna à cóclea e que são detectados no meato acústico externo. A origem das EOAs está relacionada à micromecânica das células ciliadas externas, fenômeno que parece ser modulado pelas vias auditivas eferentes. Esse tipo de emissão fornece informações fisiológicas sobre a função coclear, sem ter relação direta com o limiar fisiológico. Acredita-se que as emissões presentes estão relacionadas à integridade da função das células ciliadas externas (revisão em Lewis, 2004). Podem ser geradas de maneira espontânea ou por estimulação sonora e sua captação é feita por meio de um microfone colocado no meato acústico externo. Há vários tipos de testes de EOAs. As mais usadas na triagens auditiva são as EOAs evocadas por estímulo transiente que são emissões registradas 
em resposta a um estímulo sonoro denominado clique (Azevedo, 2004). Na figura 8b pode-se observar o resultado de um exame de EOAs evocadas por estímulo transiente realizado em indivíduo com audição normal apresentando EOAs (histograma azul) superior ao ruído do fundo (histograma vermelho).

(a)

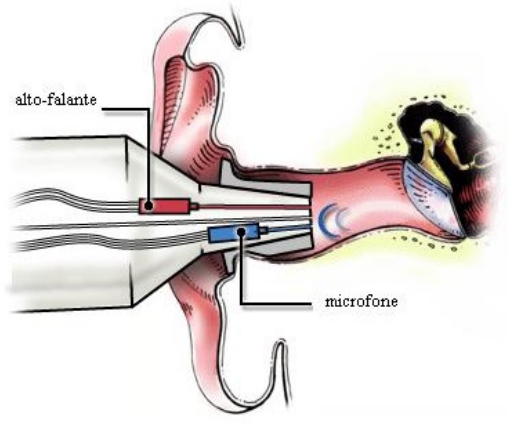

(b)

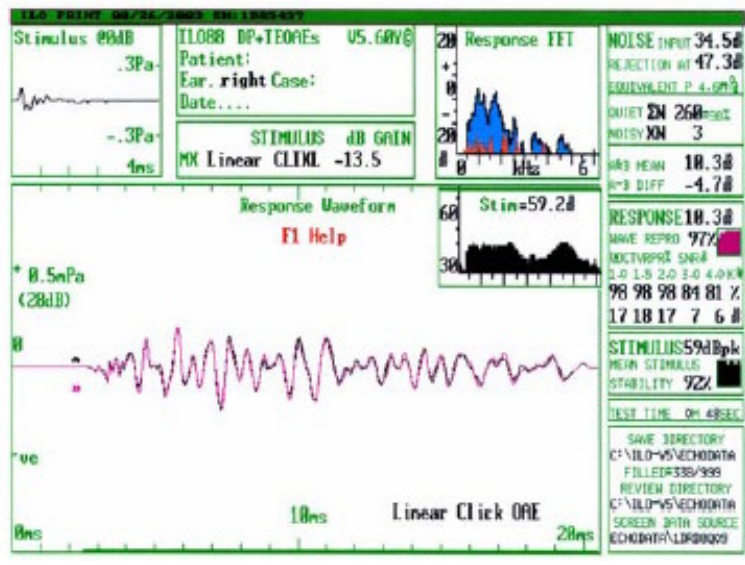

Figura 8. (a) O teste das EOAs realizado com o alto-falante para emitir o estímulo e o microfone para captar as emissões. (b) Registro das EOAs de um indivíduo com audição normal comprovada pela presença das EOAs (histograma azul) maiores do que o ruído do fundo (histograma vermelho).

\section{I.4. Neuropatia Auditiva}

Há alguns anos, o estudo da deficiência auditiva tem se baseado nos resultados obtidos com BERA, principalmente nos casos de crianças muito pequenas em que há dificuldade de realizar os procedimentos de exames audiológicos de rotina. Na prática clínica, passou-se a observar casos de pacientes com alteração ou ausência de respostas no BERA, porém com resultado normal, quase normal ou audição flutuante na audiometria tonal pura. Com a introdução das EOAs, ampliou-se a bateria de exames audiológicos e foi possível realizar uma avaliação mais efetiva do funcionamento coclear. Além disso, ficou mais fácil a identificação desse novo grupo de pacientes que apresentam alteração ou ausência de respostas no BERA, mesmo com a audição periférica (coclear) preservada. Essa nova patologia foi denominada neuropatia auditiva.

Hood (1998) definiu neuropatia auditiva como o termo utilizado para descrever condições que podem ser encontradas em pacientes de qualquer idade e que são compatíveis com função normal das células ciliadas externas e alteração na sincronia neural. Então, para o diagnóstico da neuropatia auditiva, os dois testes, BERA e EOAs, são fundamentais. Pacientes com neuropatia auditiva em geral apresentam 
ausência ou alteração das ondas do BERA e presença ou pobre efeito de supressão das EOAs. Outro fator que deve ser levado em consideração é a presença de microfonismo coclear, visto por meio do BERA, que também evidencia a preservação da função coclear. Alguns relatos evidenciam a perda posterior das EOAs em casos de neuropatia auditiva. O desaparecimento das EOAs com passar do tempo foi um dado relevante no estudo realizado por Sininger e Oba (2001) com neonatos portadores de neuropatia auditiva. Segundo esses autores, seu desaparecimento ocorre mais freqüentemente por volta dos quatro anos de idade. A audiometria tonal pura característica dos indivíduos com neuropatia auditiva pode indicar perda de audição de leve a profunda (Mason e col., 2003). Pode fazer parte também do quadro de neuropatia auditiva a audição flutuante, ou seja, em alguns momentos, o indivíduo aparenta ter audição absolutamente normal e, em outros, seu comportamento assemelha-se ao de um indivíduo com deficiência auditiva.

As estimativas da freqüência de neuropatia auditiva na população dos surdos variam entre $1 \%$ e $11 \%$ na literatura (Rance e col., 1999; Tang e col., 2004; Kumar e col., 2006). Essa diferença pode ser devida ao fato de que diferentes populações foram estudadas ou por causa de diferenças de critérios utilizados para identificar pacientes com neuropatia auditiva.

Muitos estudos foram realizados para determinar a localização específica da lesão, bem como os mecanismos responsáveis por essa alteração. Foi postulado como possíveis locais de anormalidade as células ciliadas internas, a sinapse das células ciliadas internas com o nervo coclear, o VIII nervo craniano, a aferência e a eferência das fibras do VIII nervo craniano, os neurônios do ganglio espiral e/ou anormalidades bioquímicas dos neurotransmissores (revisão em Matas e Rondina, 2004). Como não há certeza a respeito da localização específica da lesão ou anormalidade, é possível que existam diferentes tipos de patologias coletivamente chamadas de neuropatia auditiva.

Em geral, a neuropatia auditiva ocorre bilateralmente ( $96 \%$ dos casos) e a maioria dos pacientes são crianças cujos sintomas são identificados já na primeira infância. No que se refere ao sexo, estudos demonstraram não haver uma diferença significativa, com ambos os sexos apresentando números equivalentes de afetados (Sininger e Oba, 2001).

Diversos procedimentos podem ser tentados na reabilitação dos indivíduos portadores de neuropatia auditiva: reabilitação fonoaudiológica, uso de prótese 
auditiva, implante coclear e implante de tronco encefálico. Como não há conhecimento preciso a respeito da alteração em questão e há dificuldade de localização, todos esse tratamentos podem beneficiar ou não os pacientes com neuropatia auditiva, sendo difícil prever o resultado.

\section{I.5. Genética da Neuropatia Auditiva}

Os fatores de risco para neuropatia auditiva não estão claramente estabelecidos. A neuropatia auditiva pode ocorrer sem qualquer outro comprometimento clínico ou ainda estar associada com uma grande variedade de sintomas e condições.

As etiologias da neuropatia auditiva podem ser subdivididas em: metabólicas (anóxia e hiperbilirrubinemia), tóxicas (ototoxicidade), imunológica (desmielinização) e infecciosas (pós-viral), que correspondem a aproximadamente $20 \%$ dos casos; os $80 \%$ restantes podem ser hereditários ou idiopáticos (revisão em Matas e Rondina, 2004).

Nos casos hereditários, a neuropatia auditiva pode ocorrer isoladamente ou em associação a neuropatias periféricas, como nas doenças Kernicterus, Hiperbilirrubinemia neonatal, Anemia Hemolítica, Uremia, Acidose, diabetes, ototoxicidade, Charcot-Marie-Tooth, Ataxia de Friedreich, Stevens-Johnson, EhlersDanlos e Meningite (revisão em Matas e Rondina, 2004).

Em 1991, Bonfils e col. descreveram uma família com surdez progressiva de herança autossômica dominante com características sugestivas de neuropatia auditiva. Em 2002, Madden e col. estudaram 22 pacientes pediátricos. Propuseram a hipótese de que fatores genéticos eram importantes no desenvolvimento da neuropatia em 3 famílias em que ocorreram duas outras crianças afetadas. Em mais dois casos, havia histórico familiar de surdez.

Em 2003, Wang e col. demonstraram que os fatores genéticos têm papel significativo na neuropatia auditiva. Com estudos audiológicos e testes neurológicos caracterizaram os pacientes de quatro famílias chinesas como apresentando neuropatia auditiva não-sindrômica. A análise dos heredogramas sugeria herança recessiva ligada ao X em uma família e herança autossômica recessiva nas outras três famílias, o que reforça a heterogeneidade genética desse distúrbio. 


\section{I.5.1. Neuropatia auditiva com herança autossômica dominante: O loco AUNA1}

Em 2004, Kim e col. estudaram 47 membros de uma família americana de origem européia com neuropatia auditiva de herança autossômica dominante. Os jovens afetados dessa família apresentavam neuropatia auditiva confirmada por audiometria alterada, ausência de ondas no BERA e presença das EOAs. Ao longo do tempo, as EOAs desapareceram e os limiares de audição aumentaram. Foi feito diagnóstico de deficiência auditiva profunda sensório-neural. Os estudos de ligação revelaram Lod score máximo de 9,87 $(\theta=0,019)$ permitindo o mapeamento de um novo loco denominado de AUNA1 na região cromossômica 13q14-21, entre os microssatélites D13S153 e D13S1317 (5,47 cM). Dois afetados homozigotos para esse haplótipo comum a todos os afetados da família não pareciam ser mais gravemente afetados do que os heterozigotos. AUNA1 é o primeiro loco descoberto responsável pela neuropatia auditiva de herança autossômica dominante, mas o gene correspondente ainda não foi identificado.

\section{I.5.2. Neuropatia auditiva com herança recessiva ligada ao cromossomo X: $\mathrm{O}$ loco AUNX1}

Em 2003, Wang e col. estudaram uma família chinesa com sete homens afetados por surdez. Seis dos afetados apresentavam quadro de neuropatia auditiva confirmado pelos exames audiológicos (deficiência auditiva leve a profunda, ausência de ondas no BERA e presença das EOAs). Na genealogia ocorriam somente homens afetados, filhos de pais normais e mães portadoras assintomáticas com familiares homens afetados. Concluíram que a neuropatia auditiva nessa família tinha herança recessiva ligada ao cromossomo $\mathrm{X}$.

Em 2006, o mesmo grupo (Wang e col.) mapeou o loco DFNX1 responsável por neuropatia auditiva com herança recessiva ligada ao cromossomo $\mathrm{X}$, em um intervalo de 42,09 cM delimitado pelos marcadores DXS1220 e DXS8084. O gene correspondente não foi ainda identificado.

\section{I.5.3. Neuropatia auditiva com herança mitocondrial}

Em 2005, Wang e col. descreveram uma paciente chinesa portadora de neuropatia auditiva. A análise da seqüência do DNA mitocondrial nessa paciente identificou várias alterações. A maioria dessas mutações eram polimórficas e foram identificadas na população chinesa, exceto por três mutações: T1095C no gene 12S do 
RNA ribosômico, A8108G (I175V) no CO2, e C14340T (V112M) no ND6. A mutação T1095C afeta o sítio-P do RNAr 12S que é altamente conservado, sugerindo um papel importante na iniciação da síntese de proteínas mitocondriais. Ela já foi associada a deficiência auditiva em duas famílias italianas. Em uma das famílias italianas, a surdez é compatível com quadro de neuropatia auditiva, susceptibilidade a aminoglicosídeo e Parkinsonismo. As duas outras mutações também são conservadas em diferentes organismos. A presença da mutação T1095C em três famílias não aparentadas afetadas por surdez sugere que a mutação poderia estar relacionada com a neuropatia auditiva, assim como talvez também as variantes I175V e V112M.

\section{I.5.4. Neuropatia auditiva de herança autossômica recessiva}

\section{I.5.4.a. O gene $O T O F$}

Chaib e col. (1996a) mapearam um loco responsável por surdez profunda sensório-neural em uma família consangüínea libanesa na região cromossômica 2p2223 que, na época, chamado de DFNB6, foi renomeado posteriormente de DFNB9. O loco foi mapeado em um intervalo de $2 \mathrm{cM}$ delimitado pelos marcadores polimórficos D2S2303 e D2S174 com Lod score máximo de $8.03(\theta=0.00)$.

Em 1999, Yasunaga e col. mapearam mais precisamente o DFNB9, loco de uma forma pré-lingual não-sindrômica de surdez neurosensorial com herança autossômica recessiva. Estudos com várias famílias libanesas permitiram o refinamento do DFNB9 para um intervalo entre D2S158 e D2S174, uma região de 1cM. No mesmo estudo, utilizando a estratégia de clonagem posicional combinada com a análise de genes candidatos, os autores conseguiram seqüenciar um gene de 28 exons codificadores $(5 \mathrm{~kb})$, responsável pela surdez nessas famílias. A homologia detectada entre a proteína codificada por esse gene e a ferlina 1 estudada em C.elegans, levou os autores a denominar essa proteína de otoferlina e seu gene de OTOF (Figura 9). Em quatro famílias consangüineas não aparentadas eles detectaram a mutação Y730X (2416T>A) em homozigose em 21 indivíduos afetados e em heterozigose no seus pais. 


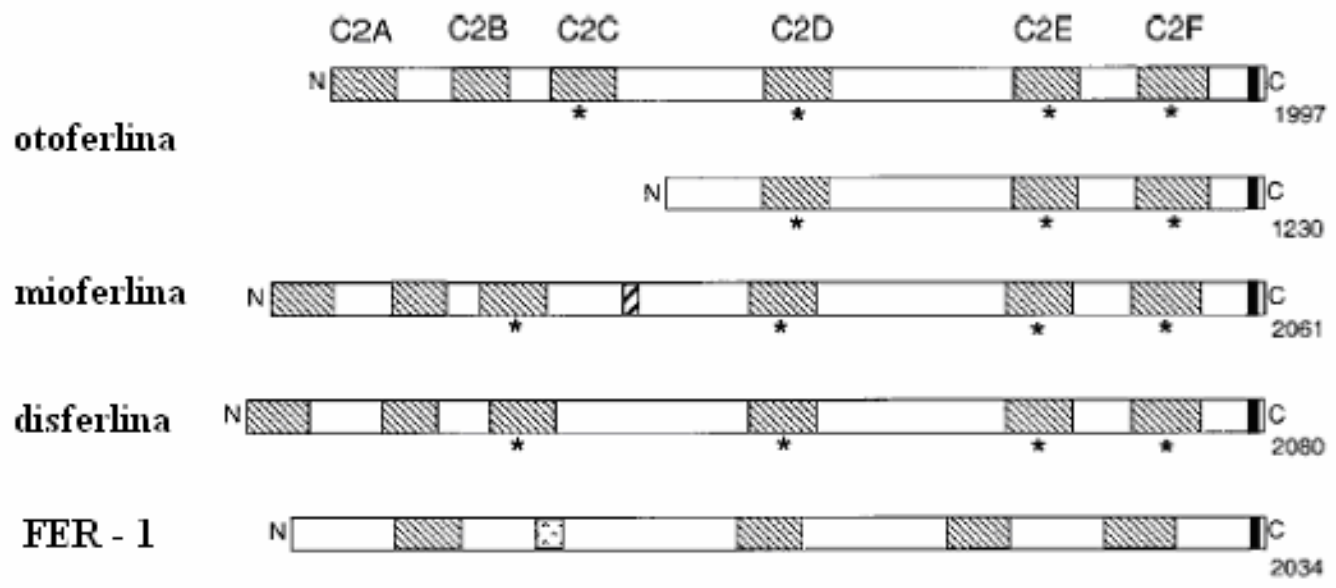

\& Domínio C2 B Domínio SH3 Dominio Saposina B Domínio transmembrânica

Figura 9. Comparação entre a otoferlina humana (isoforma longa e curta), a mioferlina, a disferlina e a proteína fer-1 descrita em C.elegans (Yasunaga e col., 2000).

Em 2000, o mesmo grupo de Yasunaga e col., identificou o RNAm da otoferlina de $7 \mathrm{~kb}$ por Northern blotting. O gene OTOF então compõe- se de 48 exons codificadores, com o primeiro e o último codificando também a 5'-UTR e a 3'-UTR, respectivamente.

OTOF é um membro da família dos genes de mamíferos relacionados ao gene do Caenorhabditis elegans fer-1. Os dois outros membros dessa família, a disferlina e mioferlina, têm seis domínios previstos C2 (Figura 9). O cDNA de 7Kb (GenBank AF183185) isolado do gene OTOF a partir de células do cérebro permite prever um quadro de leitura de 1997 aminoácidos e uma proteína citosólica com a região Cterminal ancorada na membrana com seis domínios previstos $\mathrm{C} 2$. Os quatro últimos domínios $\mathrm{C} 2$ ligam ao $\mathrm{Ca}^{++}$interagindo com fosfolipídeos e proteínas. Todas as proteínas possuindo domínios $\mathrm{C} 2$ estão envolvidas na fusão das vesículas sinápticas à membrana plasmática. Por isso, a otoferlina parece funcionar no transporte de membrana, ativada pelo aumento da concentração do $\mathrm{Ca}++$. Supõe-se que seja importante na fusão das vesículas sinápticas das células ciliadas internas (Yasunaga e col., 2000; Varga e col., 2003).

A análise da seqüência dos aminoácidos da otoferlina mostra a porção Cterminal hidrofóbica (de 33 aminoácidos) incluindo uma série de resíduos de leucina que se prevê formar um domínio transmembrânico. Não há peptídeo líder, nem outro sinal de endereçamento da proteína. Isso sugere que a otoferlina seja uma proteína citosólica. Há também 4 sítios de $\mathrm{N}$-glicosilação e 13 sítios de fosforilação. 
Comparando-se as seqüências, mostra-se que a otoferlina é homóloga à proteína fer-1 de nematóide e à disferlina e mioferlina humana com 23\%, 31\% e 33\% aminoácidos idênticos, e 49\%, 55\% e 43\% de aminoácidos similares, respetivamente (Yasunaga e col, 2000).

O RNA mensageiro da otoferlina é expresso em vários tecidos principalmente cérebro, cóclea e aparelho vestibular. Estudos de hibridização in situ em camundongo mostram que o transcrito é expresso nas células ciliadas internas e externas neonatais, com maior quantidade observada nas células ciliadas internas. O padrão de expressão do RNAm da otoferlina nas células ciliadas internas não muda durante a maturação pós-natal da cóclea. Porém, o sinal diminui progressivamente do ápice para base das células ciliadas externas e desaparece aos 8 dias de vida (Judice e col., 2002). O transcrito existe também nas células sensoriais tipo I do aparelho vestibular (Yasunaga e col., 1999).

O RNAm do gene OTOF tem diversas isoformas, algumas curtas (5kb) e outras longas $(7 \mathrm{~kb})$. Os 19 primeiros exons são exclusivos das isoformas longas, as quais contêm seis domínios previstos $\mathrm{C} 2$, enquanto as isoformas curtas só contêm os três últimos domínios (Figura 10). Por meio de RT-PCR, foram detectadas as isoformas longas na cóclea e no cérebro humanos e em vários tecidos de camundongo, além da cóclea e cérebro. As isoformas curtas foram identificadas nos tecidos humanos como coração, placenta, fígado, pâncreas, músculo esquelético, rim e cérebro. Foram encontrados dois tipos de isoforma curta - isoforma curta 1 e isoforma curta 2 - diferenciadas na região 5' (Figura 10). Não foram detectadas isoformas curtas no camundongo (Yasunaga e col, 2000). 

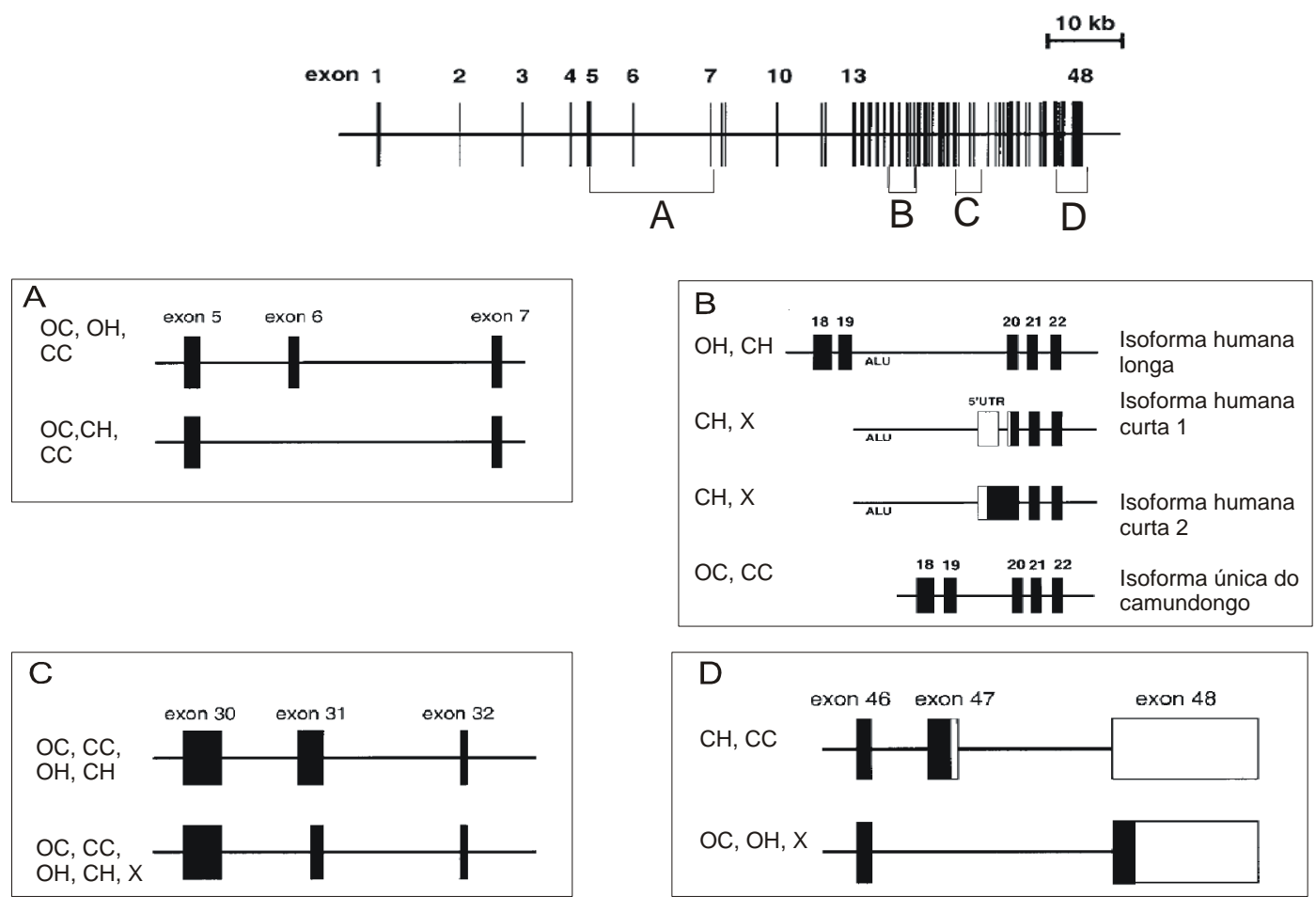

Figura 10. Esquema representativo dos introns e exons do gene OTOF (em cima) e detalhes das regiões dos exons 5-7 (A), 18-22 (B), 30-32 (C) e 46-48 (D) mostrando os diferentes padrões de splicing alternativo nessas regiões; $\mathrm{OH}$ - cóclea humana, $\mathrm{OC}$ - cóclea de camundongo, $\mathrm{CH}$ - cérebro humano, $\mathrm{CC}$ - cérebro de camundongo e $\mathrm{X}$ - outros tecidos humanos. As seqüências codificadoras de aminoácidos estão indicadas em caixas pretas e as regiões não codificadoras de aminoácidos estão em caixas brancas (modificado de Yasunaga e col., 2000).

Além disso, o RNAm sofre outros tipos de splicing alternativo detectados tanto em camundongo como em humano (Figura 10). O exon 6 presente na cóclea, está omitido no cérebro. $\mathrm{O}$ exon 31 possui dois sítios aceptores de splicing. O exon 47 é omitido na cóclea, coração, e rins, levando a uma diferente forma de seqüência da porção C-terminal na isoforma do cérebro, a qual inclui o exon 47. O exon 48 exclusivamente coclear e codifica a porção C-terminal de 60 aminoácidos da otoferlina (Yasunaga e col., 2000; Varga e col, 2003).

Em 2003, Varga e col identificaram, por meio de estudos de ligação, o gene OTOF como responsável por neuropatia auditiva de herança recessiva em quatro famílias. Essas famílias mostraram ligação com marcadores em uma região pequena do cromossomo 2, a qual contém o gene da otoferlina. Mutações foram descobertas no gene da otoferlina em 3 dessas 4 famílias estudadas com neuropatia auditiva (Tabela II).

No mesmo ano, Rodriguez-Ballesteros e col. (2003) publicaram um estudo de correlação genótipo-fenótipo onde observaram que dentre 21 indivíduos que carregavam duas mutações no gene $O T O F, 11$ apresentavam neuropatia auditiva. Esse 
fato é muito importante pois pôde ajudar a direcionar o diagnóstico molecular para esse gene com base no quadro clínico da perda auditiva.

Até agora, vários pesquisadores identificaram diferentes mutações no gene OTOF que são responsáveis pela deficiência auditiva em pacientes com neuropatia auditiva ou quadros de surdez em que não foi investigado detalhadamente o tipo de lesão (Tabela II). Uma dessas mutações, I515T, foi associada a sensibilidade à temperatura em duas crianças norte-americanas. As crianças apresentavam neuropatia auditiva somente quando estavam febris (Varga e col., 2006; Ensembl).

Além disso, várias alterações no gene OTOF foram descritas na literatura como polimórficas e sem efeitos fenotípicos (Migliosi e col., 2002; Mirghomizadeh e col., 2003; Varga e col., 2006).

Em 2002, Migliosi e col. detectaram uma mutação muito freqüente, a Q829X $(2485 C>G)$, em famílias espanholas com surdez. Essa mutação foi detectada em 12/270 propósitos surdos não-aparentados, nos quais mutações no gene da conexina 26 já tinham sido excluídas. A mutação Q829X foi responsável por 3\% de todos os casos de deficiência auditiva recessiva pré-lingual na população espanhola. Esse resultado sugeriu que a mutação Q829X no gene OTOF poderia ter importância populacional significativa na etiologia da surdez. 
Tabela II. Famílias já descritas com mutações patogênicas no gene OTOF (DFNB9). SNSAR = surdez não-sindrômica autossômica recessiva, NANSR = neuropatia auditiva não-sindrômica recessiva.

\begin{tabular}{|c|c|c|c|c|c|}
\hline Localização & $\begin{array}{l}\text { Alteração de } \\
\text { dinucleotídeo }\end{array}$ & $\begin{array}{l}\text { Alteração de } \\
\text { aminoácidos }\end{array}$ & $\begin{array}{l}\text { Quadro } \\
\text { clínico }\end{array}$ & $\begin{array}{l}\text { Origem e número de } \\
\text { famílias estudadas }\end{array}$ & Referências \\
\hline exon8 & $709 \mathrm{C}>\mathrm{T}$ & $\mathrm{R} 237 \mathrm{X}$ & NSRHL & $\begin{array}{l}\text { Emirades Árabes } \\
\text { Unidos (1) }\end{array}$ & Houseman e col., 2001 \\
\hline intron 8 & IVS $8-2 \mathrm{~A}>\mathrm{G}$ & & NSRHL & Índia (1) & Yasunaga e col., 2000 \\
\hline exon 13 & 1180-1181insG & E393fs & NSRHL & Espanha (1) & Del Castillo e col., 2005a \\
\hline exon 14 & 1236delC & P412fs & NSRHL & Espanha (1) & Del Castillo e col., 2005a \\
\hline exon 15 & $1469 \mathrm{C}>\mathrm{A}$ & P490Q & NSRHL & Turquia (1) & Mirghomizadeh e col., 2002 \\
\hline exon 15 & $1544 \mathrm{~T}>\mathrm{C}$ & $\mathrm{I} 515 \mathrm{~T}$ & $\begin{array}{l}\text { NSRHL, } \\
\text { NSRAN }\end{array}$ & $\begin{array}{l}\text { Turquia (1), Estados } \\
\text { Unidos (1) }\end{array}$ & $\begin{array}{l}\text { Mirghomizadeh e col., 2002; } \\
\text { Varga e col., } 2006\end{array}$ \\
\hline exon 16 & 1601delC & P534fs & NSRHL & Espanha (1) & Del Castillo e col., 2005a \\
\hline exon 16 & $1651 \mathrm{delG}$ & & NSRAN & Estados Unidos (1) & Varga e col., 2003 \\
\hline exon 17 & 1886-1887 insA & K629fs & NSRAN & Estados Unidos (1) & Varga e col., 2006 \\
\hline intron 18 & IVS $18+1 \mathrm{G}>\mathrm{T}$ & & NSRAN & Estados Unidos (1) & Varga e col., 2006 \\
\hline exon 19 & $2122 \mathrm{C}>\mathrm{T}$ & R708X & NSRHL & Espanha (1) & $\begin{array}{l}\text { Rodriguez-Ballesteros e col., } \\
2003\end{array}$ \\
\hline exon21 & 2348 delG & G783fs & NSRAN & Estados Unidos (1) & Varga e col., 2006 \\
\hline exon21 & $2381 \mathrm{G}>\mathrm{A}$ & R794H & NSRHL & Estados Unidos (1) & Varga e col., 2006 \\
\hline Exon 22 & $2485 \mathrm{C}>\mathrm{T}$ & Q829X & $\begin{array}{l}\text { NSRHL, } \\
\text { NSRAN }\end{array}$ & $\begin{array}{l}\text { Espanha (26), Cuba } \\
\text { (1), Argentina (2), } \\
\text { França (3) } \\
\text { UK(1),Estados } \\
\text { Unidos(1). }\end{array}$ & $\begin{array}{l}\text { Migliosi e col., 2002; } \\
\text { Rodriguez-Ballesteros e col., } \\
\text { 2003; Gallo-Terán e col., } \\
\text { 2004; Reynoso e col., 2004; } \\
\text { Loundon e col., 2005; } \\
\text { Rouillon e col., 2006; Varga } \\
\text { e col., } 2006\end{array}$ \\
\hline Exon 23 & $2649 \mathrm{C}>\mathrm{A}$ & C883X & NSRHL & Espanha (1) & Del Castillo e col., 2005a \\
\hline Exon 24 & 2684-2685delGG & G895fs & NSRHL & Espanha (1) & Del Castillo e col., 2005a \\
\hline intron 24 & IVS $24+1 G>A$ & & NSRHL & Oriente Médio (1) & Adato e col., 2000 \\
\hline Exon 25 & $\begin{array}{l}\text { 2905- } \\
\text { 2923del19insC }\end{array}$ & A969fs & NSRHL & Espanha (1) & Del Castillo e col., 2005a \\
\hline Exon26 & $3032 \mathrm{~T}>\mathrm{C}$ & L1011P & NSRAN & Turquia(1) & Tekin e col., 2005 \\
\hline intron 28 & IVS $28-2 \mathrm{~A}>\mathrm{C}$ & & NSRAN & $\mathrm{UK}(1)$ & Varga e col., 2006 \\
\hline intron 35 & IV $535+1 \mathrm{G}>\mathrm{T}$ & & NSRHL & Espanha (1) & Del Castillo e col., 2005a \\
\hline exon 36 & $4275 \mathrm{G}>\mathrm{A}$ & W1425X & NSRAN & Espanha (1) & $\begin{array}{l}\text { Rodríguez-Ballesteros e col., } \\
2003\end{array}$ \\
\hline intron 36 & IVS $36+2 T>G$ & & NSRAN & Espanha (1) & $\begin{array}{l}\text { Rodríguez-Ballesteros e col., } \\
2003\end{array}$ \\
\hline exon 37 & $4491 \mathrm{~T}>\mathrm{A}$ & Y1497X & NSRHL & Líbano (4) & Yasunaga e col., 1999 \\
\hline exon 38 & $4559 \mathrm{G}>\mathrm{A}$ & R1520Q & NSRAN & França (1) & Loundon e col., 2005 \\
\hline intron 39 & IVS $39+1 G>C$ & & NSRAN & Estados Unidos (1) & Varga e col., 2006 \\
\hline exon 44 & $5473 \mathrm{C}>\mathrm{G}$ & $\mathrm{P} 1825 \mathrm{~A}$ & NSRHL & Espanha (1) & Migliosi e col., 2002 \\
\hline intron 44 & IVS44+1G>A & & NSRAN & França (1) & Rouillon e col., 2006 \\
\hline exon 48 & $5816 \mathrm{G}>\mathrm{A}$ & R1939Q & NSRAN & Estados Unidos (1) & Varga e col., 2003 \\
\hline exon 48 & $\begin{array}{l}5860- \\
5862 \text { delATC }\end{array}$ & I1954del & NSRAN & Espanha (1) & $\begin{array}{l}\text { Rodríguez-Ballesteros e col., } \\
2003\end{array}$ \\
\hline exon 48 & $5960 \mathrm{C}>\mathrm{G}$ & P1987R & NSRAN & Estados Unidos (1) & Varga e col., 2003 \\
\hline
\end{tabular}




\section{I.5.4.b. Neuropatia auditiva ou patologia endococlear?}

Em 2005, Loundon e col. descreveram uma criança com deficiência auditiva profunda bilateral, confirmada pela ausência das ondas do BERA, mas que apresentava as EOAs. A ausência de histórico médico relevante, o aproveitamento da prótese auditiva e o sucesso do implante coclear sugeriam uma provável patologia endococlear (de células ciliadas internas). Testes genéticos identificaram duas mutações no gene OTOF (IVS44+ 1G>A e Q829X), o que reforçou a idéia de disfunção das células ciliadas internas, dado que o principal local de expressão desse gene são as células ciliadas internas. Classicamente, pacientes com neuropatia auditiva raramente se beneficiam da prótese auditiva ou do implante coclear. Por isso, os autores sugeriram reservar o termo neuropatia auditiva para pacientes com deficiência auditiva profunda associada a uma síndrome neurológica ou com história perinatal relevante. Em contrapartida, no caso dos pacientes que apresentam EOAs preservadas e ondas do BERA ausentes, com mutação no gene $O T O F$, eles supõem que o termo patologia endococlear seria o mais adequado. Os autores chamaram a atenção para os bons resultados com prótese auditiva ou implante coclear obtidos com esse tipo de paciente.

\section{I.5.4.c. O gene DFNB59 (PJVK)}

Em 2006, Delmaghani e col. identificaram um novo gene, no loco DFNB59, na região cromossômica 2q31,1-q31,3 responsável por neuropatia auditiva autossômica recessiva. Foram identificadas as mutações patogênicas R183W e T54I nesse gene em quatro famílias consangüineas iranianas.

O gene DFNB59 (PJVK) codifica uma proteína que foi denominada pejvaquina. A pejvaquina é uma proteína de 352 resíduos semelhante à proteína DFNA5-gasdermina-MLZE, com função desconhecida, mas já relacionada com surdez (loco DFNA5). Por imunohistofluorescência, os autores detectaram a pejvaquina nos corpos celulares dos neurônios das vias auditivas aferentes. Por causa da sua localização, supõe-se que a pejvaquina esteja envolvida na propagação dos potenciais de ação ou no tráfico intracelular. Para estudar melhor o efeito da mutação R183W, os autores desenvolveram o camundongo Dfnb59 knock-in. A linhagem de camundongo homozigota para essa variante tem um quadro de surdez semelhante ao dos pacientes com neuropatia auditiva, com ondas do BERA anormais, indicando uma disfunção neural. 
A identificação de genes responsáveis por neuropatia auditiva é um dos desafios que contribui com a compreensão das bases moleculares dos diferentes fenótipos de surdez. Esse conhecimento é importante para um melhor diagnóstico diferencial, desenvolvimento de tratamentos mais específicos e aconselhamento genético mais preciso. 


\section{OBJETIVOS}




\section{OBJETIVOS}

O objetivo desse projeto foi estudar a importância do gene $O T O F$ como causa de surdez inespecífica ou de neuropatia auditiva em famílias brasileiras. Para atingir esse objetivo, verificamos:

1. A freqüência da mutação Q829X $(2485 \mathrm{C}>\mathrm{G})$ no exon 22 do gene $O T O F$ em todos pacientes com surdez de nossa casuística (343 propósitos).

2. A ocorrência de outras mutações no gene $O T O F$ entre casos de surdez consistentes com herança autossômica recessiva (não associados aos genes GJB2 e GJB6).

3. A ocorrência de outras mutações no gene $O T O F$ entre casos familiais ou isolados que já foram clinicamente diagnosticados como portadores de neuropatia auditiva ou que foram diagnosticados como tendo alterações de tronco encefálico.

4. Se os indivíduos que têm mutações no gene $O T O F$ sempre apresentam a neuropatia auditiva ou se outros tipos de surdez podem ocorrer.

5. A frequiência dos indivíduos com neuropatia auditiva têm mutação no gene OTOF. Pretendemos estabelecer se mutações no gene $O T O F$ são causa freqüente de neuropatia auditiva na nossa população, classicamente atribuída principalmente a causas tóxicas e metabólicas. Esse foi até o momento, o aspecto menos investigado na literatura sobre o gene $O T O F$. 


\section{CASUÍSTICA E MÉTODOS}




\section{CASUÍSTICA E MÉTOdOS}

\section{III.1. Casuística}

Os pacientes foram encaminhados, principalmente, pela instituição DERDIC Divisão de Educação e Reabilitação de Distúrbios da Comunicação da Pontifícia Universidade Católica de São Paulo. Essa instituição compreende uma divisão de ensino, uma divisão clínica e um conjunto de pessoas associadas ao Programa de Orientação Ocupacional e Ensino - POOE. Outros pacientes foram enviados pelo Hospital das Clínicas da Faculdade de Medicina da Universidade de São Paulo, pelo CEPRO - Centro de Ensino Profissionalizante Rotary do Colégio Rio Branco, pelo Departamento de Biologia Celular Genética da Universidade Estadual de Maringá Paraná e pelo Dr. Décio Brunoni da Universidade Federal de São Paulo. A maioria dos propósitos foram atendidos no Centro de Estudos do Genoma Humano, do Departamento de Genética e Biologia Evolutiva do Instituto de Biociências da Universidade de São Paulo. Parte dos indivíduos encaminhados pela DERDIC foram examinados na sede dessa instituição.

Todas as pessoas portadoras de deficiência auditiva que compareceram ao atendimento realizado na Universidade de São Paulo ou na DERDIC foram entrevistadas e preencheram o termo de consentimento livre e esclarecido para o exame e a utilização dos dados para pesquisa. Na entrevista, investigou-se a existência de consangüinidade entre os pais, a história familial, os exames de audição realizados e os possíveis fatores ambientais que poderiam ser responsáveis pelo quadro, como contato com medicamentos ototóxicos, problemas na gestação ou no parto. Cópia da ficha de anamnese está apresentada no Anexo I.

Nossa casuística foi constituída por 343 propósitos com distúrbios auditivos. Foram excluídos dessa casuística somente os indivíduos diagnosticados como portadores de síndromes conhecidas que incluem surdez como sinal. Nem sempre foi possível caracterizar o tipo de surdez nos indivíduos da casuística por falta de informações clínicas ou genealógicas. Dos caracterizados, 42,3\% dos casos foram classificados como familiais e 57,7\% restantes isolados. Dentre os indivíduos em que foi possível obter a idade de manifestação de deficiência auditiva, foi observado que $72,9 \%$ dos propósitos apresentavam surdez pré-lingual e 27,1\% apresentavam surdez pós-lingual. A maioria dos indivíduos apresentavam surdez bilateral, enquanto somente $2 \%$ apresentou surdez unilateral. Nos casos em que foi possível avaliar se a perda auditiva evoluiu, 52,8\% dos propósitos tinham surdez estacionária e 39,5\% 
surdez progressiva. Observamos também que 70,2\% dos casos eram de deficiência auditiva neurossensorial, 2,6\% dos casos eram de perda mista e em 1,4\% a perda era condutiva. Nos casos restantes, cerca de $26 \%$ da amostra, não foi esclarecida a natureza do comprometimento auditivo. Quanto ao limiar de audição, 58,6\% dos casos foram classificados como apresentando perda profunda, $18,5 \%$ como perda severa (ou grave), $19 \%$ como perda moderada e em 3,8\% dos casos a perda era leve.

As mutações 35delG e 167delT (gene GJB2 da conexina 26), $\Delta(G J B 6$ D13S1830) e $\Delta(G J B 6-\mathrm{D} 13 \mathrm{~S} 1854)$ (gene GJB6 da conexina 30) e A1555G, mitocondrial, (gene RNAr 12S) foram testadas em todos os pacientes.

Nossa casuística foi dividida em três grupos principais:

a) O primeiro grupo compreendeu a casuística total de 343 propósitos estudados no laboratório. Como a mutação Q829X no gene OTOF é a terceira mutação mais frequiente que causa surdez de herança autossômica recessiva na população espanhola, testamos essa mutação em toda a casuística para verificar sua freqüência na população brasileira.

b) Dos 343 propósitos, foram selecionados 64 propósitos para serem submetidos ao estudo de microssatélites vizinhos ao gene OTOF. As mutações 35delG, 167delT, $\Delta($ GJB6-D13S1830), $\Delta($ GJB6-D13S1854) e A1555G haviam sido excluídas nesses 64 casos. Constituíam esse grupo 52 casos familiais ou isolados de surdez sugestivos de herança autossômica recessiva, ou seja, famílias com consangüinidade ou com dois ou mais afetados na irmandade, 11 pacientes clinicamente documentados como portadores de neuropatia auditiva (4 pertencem também à classe de herança autossômica recessiva) e 5 casos clinicamente documentados como portadores de alteração no tronco encefálico após o exame do BERA. Os 11 casos de neuropatia auditiva foram clinicamente diagnosticados pelos profissionais da DERDIC (9 casos), pelo Departamento de Otorrinolaringologia da Faculdade de Medicina da Universidade de São Paulo (1 caso) e pelo Dr. Orozimbo Alves Costa Filho (1 caso), após realização dos exames de audiometria, BERA e EOAs.

c) Os 64 casos foram também submetidos ao estudo de mutações por meio de SSCP (do inglês Single Strand Conformational Polymorphism) de 8 exons no gene OTOF, nos quais já tinham sido descritas mutações na época em que esse projeto começou.

d) Nos casos em que análise dos microssatélites mostrou compatibilidade com ligação ao gene OTOF (7 pacientes) e nos 11 casos de neuropatia auditiva (4 desses 
eram familiais e também mostravam compatibilidade com ligação ao gene OTOF), todos os exons do gene OTOF foram seqüenciados (total de 18 pacientes).

Contamos também no laboratório com cerca de 100 amostras colhidas de pessoas ouvintes que foram utilizadas como controles nos estudos de mutações. Essas amostras foram cedidas por colegas do Instituto de Biociências, moradores do Conjunto Residencial da Universidade de São Paulo - CRUSP e doadores de sangue da Fundação Pró-Sangue Hemocentro de São Paulo. Todos os que concordaram em participar do estudo foram entrevistados quanto à existência de deficientes auditivos na família e também assinaram o termo de consentimento livre e esclarecido. Os indivíduos foram classificados como brancos, pardos e negros, o que permitiu a divisão dessa amostra em um grupo constituído por 50 indivíduos classificados como brancos e um grupo constituído por 50 indivíduos classificados como pardos ou negros.

\section{III.2. Métodos}

\section{III.2.1. Extração de DNA e estimativa de concentração}

A maior parte das amostras de DNA foi obtida a partir de linfócitos de sangue periférico, seguindo a rotina do Laboratório de Genética Humana, utilizando-se da técnica de extração de DNA de fenol/clorofórmio. Em algumas amostras, o DNA foi extraído por meio do GFX Genomic Blood DNA Purification Kit (Amersham) ou pelo aparelho Autopure LS (Gentra Systems).

Após a extração, o DNA foi quantificado no espectrofotômetro HITACHI - U2000 e foi preparada uma diluição em água de cerca de 60ng/ $\mu 1$ de DNA. Para confirmação, a concentração após a diluição foi estimada por meio de eletroforese em gel de agarose a $0,8 \%$ por comparação à massa das bandas do padrão de peso molecular $\lambda \mathrm{DNA} /$ HindIII (Invitrogen).

\section{III.2.2. Triagem da mutação Q829X no exon 22 do gene $O T O F$}

A detecção da mutação Q829X foi realizada com base no protocolo descrito por Migliosi e col.(2002). O exon 22 do gene $O T O F$ foi amplificado através da reação em cadeia da polimerase (PCR - Polymerase Chain Reaction) do tipo Touch Down utilizando os primers descritos por Yasunaga e col.(2000): 5'- CC TGG TTG TGA GAA GGT G - 3' e 5' - GGG TCT AGC CTC CTG ATT G - 3'. Este tipo de PCR se 
caracteriza por uma temperatura inicial de hibridação elevada $\left(69^{\circ} \mathrm{C}\right)$ com diminuição progressiva de meio grau nas sucessivas fases até chegar a $62^{\circ} \mathrm{C}$, característica esta que permite obter produto altamente específico. Para um volume final de reação de $25 \mu \mathrm{L}$, contendo $100 \mathrm{ng}$ de DNA total, foram utilizados 0,2 pmoles de cada primer, $1 \mathrm{U}$ de Taq polimerase, $1,5 \mathrm{mM}$ de $\mathrm{MgCl}_{2}, 20 \mathrm{mM}$ TRIS $\mathrm{pH}=8,4,50 \mathrm{mM} \mathrm{KCl}$ e $0,3 \mathrm{mM}$ de cada dNTP. As condições da amplificação foram as seguintes: um ciclo de desnaturação a $94^{\circ} \mathrm{C}$ por 4 min, 14 ciclos "touchdown" de desnaturação a $94^{\circ} \mathrm{C}$ por 30 s, hibridação a $69^{\circ} \mathrm{C}$ por 40 s para o primeiro ciclo com redução de $0,5^{\circ} \mathrm{C}$ por ciclo e extensão a $72^{\circ} \mathrm{C}$ por $1 \mathrm{~min}, 23$ ciclos de desnaturação a $94^{\circ} \mathrm{C}$ por $30 \mathrm{~s}$, hibridação a $62^{\circ} \mathrm{C}$ por 40 s, extensão a $72^{\circ} \mathrm{C}$ por 1 min e extensão final a $72^{\circ} \mathrm{C}$ por $10 \mathrm{~min}$. A verificação da amplificação do produto (298pb) foi feita em gel de agarose a 2\% após coloração com brometo de etídeo. Em seguida, $3 \mu \mathrm{L}$ do produto de PCR foram digeridos com 15 unidades da enzima de restrição $B f a$ I. Foi utilizada como controle amostra de DNA de indivíduo previamente identificado como homozigoto quanto à mutação Q829X (amostra gentilmente cedida por Rodríguez-Ballesteros, M). O produto foi submetido à eletroforese em gel de poliacrilamida a $6 \%$ e visualizado após coloração por impregnação com nitrato de prata (Santos e col., 1993).

A digestão com essa enzima origina dois fragmentos de restrição (291pb e $7 \mathrm{pb}$ ) em amostras de indivíduos que não apresentam a mutação e três fragmentos (168pb, 123pb e 7pb) nas amostras dos indivíduos que apresentam a mutação. Amostras dos heterozigotos para esta mutação irão apresentar os fragmentos de 291pb, 168pb, 123pb e 7pb (Figura 11).

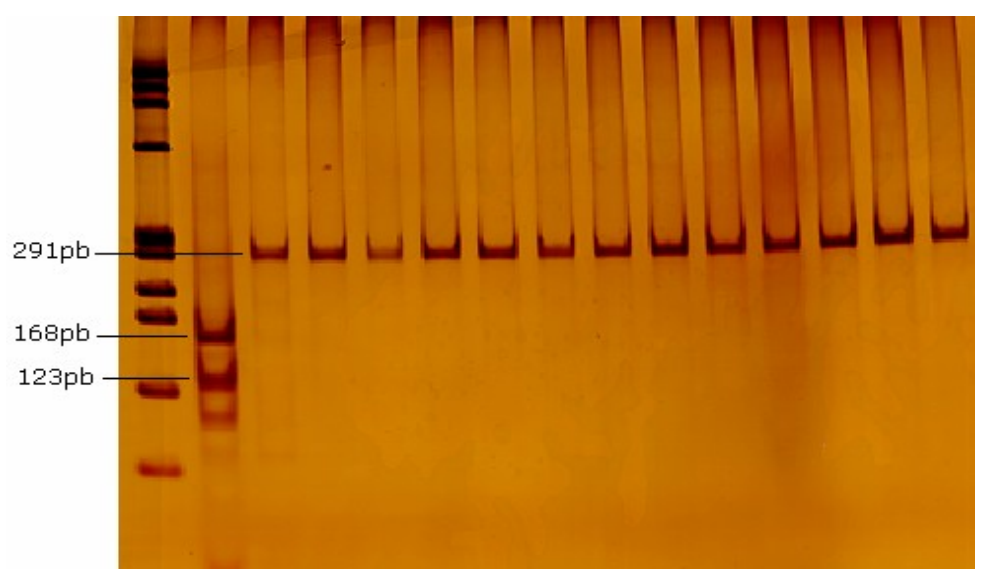

Figura 11. Exemplo de resultado da digestão com enzima de restrição $B f a \mathrm{I}$ dos produtos amplificados do exon 22 do gene OTOF: na pista 1 está o padrão de peso molecular $\mathrm{Fx}$, na pista 2 está a amostra controle, homozigota quanto à mutação Q829X e nas demais são amostras de indivíduos com resultados normais. 


\section{III.2.3. Análise de microssatélites}

Para os estudos de ligação, nossa estratégia foi amplificar os fragmentos polimórficos de cinco marcadores de microssatélites (D2S367, D2S165, D2S305, D2S168, D2S162) vizinhos ao gene OTOF.

Para amplificação desses marcadores moleculares pertencentes ao kit ABI PRISM $^{\circledR}$ Linkage Mapping Set v. 2.5-MD10 da Applied Biosystems, o volume de reação foi $7 \mu \mathrm{l}$ ou $10 \mu \mathrm{l}$ contendo entre 50ng e 100ng de DNA genômico, $0,3 \mu l$ ou $0,66 \mu \mathrm{l}$ de uma mistura de primers a $5 \mu \mathrm{M}, 1,5 \mathrm{U}$ de Taq polimerase, $0,27 \mathrm{mM} \mathrm{dCTP}$, 0,27mM dTTP, $0,27 \mathrm{mM}$ dGTP e 0,27mM dATP; 1,3 a 2,0mM $\mathrm{MgCl}_{2}, 20 \mathrm{mM}$ TRIS $\mathrm{pH}=8,4 ; 50 \mathrm{mM} \mathrm{KCl}$. As condições de amplificação foram desnaturação inicial a $95^{\circ} \mathrm{C}$ por $12 \mathrm{~min}, 10$ ciclos de desnaturação a $94^{\circ} \mathrm{C}$ por $15 \mathrm{~s}$, annealing a $55^{\circ} \mathrm{C}$ ou $54^{\circ} \mathrm{C}$ por $15 \mathrm{~s}$ e extensão a $72^{\circ} \mathrm{C}$ por 30 s, seguidos de 20 ciclos de desnaturação a $89^{\circ} \mathrm{C}$ por $15 \mathrm{~s}$, annealing a $55^{\circ} \mathrm{C}$ ou $54^{\circ} \mathrm{C}$ por $15 \mathrm{~s}$ e extensão a $72^{\circ} \mathrm{C}$ por 30 s e extensão final a $72^{\circ} \mathrm{C}$ por 10min.

A análise dos genótipos em relação aos cinco marcadores moleculares fluorescentes foi realizada no aparelho MegaBACE ${ }^{\mathrm{TM}} 1000$ da Amersham Biosciences utilizando o programa Genetic Profiler versão 1.5. A Figura 12 representa um gráfico obtido após análise dos eletroferogramas no Genetic Profiler, com o tamanho dos alelos observados para o marcador D2S165.
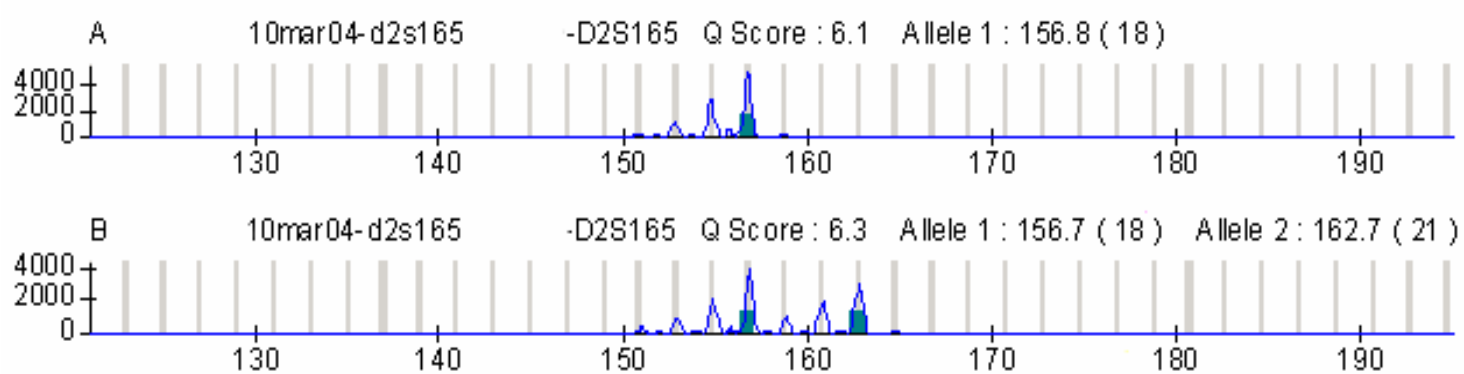

Figura 12. Os gráficos acima indicam os picos de fluorescência dos alelos amplificados com os "primers" referentes ao marcador molecular D2S165 do kit "ABI PRISM ${ }^{\circledR}$ Linkage Mapping Set v. 2.5-MD10". A parte A mostra um indivíduo homozigoto para os fragmentos de $157 \mathrm{pb}$; a parte B mostra um indivíduo heterozigoto para os fragmentos de $157 \mathrm{pb}$ e $163 \mathrm{pb}$.

\section{III.2.4. Pesquisa de outras mutações no gene $O T O F$ por SSCP}

A triagem das mutações em alguns exons do gene $O T O F$ foi realizada por SSCP, a partir dos produtos da PCR obtidos com os primers publicados por Yasunaga e col. (2000) (Tabela III). 
Tabela III. Primers utilizados para amplificação dos exons 5, 15, 16, 19, 22, 36, 37 e 48 (Yasunaga e col., 2000)

\begin{tabular}{|c|c|c|c|}
\hline Exon & Primers Sense & Primers Anti-sense & $\begin{array}{l}\text { Tamanho dos } \\
\text { fragmentos }\end{array}$ \\
\hline 5 & $5^{\prime}$ - TCCAGTGAGGCAAGGGTGT - 3' & 5' - CTTGGATGTCTCTCCAGAAG - 3' & $434 \mathrm{pb}$ \\
\hline 15 & 5' - TGCCACGCCCTCACCTGT - 3' & 5' - TGAAGAGAGGGCATCTCACA - 3' & $303 \mathrm{pb}$ \\
\hline 16 & 5' - TCAGCACCCAGGAGCTGG - 3' & 5' - CCTGGGACCCAGGTGACT - 3' & $405 \mathrm{pb}$ \\
\hline 19 & 5' - TCСТCСАСТCСАCСAATGC - 3' & 5' - CCTCTGACAGCGCCGTCT - 3' & $308 \mathrm{pb}$ \\
\hline 22 & 5' - CC TGG TTG TGA GAA GGT G -3 , & $5^{\prime}-$ GGG TCT AGC CTC CTG ATT G - $3^{\prime}$ & $298 \mathrm{pb}$ \\
\hline 36 & 5' - GGCGCATGATCCTGCAG - 3' & 5' - GCAGTGGTGGGAGGTGAG - 3' & $299 \mathrm{pb}$ \\
\hline 37 & 5' - CTCCTGGTGCTGTTAGCTAT - 3' & 5' - GATGAGGAGACTTGCAAGGAG - 3' & $258 \mathrm{pb}$ \\
\hline 48 & 5' - TTGGGGGTCCAGAAGGACAGA - 3, & 5' - TCGGCCCAAGGCATGAAGA - 3' & $399 \mathrm{pb}$ \\
\hline
\end{tabular}

O método de SSCP baseia-se nas diferentes velocidades de migração eletroforética de fragmentos amplificados por PCR em gel não desnaturante.

Para realização da PCR dos exons 5, 15, 16, 37 e 48 do gene $O T O F$, em um volume final de reação de $25 \mu \mathrm{L}$, contendo 50-100ng de DNA total, foram utilizados 0,4pmoles de cada primer, 1,0U de Taq polimerase, 1,5mM de $\mathrm{MgCl}_{2}, 20 \mathrm{mM}$ TRIS $\mathrm{pH}=8,4,50 \mathrm{mM} \mathrm{KCl} \mathrm{e} 0,2 \mathrm{mM}$ de cada dNTP. As condições da amplificação foram as seguintes: desnaturação inicial $96^{\circ} \mathrm{C}$ por $5 \mathrm{~min}, 30$ ciclos de desnaturação a $94^{\circ} \mathrm{C}$ por 40 s, hibridação a $55^{\circ} \mathrm{C}$ por 30 s e extensão a $72^{\circ} \mathrm{C}$ por 1 min e extensão final a $72^{\circ} \mathrm{C}$ por 10 min. Os exons 19, 22 e 36 do gene $O T O F$ foram amplificados através da PCR do tipo Touch Down, com a mesma estratégia descrita para estudo da mutação Q829X (item III.2.2).

Utilizamos a eletroforese vertical em gel $M D E^{\circledR}$ Gel Solution for heteroduplex and SSCP analysis (Cambrex Bio Science Rockland, Inc.) com adição de glicerol (5\% para os exons 5 e 15 e $3 \%$ para os demais). Os produtos de PCR foram acrescidos de SSCP loading buffer (formamida 95\%, EDTA 0,02M, xilenocianol 0,5\%, azul de bromofenol $0,5 \%$ ) na proporção $1: 1$, sendo que $8 \mu \mathrm{l}$ da mistura eram utilizados para aplicação no gel. As condições de eletroforese, como a velocidade de migração (12 a 20 horas) e a temperatura (ambiente ou $4^{\circ} \mathrm{C}$ ), foram adaptadas dependendo do tamanho de cada fragmento (100 a 400pb) e a velocidade de migração no gel. Assim, enquanto alguns amplicons migraram a $6 \mathrm{~W}$ por 12 horas à temperatura ambiente, outros migraram a $8 \mathrm{~W}$ por 20 horas a $4^{\circ} \mathrm{C}$. Os produtos eram visualizados após coloração com nitrato de prata descrita por Bassam e cols. (1991) e, depois de corado, o gel era fotografado com filme Tyopaque TR-DO (Typon) ou a imagem digitalizada com scanner foi armazenada. 
Os fragmentos que exibiram padrões de migração alterados foram submetidos ao seqüenciamento do DNA para a identificação precisa da mutação.

\section{III.2.5. Seqüenciamento do gene $O T O F$}

O seqüenciamento do DNA foi utilizado para identificar mutações em todos os exons nos propósitos com neuropatia auditiva (11 casos), nos propósitos das famílias em que o estudo de ligação foi consistente com a ligação ao gene OTOF (7 casos) e nos indivíduos que apresentaram fragmentos com migração alterada no SSCP, os exons com alteração foram seqüenciados.

Em primeiro momento, uma reação de PCR foi realizada em duplicata utilizando os primers da Tabela III ou IV. Após amplificação, os produtos de PCR foram purificados utilizando o GFXTM PCR DNA and Gel Band Purification on Kit (Amersham Biosciences) e em seguida quantificados em gel de agarose 2\%, utilizando como padrão o "low DNA mass ladder" (Invitrogen). Depois de purificados e quantificados, os produtos de PCR foram preparados para as reações de seqüenciamento em ambas as direções, nas seguintes condições: 30-60ng de DNA (amplificado e purificado), 0,5pmol de primer, $4 \mu \mathrm{l}$ de DYEnamic ET terminator reagent premix e água para completar o volume de reação para $10 \mu \mathrm{l}$. A mistura foi submetida a 30 ciclos de desnaturação de 20 s a $95^{\circ} \mathrm{C}$, hibridação de 15 s à temperatura correspondente a cada exon $\left(55^{\circ} \mathrm{C}\right.$ para os exons $5,15,16,37$ e 48 e $60^{\circ} \mathrm{C}$ para os restantes) e extensão de 1 minuto a $60^{\circ} \mathrm{C}$. Depois, os produtos foram purificados com AutoSeq96 Dye Terminator Clean $U p$ segundo instruções do fabricante ou precipitados com etanol. Essa precipitação compreende duas centrifugações de 15min cada, à velocidade máxima. A primeira utiliza etanol a 100\% com a finalidade de precipitar o DNA no fundo do tubo. A segunda centrifugação utiliza etanol $70 \%$ com a finalidade de lavar o DNA precipitado. Após essa etapa, deixou-se secar o DNA precipitado por uma noite para resuspendê-lo depois com Loading Buffer. Após a ressuspensão, a reação de seqüenciamento foi analisada no equipamento MegaBACE ${ }^{\mathrm{TM}} 1000$ (Amersham Biosciences).

Todos os exons foram seqüenciados pelo menos duas vezes, uma vez com o primer sense e uma vez com o primer anti-sense. Em alguns, quando a seqüência sense ou anti-sense não foi obtida por problemas técnicos, a seqüência da fita obtida era repetida para confirmação. 
Tabela IV. Primers para amplificação dos demais exons do gene OTOF (Migliosi e col., 2002).

\begin{tabular}{|c|c|c|c|}
\hline Exon & Primers Sense & Primers Anti-sense & $\begin{array}{c}\text { Tamanho dos } \\
\text { fragmentos }\end{array}$ \\
\hline 1 & 5' - GCAGAGAAGAGAGAGGCGTGTGA - 3' & 5' - AGCTGGCGTCCCTCTGAGACA - $3^{\prime}$ & $203 \mathrm{pb}$ \\
\hline 2 & $5^{\prime \prime}$ - CTGTTAGGACGACTCCCAGGATGA - 3' & $5^{\prime}$ - CCAGTGTGTGCCCGCAAGA - $3^{\prime}$ & $239 \mathrm{pb}$ \\
\hline 3 & 5' - CCCCACGGCTCCTACCTGTTAT - 3' & 5' - GTTGGGAGTGTAGGTCCCCTTTTTA - 3' & $256 \mathrm{pb}$ \\
\hline 4 & $5^{\prime}$ - GAGTCCTCCCCAAGCAGTCACAG - 3' & 5' - ATTCCCCAGACCACCCCATGT - 3' & $290 \mathrm{pb}$ \\
\hline 6 & 5' - ACGTGTCCCCTTGTCTCCTCATTT - 3' & $5^{\prime}$ - CCATGACCCGTGCCAGCTCTA - $3^{\prime}$ & $226 \mathrm{pb}$ \\
\hline 7 & $5^{\prime}$ - GTCCCTCTCCCTGCACCTCATT - $3^{\prime}$ & $5^{\prime}$ - TCCTAGAGGGCCACGCATCACT - $3^{\prime}$ & $263 \mathrm{pb}$ \\
\hline 8 & 5' - CAGCCCACCTAACCAGTCTTTCA - $3^{\prime}$ & 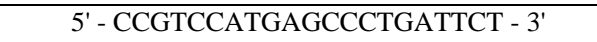 & $267 \mathrm{pb}$ \\
\hline 9 & $5^{\prime}$ - CCTCCTCCCCCACAAGCAGTC - $3^{\prime}$ & 5' - CTAGGAATGCCTCCCAGGAACAAG - 3' & $281 \mathrm{pb}$ \\
\hline 10 & 5' - TAGGCTCAGGCAGCTTTCCTTCT - 3' & 5' - GCCACCCTCCTGCCATATTTACA - 3' & $231 \mathrm{pb}$ \\
\hline 11 & 5' - TGGGGCTCAGGGCAAATGTCT - 3' & 5' - CACGGCGCTGCCTCTTTATCAT - 3' & $295 \mathrm{pb}$ \\
\hline 12 & 5' - GCCCTCCCACTTCACCACAAA - 3' & $5^{\prime}$ - AGCCTGCACACCTCGACTGACT - $3^{\prime}$ & $227 \mathrm{pb}$ \\
\hline 13 & $5^{\prime}$ - CGCTCTGGGTGGGGGTGTCT - 3' & 5' - ACGGGTGGCAGGTGCTCTCA - 3' & $306 \mathrm{pb}$ \\
\hline 14 & 5' - TGGCCCTGGCTGTATGTGCT - 3' & 5' - CCAGGCCCCACACCCATCA - 3' & $290 \mathrm{pb}$ \\
\hline 17 & 5' - CCGACCTGCCACCCTTACTCAA - 3' & 5' - GGGTCAACGTTCCCTACAAGAGTGA - 3' & $299 \mathrm{pb}$ \\
\hline 18 & 5' - GCCTGGTGGGGAATGCACTCTA - 3' & 5' - GAGGCGGGAGGTGAGGTCTTG - 3' & $305 \mathrm{pb}$ \\
\hline 5'UTR & 5' - GCTCACCAGAGCCACAGACTCACA - 3' & 5' - CCTCCCCAGCCTCCCCAAAT - $3^{\prime}$ & $226 \mathrm{pb}$ \\
\hline 20 & 5' - TGATCAACAGGGAGGAGGCATTT - 3' & 5' - GCAGGGTCCCCTTTGTCCAGTT - 3' & $244 \mathrm{pb}$ \\
\hline 21 & $5^{\prime}$ - TGCCAGGGCTGGGCAGAT - $3^{\prime}$ & 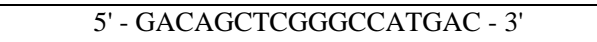 & $261 \mathrm{pb}$ \\
\hline 23 & 5' - GGGGCTCAATCAGGAGGCTAGA - 3' & 5' - CTGCCCCCTCCAGCACCTTA - 3' & $285 \mathrm{pb}$ \\
\hline 24 & 5' - TGGTGACCCCATGCCCAC - 3' & 5' - GGCCTGGTACATGTGCGC - 3' & $344 \mathrm{pb}$ \\
\hline 25 & 5' - GGCTGCCCATCCTGGAACCT - 3' & $5^{\prime}$ - TCACAGGCTTCTGGTGCTCTCAAA - 3' & $221 \mathrm{pb}$ \\
\hline 26 & ${\text { 5' - TGCCCCCCCCTCTGTCACTT - } 3^{\prime}}^{\prime}$ & 5' - GCAGGTGGAGTGCAGGGAACAA - 3' & $256 \mathrm{pb}$ \\
\hline 27 & 5' - CCAAGAGGCTTCTGGGTTGTCTGTT - 3' & $5^{\prime}$ - CCCAGCCCTAGGCCCCAACT - 3' & $262 \mathrm{pb}$ \\
\hline 28 & 5' - GGCAAACAACTCATGGGGAAAGA - 3' & 5' - TGGTGGGAGGGGGATGACAA - 3' & $281 \mathrm{pb}$ \\
\hline 29 & 5' - CATGGCTGGCTCCCTTGACTAA - 3' & 5' - CTCCAAGAAGGGGCAGAGGAA - 3' & $307 \mathrm{pb}$ \\
\hline 30 & 5' - CGGCTTCCTCTGCCCCTTCT - 3' & 5' - GCTTGGTGGCAGGGTGGATGT - 3' & $245 \mathrm{pb}$ \\
\hline 31 & 5' - GCCCCGCCAATCTCACTGTT - 3' & 5' - GATGTGTCACACGAAGTTGCATGTT - 3' & $259 \mathrm{pb}$ \\
\hline 32 & $5^{\prime}$ - CCAGGCCCCAGTGGCTGATT - 3' & 5' - GAGTCCTGCACTCACCCAGCTCTT - 3' & $250 \mathrm{pb}$ \\
\hline 33 & $5^{\prime}$ - GGTGGAGGCTCTCGGGATTGT - 3' & 5' - GAAGCTGGACAGGAGGGTCTGAGT - 3' & $263 \mathrm{pb}$ \\
\hline 34 & 5' - CTTAAGCAGAGCACATGGTGGACTT - 3' & 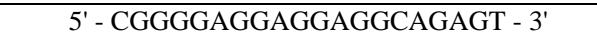 & $256 \mathrm{pb}$ \\
\hline 35 & 5' - GGCCTTCCTGCTCTGCTCATTT - 3' & 5' - CGCCCCCACACACCCTAGAA - 3' & $232 \mathrm{pb}$ \\
\hline 38 & $5^{\prime}$ - CTGGCAGGGGCACTGAAGATGA - $3^{\prime}$ & $5^{\prime}$ - GCAGGGGAGGGCACCAAGAA - 3' & $222 \mathrm{pb}$ \\
\hline 39 & 5' - CTCCCACCCTAGCCAATCCTTAA - $3^{\prime}$ & 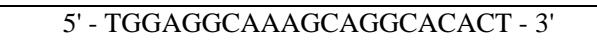 & $273 \mathrm{pb}$ \\
\hline 40 & 5' - CCAGCCCCTCCAAGCCTGT - 3' & $5^{\prime}$ - GCCCCTCCTGGCCTCTGAA - 3' & $260 \mathrm{pb}$ \\
\hline 41 & 5' - AGTCCCTAGTCCCAGCAAAGGTCTT - 3' & $5^{\prime}$ - CCCAATACCCAAGAACCCCAGTC - 3' & $251 \mathrm{pb}$ \\
\hline 42 & 5' - GGTTAGGAGGGAGAGGAGAGCTGAT - 3' & 5' - GTTGGGCCGTGGTGGGAAGT - 3' & $237 \mathrm{pb}$ \\
\hline 43 & 5' - CCAAGACCCCAGGGCTTCTCT - 3' & 5' - CTCCCACCCACAGCCACCTT - $3^{\prime}$ & $300 \mathrm{pb}$ \\
\hline 44 & $5^{\prime \prime}$ - GGCTGCGGGTCTGGAGATGT - 3' & 5' - CCCATCCCTGCCCTGCTCT - 3' & $296 \mathrm{pb}$ \\
\hline 45 & 5' - CACCCCAGCCCTGTTCACTCT - $3^{\prime}$ & 5' - CCAGTCCCAGCCCTGCCTAC - 3' & $269 \mathrm{pb}$ \\
\hline 46 & 5' - GGCAGTAGGCAGGGCTGGGACT - 3' & 5' - GGGTGTCTGGGGATCGTCTCCTT - 3' & $266 \mathrm{pb}$ \\
\hline 47 & $5^{\prime \prime}$ - CCTCTGCGCTCTCTACCCTTCATA - 3' & 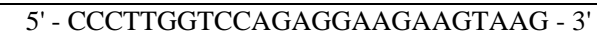 & $264 \mathrm{pb}$ \\
\hline
\end{tabular}




\section{III.2.6. Clonagem}

No caso de deleções detectadas em heterozigose, foi realizada a clonagem dos produtos de PCR em plasmídeos para separar os dois alelos para seqüenciamento. A clonagem foi realizada por meio do kit pGEM-T Easy Vector Systems I (Promega), de acordo a metodologia especificada pelo fabricante. Após obtenção das colônias de bactérias transformadas com os plasmídeos recombinantes, elas foram submetidas a uma reação de PCR com os primers correspodentes a cada exon (Tabelas III e IV). Depois as amostras foram submetidas ao seqüenciamento utilizando o protocolo descrito em III.2.5.

\section{III.2.7. Programas computacionais utilizados para avaliação do efeito das mutações}

Foram utilizados três programas na intenção de avaliar a natureza patogênica ou não das mutações identificadas no gene OTOF: PolyPhen, Blast e ProDom. O programa computacional PolyPhen (http://www.polyphen.com) avalia o potencial efeito das mutações encontradas sobre a função das proteínas, levando em conta a natureza e a conservação dos aminoácidos envolvidos na troca. O Blast (http://www.nci.nlm.nih.gov/BLAST) do Centro Nacional de Informação Biotecnológica (em inglês NCBI) e o programa ProDom (http://prodom.prabi.fr/prodom/current/html/home.php) comparam seqüências de nucleotídeos ou proteínas a um banco de dados de seqüencias de diferentes espécies ou diferentes de proteínas da mesma família, verificando sua conservação.

\section{III.2.8. Estudos Complementares}

Seguindo a rotina do Laboratório de Genética Humana, todos os propósitos foram testados quanto às mutações 35delG, 167delT, $\Delta(G J B 6-\mathrm{D} 13 \mathrm{~S} 1830)$ e $\Delta(G J B 6-$ D13S1854) (genes das conexinas 26 e 30). Esse estudo foi realizado pela aluna de mestrado Ana Carla Batissoco e parte das amostras fez parte da sua dissertação de mestrado: "Mutações nos genes GJB2 e GJB6 em indivíduos com deficiência auditiva" apresentada ao Programa de Pós-Graduação do Instituto de Biociências da Universidade de São Paulo em 2006. Os propósitos foram também testados em relação a mutação A1555G no gene $12 \mathrm{~S}$ rRNA do DNA mitocondrial pelo aluno Ronaldo Serafim Abreu Silva. Parte da casuística foi incluída na sua dissertação de mestrado: "Pesquisa de mutações mitocondriais associadas à deficiência auditiva" 
apresentada ao Programa de Pós-Graduação do Instituto de Biociências da Universidade de São Paulo em 2003 e a metodologia está descrita em Abreu-Silva e col.(2006). 
IV. RESULTADOS E DISCUSSÃO 


\section{RESULTADOS E DISCUSSÃO}

\section{IV.1. Triagem da mutação Q829X no exon 22 do gene $O T O F$}

$\mathrm{Na}$ nossa casuística, a mutação Q829X foi pesquisada por meio de PCR seguida de digestão com enzima de restrição em 343 propósitos. Não foi identificada em nenhum propósito.

A mutação Q829X é a terceira mais freqüente causa de deficiência auditiva hereditária na população espanhola depois das mutações 35delG do gene GJB2 e $\Delta($ GJB6-D13S1830) do gene GJB6 (Migliosi e col., 2002; Del Castillo e col., 2003). Foi encontrada em 12 entre 270 casos de surdez de herança autossômica recessiva, 11 indivíduos eram espanhóis e 1 era cubano (Migliosi e col., 2002). Foi responsável por $3,5 \%$ dos casos de surdez da amostra total. Os pacientes homozigotos e heterozigotos para a mutação Q829X apresentavam neuropatia auditiva ou surdez profunda neurossensorial pré-lingual (Rodriguez-Ballesteros e col., 2003; Gallo-Terán e col., 2004; Loundon e col., 2005; Rouillon e col., 2005; Varga e col., 2006).

Essa mutação foi identificada também em heterozigose em duas famílias argentinas (2/32), duas famílias francesas, uma família de origem mexicana e uma família caucasiana da Inglaterra (Reynoso e col., 2004; Rouillon e col., 2005; Varga e col., 2006). No entanto, não deve ser causa importante de surdez na nossa população dado que não foi encontrada nenhuma vez em nossa amostra.

\section{IV.2. Análise de microssatélites}

Dos 343 propósitos, foram selecionados 64 pacientes para serem submetidos a estudos com cinco marcadores de microssatélites próximos ao gene OTOF. Dos 64 propósitos, 52 eram casos familiais ou isolados de surdez sugestivos de herança autossômica recessiva (famílias com consangüinidade ou com dois ou mais afetados na irmandade), 11 eram casos de pacientes clinicamente diagnosticados como portadores de neuropatia auditiva (4 também pertenciam ao grupo de herança autossômica recessiva) e 5 casos eram clinicamente documentados como portadores de alterações no tronco encefálico.

Os marcadores selecionados, do centrômero para o telômero, foram D2S367, D2S165, D2S305, D2S168 e D2S162. De acordo com o mapa Marshfield (http://www.ncbi.nlm.nih.gov/mapview), o gene OTOF está localizado entre os marcadores D2S165 e D2S305 (Anexo II p.82). 
Nos propósitos que nasceram de casamento consangüíneo, espera-se encontrar homozigoze em relação aos marcadores testados. Nas famílias com dois ou mais afetados, espera-se encontrar os mesmos haplótipos em todos afetados.

Com esse raciocínio, dentre as 64 famílias, conseguimos excluir ligação com o gene $O T O F$ em 34 casos, 19 não foram conclusivos e 11 indicaram compatibilidade com ligação ao gene OTOF. Os resultados completos da análise de microssatélites estão apresentados no Anexo II.

Os propósitos das 11 famílias com resultados compatíveis com ligação ao gene $O T O F$ foram selecionados para o seqüenciamento de todos os exons. Em 4 desses casos, os propósitos tinham também neuropatia auditiva (Anexo II, Famílias $26,33,37$ e 63$)$.

\section{IV.3. Análise de SSCP seguida de seqüenciamento dos exons com alteração}

Simultaneamente ao estudo de ligação, os 64 casos mencionados no item IV.2. foram submetidos ao estudo de mutações por meio de SSCP.

Os 64 propósitos selecionados foram triados para mutações em oito exons do gene $O T O F$ nos quais já havia mutações descritas na literatura (Tabela II). Os exons estudados foram os exons $5,15,16,19,22,36,37$, e 48. Os exons contendo alterações foram sequienciados. O resumo dos resultados dos testes de detecção de mutações por SSCP seguidos de seqüenciamento encontra-se na Tabela V.

Tabela V. Mutações encontradas nos exons dos pacientes que mostraram alteração no SSCP.

\begin{tabular}{|c|c|c|c|c|c|c|}
\hline Exon & Propósito(s) & $\begin{array}{l}\text { Alteração de } \\
\text { nucleotídeos }\end{array}$ & $\begin{array}{l}\text { Alteração de } \\
\text { aminoácidos }\end{array}$ & Freqüência & Genótipo & Referências \\
\hline 5 & vários & $372 \mathrm{~A}>\mathrm{G}$ & $\mathrm{T} 124 \mathrm{~T}$ & $13 / 64$ & $\begin{array}{c}\text { Homozigose / } \\
\text { Heterozigose }\end{array}$ & $\begin{array}{c}\text { Migliosi e col., 2002; } \\
\text { Varga e col., } 2006\end{array}$ \\
\hline 5 & vários & IVS5 + 10A > T & intron & $4 / 64$ & Heterozigose & não descrita \\
\hline 15 & 20 & 1552-1567del16 & $\mathrm{R} 518 f s$ & $1 / 64$ & Heterozigose & não descrita \\
\hline 16 & 41 & IVS16 - 34C>T & intron & $1 / 64$ & Heterozigose & não descrita \\
\hline 19 & 28 & $2168 \mathrm{G}>\mathrm{A}$ & $\mathrm{R} 723 \mathrm{H}$ & $1 / 64$ & Heterozigose & não descrita \\
\hline 22 & 54 & $2464 \mathrm{C}>\mathrm{T}$ & R822W & $1 / 64$ & Heterozigose & Varga e col., 2006 \\
\hline 22 & 10 & $2512 \mathrm{C}>\mathrm{T}$ & L838L & $1 / 64$ & Heterozigose & não descrita \\
\hline 36 & 54 & $4332 \mathrm{C}>\mathrm{T}$ & $\mathrm{T} 1444 \mathrm{~T}$ & $1 / 64$ & Heterozigose & não descrita \\
\hline 36 & vários & $4341 \mathrm{G}>\mathrm{A}$ & E1447E & $2 / 64$ & $\begin{array}{l}\text { Heterozigose } \\
\text { Homozigose / }\end{array}$ & não descrita \\
\hline 36 & vários & IVS36+53delCCinsT & intron & $15 / 64$ & Heterozigose & não descrita \\
\hline 37 & 43 & $4435 \mathrm{G}>\mathrm{A}$ & G1479S & $1 / 64$ & Heterozigose & não descrita \\
\hline
\end{tabular}


Dentre os 64 propósitos, conseguimos identificar onze alterações diferentes: três alterações intrônicas [IVS5+10A >T, IVS16-34C>T e IVS36+53delCCincT], quatro alterações silenciosas, ou seja, a substituição de nucleotídeo não leva a troca de aminoácidos [372A>G (T124T), 2512C>T (L838L), 4332C>T (T1444T) e 4341G>A (E1447E)], três alterações não-sinônimas, ou seja, nas quais a substituição de nucleotídeo leva a troca de aminoácido [2168G $>$ A (R723H), 2464C > T (R822W), 4435G>A (G1479S)] e uma deleção de 16 pares de bases [1552-1567del16].

As alterações IVS5+10A $>T$, IVS16-34C $>T$ e IVS36+53delCCincT são substituições intrônicas, distantes dos sítios de splicing. A variante IVS5+10A $>\mathrm{T}$ foi encontrada em quatro amostras em heterozigose (propósitos 27, 43, 48 e 53). Concluímos que ligação ao gene $O T O F$ é improvável nas famílias 27, 43 e 48, nas quais os pacientes são filhos de casais consangüineos (Anexo II). Na família 53, a análise dos microssatélites não foi conclusiva pois não temos certeza da consangüinidade dos pais, nem temos amostras de DNA dos irmãos afetados. Como a substituição está relativamente longe dos sítios de splicing, o estudo de microssatélites não indica ligação ao gene $O T O F$ e sua freqüência é relativamente alta na nossa amostra $(6,25 \%)$, consideramos que essa variante é provavelmente um polimorfismo não patogênico. A variante IVS16-34C > T foi identificada em heterozigose no propósito 41. Como ele é filho de primos de segundo grau, esperávamos que uma mutação em homozigose fosse responsável pela surdez. Portanto, é improvável que essa variante seja a causa de surdez. A variante IVS36+53delCCinsT foi encontrada em 15 amostras da casuística de 64 propósitos (23,4\% dos cromossomos). Por ser intrônica e estar em alta freqüência, essa mutação provavelmente não é patogênica.

As alterações 372A $>\mathrm{G}$ (T124T), 2512C $>\mathrm{T}$ (L838L), 4332C $>\mathrm{T}$ (T1444T) e 4341G>A (E1447E) são silenciosas. A variante 372A>G (T124T) foi identificada pela análise de SSCP no exon 5 em 13 amostras que tiveram um padrão de migração similar, mas diferente do padrão apresentado pelos controles. Essa alteração foi descrita na literatura como polimorfismo não patogênico (Migliosi e col., 2002; Varga e col., 2006). No exon 22, foi encontrada a variante 2512C>T (L838L) na amostra 10. No exon 36, foram encontradas as variantes 4332C >T (T1444T) no propósito 54 e 4341G>A (E1447E) nos propósitos 12 e 37. Essas substituições de nucleotídeos não mudam os aminoácidos, por isso foram consideradas como variantes provavelmente sem efeito. 
As alterações 2168G>A (R723H), 2464C>T (R822W), 4435G>A (G1479S) são variantes não-sinônimas. A alteração 2168G>A (R723H) foi identificada no exon 19. Ela leva à substituição de uma arginina por uma histidina, ambos com características polares, no resíduo 723. Essa variante foi identificada em heterozigose na propósita 28, filha de pais consangüíneos, enquanto esperávamos uma mutação em homozigose responsável pela surdez. A análise do programa PolyPhen indicou essa substituição como provavelmente benigna. Os programas Blast e ProDom mostraram que essa região não é conservada entre espécies e entre proteínas da mesma família. Por isso, consideramos a mutação $\mathrm{R} 723 \mathrm{H}$ não patogênica. A variante $2464 \mathrm{C}>\mathrm{T}$ (R822W) causa troca de arginina por triptofano. Foi descrita por Varga e col.(2006) como polimorfismo não patogênico, pois foi encontrada na população norte-americana ouvinte. A mutação 4335G>A (G1479S) foi encontrada em heterozigose no indivíduo 43. A substituição de $G$ por A causa uma troca de glicina $(G)$ por serina $(S)$. Os dois aminoácidos são pequenos mas a glicina $(\mathrm{G})$ é hidrofóbica enquanto a serina $(\mathrm{S})$ é polar. Como a posição 1479 está fora dos domínios C2, considerados essenciais para a função da proteína, a troca não deve ter um efeito patogênico. De acordo com o programa ProDom, essa posição não é conservada. O programa Blast mostrou que a otoferlina da cóclea do Gallus gallus apresenta uma serina na posição correspondente a posição 1479. Segundo o programa PolyPhen, essa troca é benigna, o que provavelmente é o caso.

A última mutação identificada pela técnica de SSCP foi uma deleção de 16 bases. A variante 1552-1567del16 encontrada na amostra 20, é considerada patogênica pois causa parada prematura da tradução. Como apresenta neuropatia auditiva, a paciente foi incluída também no grupo de seqüenciamento completo do gene. No item IV.4.2.c discutiremos melhor essa mutação e o quadro clínico da paciente.

Em resumo, a triagem de mutação no gene OTOF pela técnica de SSCP permitiu a identificação de uma mutação exônica certamente patogênica e sete substituições exônicas provavelmente benignas, das quais cinco nunca haviam sido descritas. Futuros estudos funcionais e estudos populacionais devem ser realizados para verificar a natureza patogênica das novas substituições, mas nenhum dos casos de nosso estudo nos quais elas foram observadas fala a favor dessa hipótese. 


\section{IV.4 Seqüenciamento completo do gene $O T O F$}

\section{IV.4.1 Discussão do significado das alterações identificadas}

As amostras dos propósitos das onze famílias selecionadas por meio do estudo dos microssatélites e de mais sete casos de neuropatia auditiva foram submetidos ao seqüenciamento completo de todos os exons do gene OTOF (total de 18 pacientes). O resultado do seqüenciamento desses pacientes encontra-se resumido na Tabela VI.

Identificamos no total 58 alterações diferentes, somando-se os resultados do seqüenciamento completo do gene e da análise por SSCP seguido de seqüenciamento. Encontramos 40 variantes exônicas (Tabela VII) e 18 alterações intrônicas (Tabela VIII).

No item IV.3, caracterizamos 10 dessas variantes como, provavelmente, não patogênicas [372A>G (T124T), IVS5+10A>T, IVS16-34C>T, 2168G>A (R723H), 2464C $>\mathrm{T}(\mathrm{R} 822 \mathrm{~W}), 2512 \mathrm{C}>\mathrm{T}(\mathrm{L} 838 \mathrm{~L}), 4332 \mathrm{C}>\mathrm{T}(\mathrm{T} 1444 \mathrm{~T}), 4341 \mathrm{G}>\mathrm{A}(\mathrm{E} 1447 \mathrm{E})$, IVS36+53delCCinsT, 4435G>A (G1479S)] e uma deleção como provavelmente patogênica [1552-1567del16]. Das 47 alterações restantes, 26 são mutações não descritas na literatura e 21 são alterações que já foram previamente descritas (Migliosi e col., 2002; Varga e col., 2006; Ensembl).

Das 21 alterações já descritas na literatura, nove são consideradas variantes silenciosas sem efeito fenotípico [2022C > T (D674D), 2580C > G (V860V), 2613C > T (L871L), 2703G >A (S901S), 2736G>C (L912L), 4677G>A (V1559V), 4767C > T (R1589R), 5391C >T (F1797F), 5655C >T (R1885R)]. Seis são polimorfismos intrônicos considerados não patogênicos [IVS2+62C $>\mathrm{T}$, IVS3+55C $>\mathrm{T}$, IVS5+39A>G, IVS32+22G>A, 5'UTR da isoforma curta -136delCC e -259C>T]. A variante -136delCC está no intron 19 que corresponde à região 5'UTR da isoforma curta do gene OTOF. Esse polimorfismo foi encontrado em $38,8 \%$ da população européia ouvinte (Mirghomizadeh e col., 2003). Na nossa amostra de 18 pacientes foi encontrada em 66,7\% dos cromossomos. Quatro das variantes já descritas são variantes não-sinônimas [158C > T (A53V), 244C > T (R82C), 2317C > T (R773C), 4936C > T (P1646S)]. Foram consideradas como polimorfísmos sem efeitos por causa das freqüências superiores a $1 \%$ observadas na população ouvinte espanhola e norteamericana (Migliosi e col., 2002; Varga e col., 2006). Apesar do tamanho pequeno da nossa amostra (18), R82C foi encontrada em 38,9\% dos cromossomos o que indica que ela deve ser um polimorfismo também na população brasileira. 
Tabela VI. Resultado do seqüenciamento dos 48 exons em 18 propósitos. A cor vermelha indica mutação certamente patogênica, a cor verde indica mutação não sinônima ou intrônica ainda não descrita e a cor cinza indica variante provavelmente não patogênica. "na" indica paciente com neuropatia auditiva; "+/-" indica mutação em heterozigose; "+/+" indica alteração em homozigose.

\begin{tabular}{|c|c|c|c|c|c|c|c|c|c|c|c|c|c|c|c|c|c|c|c|}
\hline & $\begin{array}{c}\text { PROPÓSITOS } \\
\text { (na) }\end{array}$ & $\begin{array}{c}1 \\
(\mathrm{na})\end{array}$ & 6 & 7 & 9 & $\begin{array}{r}20 \\
\text { (na) } \\
\end{array}$ & \begin{tabular}{|c|}
$\begin{array}{c}21 \\
(\mathrm{na})\end{array}$ \\
\end{tabular} & \begin{tabular}{|c|}
$\begin{array}{c}26 \\
(\mathrm{na})\end{array}$ \\
\end{tabular} & 29 & $\begin{array}{r}33 \\
\text { (na) } \\
\end{array}$ & 36 & $\begin{array}{c}37 \\
\text { (na) } \\
\end{array}$ & $\begin{array}{r}39 \\
\text { (na) } \\
\end{array}$ & 46 & 51 & \begin{tabular}{|c|}
52 \\
(na) \\
\end{tabular} & \begin{tabular}{|c|}
59 \\
(na)
\end{tabular} & $\begin{array}{r}63 \\
\text { (na) } \\
\end{array}$ & \begin{tabular}{|c|}
64 \\
(na) \\
\end{tabular} \\
\hline \multirow{9}{*}{\begin{tabular}{|c|}
$\mathrm{M}$ \\
$\mathrm{U}$ \\
$\mathrm{T}$ \\
$\mathrm{A}$ \\
$\mathrm{C}$ \\
$\tilde{O}$ \\
$\mathrm{E}$ \\
$\mathrm{S}$
\end{tabular}} & G17G & & & & & & $+/-$ & & & $+/-$ & & $+/-$ & & & & & & & \\
\hline & R33Q & $+/-$ & & & & & & & & & & & & & & & & & \\
\hline & $\mathrm{A} 53 \mathrm{~V}$ & $+/-$ & & & & & & & & & & & & & & & & & $+/-$ \\
\hline & $\mathrm{R} 82 \mathrm{C}$ & $+/-$ & $+/+$ & $+/-$ & & $+/-$ & $+/-$ & & & & $+/-$ & & $+1-$ & & $+/-$ & & $+/-$ & $+/+$ & $+/-$ \\
\hline & $\mathrm{T} 124 \mathrm{~T}$ & & & $+/-$ & $+/+$ & & $+/-$ & & $+/-$ & & & & $+/-$ & $+/-$ & & $+/+$ & & & $+/-$ \\
\hline & R518fs & & & & & $+1-$ & & & & & & & & & & & & & \\
\hline & G614E & & & & & & & & & & & & & & & ++- & & & \\
\hline & D674D & & & & $+/+$ & & & & & & & & & & & $+/-$ & & & \\
\hline & R773C & & & & & & & & & & & & & & & $+/-$ & & & \\
\hline \multirow{26}{*}{$\begin{array}{l}E \\
X \\
O \\
N \\
I \\
C \\
A \\
S\end{array}$} & G783fs & & & & & & & & & & & & $+1-$ & & & & & & \\
\hline & $\mathrm{E} 801 \mathrm{~L}$ & $+/-$ & & & & & & & & & & $+1-$ & 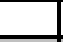 & & & & & & \\
\hline & V860V & & $+/-$ & $+/+$ & $+/+$ & $+/-$ & $+/+$ & $+/+$ & $+/-$ & & $+/-$ & $+/-$ & $+/-$ & $+/-$ & $+/+$ & $+/-$ & & $+/-$ & $+/+$ \\
\hline & L871L & & & & & & & & & & & & & $+/-$ & & & & & \\
\hline & S901S & & & & & & & & & & & & & $+/-$ & & & & & \\
\hline & L912L & $+/-$ & & $+/+$ & $+/+$ & $+/-$ & $+/+$ & $+/+$ & $+/-$ & $+/-$ & $+/-$ & $+1-$ & & $+/+$ & $+/+$ & $+/+$ & & $+/-$ & $+/+$ \\
\hline & A969fs & & $+1-$ & & & & & & & & & & & 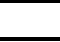 & & 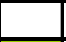 & & & \\
\hline & R1080P & & & & & & & & & & & & & & & $+/-$ & & & \\
\hline & R1134X & & & & & & & $+/+$ & & & & & & & & & & & \\
\hline & C1251G & & & $+/-$ & & & & & & & $+/-$ & & & & & & & $+/-$ & \\
\hline & E1447E & & & & & & & & & & & $+1-$ & & & & & & & \\
\hline & D1528N & & & $+/+$ & & & & $+/+$ & & & & & & & & & & & \\
\hline & $\mathrm{K} 1512 \mathrm{~K}$ & & & & & & & & & & & & & $+/-$ & & & & & \\
\hline & V1559V & & & & & & & & & & & & & $+/-$ & & & & & \\
\hline & R1589R & & & & & & $+/-$ & & & & & & & & & & & & \\
\hline & P1646S & & & & & & & & & $+/-$ & & $+/-$ & & & & $+/-$ & & & \\
\hline & G1654S & & & & & & & & & $+/-$ & & & & & & & & & \\
\hline & E1661K & & & & & & & & & & & & & & & & & $+/-$ & \\
\hline & $\mathrm{T} 1688 \mathrm{M}$ & & & $+/-$ & & & & & & & & & & & & & & & \\
\hline & $\mathrm{F} 1797 \mathrm{~F}$ & & & & & & & & & & & & & & & $+/-$ & & & \\
\hline & K1811X & & & & & & & & & & & & & & & & & $+/-$ & \\
\hline & L1851L & & & & & & & & & & & & & & & & $+/-$ & & \\
\hline & R1885R & & & & & & & & & & & & $+/-$ & & & & & & \\
\hline & $\mathrm{N} 1929 \mathrm{H}$ & & & & & & & & & & & & & & & & & & $+/-$ \\
\hline & L1934fs & & & & & & & & & & & & $+1-$ & & & & & & \\
\hline & A1980S & & & & & & & & & & & & & $+/-$ & & & & & \\
\hline \multirow{16}{*}{\begin{tabular}{|c|}
$\mathrm{M}$ \\
$\mathrm{U}$ \\
$\mathrm{T}$ \\
$\mathrm{A}$ \\
$\mathrm{C}$ \\
$\mathrm{O}$ \\
$\mathrm{O}$ \\
$\mathrm{E}$ \\
$\mathrm{S}$ \\
$\mathrm{IN}$ \\
$\mathrm{T}$ \\
$\mathrm{R}$ \\
$\hat{O}$ \\
$\mathrm{NI}$ \\
$\mathrm{C}$ \\
$\mathrm{A}$ \\
$\mathrm{S}$ \\
\end{tabular}} & IVS2+62C>T & & & & & & & & & & & $+/-$ & & & & & & & \\
\hline & IVS3+55C $>\mathrm{T}$ & $+/+$ & $+/+$ & $+/-$ & & $+/+$ & $+/-$ & $+1+$ & $+/+$ & $+/+$ & & $+/+$ & $+/+$ & $+/-$ & $+/-$ & & $+/+$ & $+/+$ & $+/-$ \\
\hline & IVS3+46G>A & & & & & & & & & & & & $+/-$ & & & & & & \\
\hline & IVS5-59A $>\mathrm{G}$ & & & & & & & & & & & $+1-$ & & & & & & & \\
\hline & IVS5+39A $>T$ & $+/+$ & $+/+$ & $+/-$ & & $+/-$ & $+/-$ & & $+/-$ & $+/+$ & $+/+$ & & $+/-$ & $+/-$ & $+/-$ & $+/+$ & $+/+$ & $+/+$ & $+/-$ \\
\hline & IVS6+28G>A & & & & & & & & & & & & & & $+/-$ & & & & \\
\hline & IVS6+29G>A & & & & & & & & & & & & & & $+/-$ & & & & \\
\hline & IVS6+73G>A & & & $+/-$ & $+1+$ & $+/-$ & $+/+$ & & $+/-$ & $+/-$ & & & $+/+$ & $+/-$ & $+/-$ & $+/+$ & & & $+/-$ \\
\hline & IVS $8+10 C>T$ & & & & & & & & & & $+/-$ & & & & & & & $+/-$ & \\
\hline & IVS12+35T $>C$ & & $+/-$ & & & & & & & & & & & & & & & & \\
\hline & IVS21+36G>A & & & $+/-$ & & & & & & & & & & & & & & & \\
\hline & IVS30-14C $>A$ & & $+1-$ & & & & & & & & & & & & & & & & \\
\hline & IVS32+22G >A & $+/-$ & & $+/-$ & & $+/-$ & $+/-$ & & $+/-$ & & & & & $+/-$ & & & $+/+$ & $+/-$ & $+/+$ \\
\hline & $\begin{array}{c}\text { IVS36+54delCC } \\
\text { insT } \\
\end{array}$ & & & & & & & & & & & $+/-$ & & & $+/-$ & & & & \\
\hline & 5'UTR-136delCC & $+/-$ & & $+/+$ & $+/+$ & $+/-$ & $+/+$ & $+/+$ & $+/-$ & $+/-$ & $+/-$ & $+1-$ & $+/-$ & $+/+$ & $+/+$ & $+1+$ & & $+/-$ & $+/+$ \\
\hline & 5'UTR-259C>T & & & $+/+$ & $+/+$ & & $+/+$ & $+/+$ & & & & & & $+/+$ & $+/+$ & $+/-$ & & & \\
\hline
\end{tabular}


Tabela VII. Resumo das variantes exônicas identificadas pelo seqüenciamento completo do gene OTOF e pela análise por SSCP seguida de seqüenciamento. Em vermelho temos as mutações certamente patogênicas, em preto as não patogênicas e em verde as variantes não-sinônimas ainda não descritas. "Hetero" indica mutação em heterozigose; "Homo" indica mutação em homozigose.

\begin{tabular}{|c|c|c|c|c|c|c|}
\hline Exon & Freqüência & $\begin{array}{l}\text { Alteração de } \\
\text { nucleotídeos }\end{array}$ & $\begin{array}{l}\text { Alteração de } \\
\text { aminoácidos }\end{array}$ & Genótipo & Patogenicidade & Referênçia \\
\hline 1 & $3 / 18$ & $51 \mathrm{C}>\mathrm{T}$ & G17G & Hetero & Não patogênica & não descrita \\
\hline 2 & $1 / 18$ & $98 \mathrm{G}>\mathrm{A}$ & R33Q & Hetero & $?$ & não descrita \\
\hline 3 & $2 / 18$ & $158 \mathrm{C}>\mathrm{T}$ & A53V & Hetero & Não patogênica & Varga e col., 2006 \\
\hline 4 & $11 / 18$ & $244 \mathrm{C}>\mathrm{T}$ & $\mathrm{R} 82 \mathrm{C}$ & Homo/ Hetero & Não patogênica & $\begin{array}{c}\text { Migliosi e col., 2002; } \\
\text { Varga e col., } 2006\end{array}$ \\
\hline 5 & $13 / 64$ & $372 A>G$ & $\mathrm{~T} 124 \mathrm{~T}$ & Homo/ Hetero & Não patogênica & $\begin{array}{l}\text { Migliosi e col., 2002; } \\
\text { Varga e col., } 2006\end{array}$ \\
\hline 15 & $1 / 64$ & 1552-1567del16 & R518fs & Hetero & Patogênica & não descrita \\
\hline 17 & $1 / 18$ & $1841 \mathrm{G}>\mathrm{A}$ & G614E & Hetero & $?$ & não descrita \\
\hline 18 & $2 / 18$ & $2022 \mathrm{C}>\mathrm{T}$ & D674D & Homo/ Hetero & Não patogênica & Varga e col., 2006 \\
\hline 19 & $1 / 64$ & $2168 \mathrm{G}>\mathrm{A}$ & $\mathrm{R} 723 \mathrm{H}$ & Hetero & $?$ & não descrita \\
\hline 21 & $1 / 18$ & $2317 \mathrm{C}>\mathrm{T}$ & $\mathrm{R} 773 \mathrm{C}$ & Hetero & Não patogênica & $\begin{array}{c}\text { Migliosi e col., 2002; } \\
\text { Varga e col., } 2006\end{array}$ \\
\hline 21 & $1 / 18$ & 2348delG & G783fs & Hetero & Patogênica & Varga e col., 2006 \\
\hline 21 & $1 / 18$ & $\begin{array}{l}2401 \mathrm{G}>\mathrm{T}, \\
2402 \mathrm{~A}>\mathrm{T}\end{array}$ & E801L & Hetero & $?$ & não descrita \\
\hline 22 & $1 / 64$ & $2464 \mathrm{C}>\mathrm{T}$ & R822W & Hetero & Não patogênica & Varga e col., 2006 \\
\hline 22 & $1 / 64$ & $2512 \mathrm{C}>\mathrm{T}$ & L838L & Hetero & Não patogênica & não descrita \\
\hline 23 & $15 / 18$ & $2580 \mathrm{C}>\mathrm{G}$ & V860V & Homo/ Hetero & Não patogênica & $\begin{array}{l}\text { Migliosi e col., 2002; } \\
\text { Varga e col., } 2006\end{array}$ \\
\hline 23 & $1 / 18$ & $2613 C>T$ & L871L & Hetero & Não patogênica & Ensembl \\
\hline 24 & $1 / 18$ & $2703 \mathrm{G}>\mathrm{A}$ & S901S & Hetero & Não patogênica & Ensembl \\
\hline 24 & $16 / 18$ & $2736 \mathrm{G}>\mathrm{C}$ & L912L & Homo/ Hetero & Não patogênica & Ensembl \\
\hline 25 & $1 / 18$ & $\begin{array}{c}\text { 2905- } \\
\text { 2923del19ins11 }\end{array}$ & A969fs & Hetero & Patogênica & $\begin{array}{l}\text { Del Castillo e col., } \\
2005 \mathrm{a}\end{array}$ \\
\hline 27 & $1 / 18$ & $3239 G>C$ & R1080P & Hetero & $?$ & não descrita \\
\hline 28 & $1 / 18$ & $3400 \mathrm{C}>\mathrm{T}$ & R1134X & Homo & Patogênica & não descrita \\
\hline 31 & $3 / 18$ & $3751 \mathrm{~T}>\mathrm{G}$ & $\mathrm{C} 1251 \mathrm{G}$ & Hetero & $?$ & não descrita \\
\hline 36 & $1 / 64$ & $4332 \mathrm{C}>\mathrm{T}$ & $\mathrm{T} 1444 \mathrm{~T}$ & Hetero & Não patogênica & não descrita \\
\hline 36 & $2 / 64$ & $4341 \mathrm{G}>\mathrm{A}$ & E1447E & Hetero & Não patogênica & não descrita \\
\hline 37 & $1 / 64$ & $4435 \mathrm{G}>\mathrm{A}$ & G1479S & Hetero & $?$ & não descrita \\
\hline 38 & $2 / 18$ & $4582 \mathrm{G}>\mathrm{A}$ & D1528N & Homo & $?$ & não descrita \\
\hline 38 & $1 / 18$ & $4537 \mathrm{~A}>\mathrm{G}$ & K1512K & Hetero & Não patogênica & não descrita \\
\hline 39 & $1 / 18$ & $4677 \mathrm{G}>\mathrm{A}$ & V1559V & Hetero & Não patogênica & Varga e col., 2006 \\
\hline 39 & $1 / 18$ & $4767 \mathrm{C}>\mathrm{T}$ & $\mathrm{R} 1589 \mathrm{R}$ & Hetero & Não patogênica & Varga e col., 2006 \\
\hline 40 & $3 / 18$ & $4936 \mathrm{C}>\mathrm{T}$ & P1646S & Hetero & Não patogênica & Varga e col., 2006 \\
\hline 40 & $1 / 18$ & $4960 \mathrm{G}>\mathrm{A}$ & G1654S & Hetero & $?$ & não descrita \\
\hline 41 & $1 / 19$ & $4981 G>A$ & E1661K & Hetero & $?$ & não descrita \\
\hline 41 & $1 / 18$ & $5063 \mathrm{C}>\mathrm{T}$ & $\mathrm{T} 1688 \mathrm{M}$ & Hetero & $?$ & não descrita \\
\hline 44 & $1 / 18$ & $5391 \mathrm{C}>\mathrm{T}$ & F1797F & Hetero & Não patogênica & $\begin{array}{c}\text { Migliosi e col., 2002; } \\
\text { Varga e col., } 2006\end{array}$ \\
\hline 44 & $1 / 18$ & $5431 \mathrm{~A}>\mathrm{T}$ & K1811X & Hetero & Patogênica & não descrita \\
\hline 45 & $1 / 18$ & $5553 \mathrm{G}>\mathrm{C}$ & L1851L & Hetero & Não patogênica & não descrita \\
\hline 45 & $1 / 18$ & $5655 \mathrm{C}>\mathrm{T}$ & R1885R & Hetero & Não patogênica & $\begin{array}{l}\text { Migliosi e col., 2002; } \\
\text { Varga e col., } 2006\end{array}$ \\
\hline 46 & $1 / 18$ & $5785 \mathrm{~A}>\mathrm{C}$ & N1929H & Hetero & $?$ & não descrita \\
\hline 46 & $1 / 18$ & 5800-5801insC & L1934fs & Hetero & Patogênica & não descrita \\
\hline 47 & $1 / 18$ & $5938 \mathrm{G}>\mathrm{T}$ & A1980S & Hetero & $?$ & não descrita \\
\hline
\end{tabular}


Tabela VIII. Resumo das variantes intrônicas identificadas pelo seqüenciamento completo do gene $O T O F$ e pela análise por SSCP seguida de seqüenciamento.

\begin{tabular}{|c|c|c|c|c|}
\hline Intron & Freqüência & $\begin{array}{c}\text { Alteração de } \\
\text { nucleotídeo }\end{array}$ & Genótipo & Referência \\
\hline 2 & $1 / 18$ & $\mathrm{IVS} 2+62 \mathrm{C}>\mathrm{T}$ & $\begin{array}{l}\text { Heterozigose } \\
\text { Heterozigose/ }\end{array}$ & Ensembl \\
\hline 3 & $14 / 18$ & $\mathrm{IVS} 3+55 \mathrm{C}>\mathrm{T}$ & Homozigose & Ensembl \\
\hline 3 & $1 / 18$ & IVS3+46G $>A$ & Heterozigose & não descrita \\
\hline 4 & $1 / 18$ & IVS5-59A>G & Heterozigose & não descrita \\
\hline 5 & $4 / 64$ & IVS5+10A $>\mathrm{T}$ & $\begin{array}{l}\text { Heterozigose } \\
\text { Heterozigose/ }\end{array}$ & não descrita \\
\hline 5 & $15 / 18$ & IVS5+39A $>T$ & Homozigose & Ensembl \\
\hline 6 & $1 / 18$ & IVS6+28G $>A$ & Heterozigose & não descrita \\
\hline 6 & $1 / 18$ & IVS6+29G >A & $\begin{array}{l}\text { Heterozigose } \\
\text { Heterozigose/ }\end{array}$ & não descrita \\
\hline 6 & $11 / 18$ & IVS6+73G $>A$ & Homozigose & não descrita \\
\hline 8 & $2 / 18$ & IVS8+10C>T & Heterozigose & não descrita \\
\hline 12 & $1 / 18$ & IVS12+35T $>C$ & Heterozigose & não descrita \\
\hline 15 & $1 / 64$ & IVS16-34C>T & Heterozigose & não descrita \\
\hline 21 & $1 / 18$ & IVS21+36G $>A$ & Heterozigose & não descrita \\
\hline 29 & $1 / 18$ & IVS30-14C>A & Heterozigose & não descrita \\
\hline 32 & $9 / 18$ & IVS32+22G $>A$ & $\begin{array}{l}\text { Heterozigose } \\
\text { Heterozigose/ }\end{array}$ & Ensembl \\
\hline 35 & $15 / 64$ & IVS36-54delCCinsT & Homozigose & não descrita \\
\hline $\begin{array}{l}5^{\prime} \text { UTR da } \\
\text { isoforma curta } \\
5^{\prime} \mathrm{UTR} \text { da } \\
\text { isoforma curta }\end{array}$ & $16 / 18$ & $\begin{array}{l}-136 \text { delCC } \\
-259 \text { delCC }\end{array}$ & $\begin{array}{l}\text { Heterozigose/ } \\
\text { Homozigose } \\
\text { Heterozigose/ } \\
\text { Homozigose }\end{array}$ & $\begin{array}{c}\text { Mirghomizadeh e col., } 2003 \\
\text { Ensembl }\end{array}$ \\
\hline
\end{tabular}

Foram identificadas na nossa amostra duas mutações já publicadas na literatura como patogênicas. A mutação 2348delG, descrita por Vargas e col. (2006), foi encontrada em heterozigose na paciente 39. Essa variante será discutida no ítem IV.4.2.e. A mutação 2905-2923del19ins11, descrita por Del Castillo e col. (2005a), foi identificada na paciente 6 em heterozigose. A alteração será discutida no ítem IV.4.2.b.

Além das alterações já descritas na literatura, identificamos 26 alterações não publicadas. Três delas são alterações silenciosas, provavelmente não patogênicas [51C > T $(\mathrm{G} 17 \mathrm{G}), 4537 \mathrm{~A}>\mathrm{G}(\mathrm{K} 1512 \mathrm{~K})$ e $5553 \mathrm{G}>\mathrm{C}(\mathrm{L} 1851 \mathrm{~L})]$ e nove são variantes intrônicas [IVS3+46G $>A$, IVS5-59A $>\mathrm{G}, \quad$ IVS6+28G $>A, \quad$ IVS6+29G $>A$, IVS6+73G $>A$, IVS8+10C $>$ T, IVS12+35T $>C, \quad I V S 21+36 G>A, I V S 30-14 C>A] . A$ variante IVS6+73G $>$ A foi encontrada em $41,7 \%$ dos cromossomos. Por isso a consideramos polimorfísmo sem efeito. As oito demais variantes intrônicas encontradas somente em um ou dois propósitos estão relativamente longe dos sítios de splicing. Uma alteração intrônica, longe dos sítios de splicing teoricamente é considerada não patogênica. No entanto, foram identificadas sequiências nos introns 
que afetam o mecanismo de splicing (Goren e col., 2006). Por isso, não podemos concluir com certeza se essas oito variantes são ou não realmente patogênicas, mas é mais provável que não tenham relação com o quadro clínico. Futuros estudos de expressão e populacionais devem ser realizados para caracterizar o significado dessas alterações intrônicas.

Dentre as 26 alterações não descritas, encontramos também 11 variantes nãosinônimas (Tabela IX). A Tabela IX resume os resultados de análises realizadas com três programas de bioinformática, PolyPhen, Blast e ProDom, além das características dos aminoácidos. Em teoria, quando mais diferentes as estruturas são, mais é provável que a troca seja patogênica.

Tabela IX. Resumo dos resultados das análises do PolyPhen, Blast, ProDom e das características dos aminoácidos envolvidos nas onze não-sinônimas mutações, não descritas. "não" significa que o aminoácido não é conservado entre as espécies e as proteínas da família ferlina; "sim” indica que o aminoácido está conservado entre as espécies e as proteínas da família ferlina.

\begin{tabular}{|c|c|c|c|c|c|c|}
\hline Exon & $\begin{array}{c}\text { Alteração de } \\
\text { nucleotídeo }\end{array}$ & $\begin{array}{c}\text { Alteração } \\
\text { de } \\
\text { aminoácido }\end{array}$ & PolyPhen & Blast & ProDom & $\begin{array}{l}\text { Características dos } \\
\text { aminoácidos }\end{array}$ \\
\hline 2 & $98 \mathrm{G}>\mathrm{A}$ & R33Q & Benigna & não & - & $\begin{array}{l}\text { Polar, básico >Polar, } \\
\text { grupo amida }\end{array}$ \\
\hline 17 & $1841 \mathrm{G}>\mathrm{A}$ & G614E & $\begin{array}{l}\text { Possivelmente } \\
\text { patogênica }\end{array}$ & $\operatorname{sim}$ & não & Não polar > Polar, ácido \\
\hline 21 & $\begin{array}{l}2401 \mathrm{G}>\mathrm{T} \\
2402 \mathrm{~A}>\mathrm{T}\end{array}$ & E801L & $\begin{array}{l}\text { Possivelmente } \\
\text { patogênica }\end{array}$ & não & não & Polar, ácido > Não polar \\
\hline 27 & $3239 G>C$ & R1080P & $\begin{array}{l}\text { Possivelmente } \\
\text { patogênica }\end{array}$ & não & não & Polar, básico > Não polar \\
\hline 31 & $3751 \mathrm{~T}>\mathrm{G}$ & $\mathrm{C} 1251 \mathrm{G}$ & $\begin{array}{l}\text { Provavelmente } \\
\text { patogênica }\end{array}$ & não & - & $\begin{array}{c}\text { Polar, grupo sulfúrico > } \\
\text { Não polar }\end{array}$ \\
\hline 38 & $4582 \mathrm{G}>\mathrm{A}$ & D1528N & Benigna & não & não & $\begin{array}{l}\text { Polar, ácido > Polar, } \\
\text { grupo amida }\end{array}$ \\
\hline 40 & $4960 \mathrm{G}>\mathrm{A}$ & G1654S & Benigna & não & não & $\begin{array}{c}\text { Não polar > Polar, grupo } \\
\text { hidroxila }\end{array}$ \\
\hline 41 & $4981 G>A$ & E1661K & Benigna & não & - & $\begin{array}{c}\text { Polar, ácido > Polar, } \\
\text { básico }\end{array}$ \\
\hline 41 & $5063 \mathrm{C}>\mathrm{T}$ & $\mathrm{T} 1688 \mathrm{M}$ & Benigna & não & não & $\begin{array}{c}\text { Polar, grupo hidroxila > } \\
\text { Não polar }\end{array}$ \\
\hline 46 & $5785 \mathrm{~A}>\mathrm{C}$ & $\mathrm{N} 1929 \mathrm{H}$ & Benigna & não & não & $\begin{array}{c}\text { Polar, grupo amida > } \\
\text { Polar, básico }\end{array}$ \\
\hline 47 & $5938 \mathrm{G}>\mathrm{T}$ & A1980S & Benigna & $\operatorname{sim}$ & $\operatorname{sim}$ & $\begin{array}{c}\text { Não polar > Polar, grupo } \\
\text { hidroxila }\end{array}$ \\
\hline
\end{tabular}

Das 11 variantes não-sinônimas, seis são provavelmente não patogênicas. As mutações 4582G>A (D1528N), 4960G>A (G1654S), 4981G>A (E1661K) e $5785 \mathrm{~A}>\mathrm{C}(\mathrm{N} 1929 \mathrm{H})$ são consideradas provavelmente não patogênicas, pois 
encontramos aspargina $(\mathrm{N})$, serina $(\mathrm{S})$, lisina $(\mathrm{K})$ e histidina $(\mathrm{H})$ nas posições correspondentes em outras espécies. A alteração 5063C $>\mathrm{T}$ (T1688M) é provavelmente não patogênica, pois foi encontrada na população espanhola ouvinte (Rodriguez-Ballesteros, comunicação pessoal). A variante 5938G>T (A1980S) está no exon 47 que está ausente na otoferlina da cóclea (Yasunaga e col., 2000). Por isso, concluímos que ela não deve ser causa de surdez. Para confirmar a natureza patogênica ou não das seis alterações, idealmente, estudos populacionais e funcionais devem ser realizados.

As cinco alterações não sinônimas restantes são provavelmente patogênicas. Elas serão discutidas em detalhe no resumo das famílias em que elas foram detectadas (item IV.4.2).

Finalmente, das 26 variantes não descritas, identificamos duas mutações sem sentido [3400C>T (R1134X), 5431A>T (K1811X)] e uma inserção [5800-5801insC (L1934fs)]. Essas mutações são provavelmente patogênicas. Elas serão também discutidas com detalhe no resumo das famílias.

Em resumo, das 58 alterações identificadas (descritas ou não descritas), onze são provavelmente a causa de surdez em sete famílias [98G>A (R33Q), 1552-1567del16 (R518fs), 1841G>A (G614E), 2348delG (G783fs), 2401G>T e 2402A>T (E801L), 2905-2923del19ins11 (A969fs), 3239G >C (R1080P), 3400C >T (R1134X), 3751T>G (C1251G), 5431A>T (K1811X), 5800-5801insC (L1934fs). Discutiremos no próximo item, o resumo de cada família e as alterações encontradas em cada uma delas.

\section{IV.4.2. Conclusões do estudo das famílias selecionadas para seqüenciamento completo do gene $O T O F$}

Em 18 propósitos, encontramos 58 alterações (Tabela VI). Não conseguimos identificar nenhuma mutação potencialmente patogênica que explicasse o quadro de surdez nas famílias 9, 21, 29, 33, 46, 51, 59 e 64.

Nas propósitas 7 e 36, encontramos a alteração 3751T $>$ G (C1251G) em heterozigose. Essa mutação troca um aminoácido com grupo sulfúrico por um aminoácido sem esse grupamento. A falta do grupo sulfúrico pode comprometer o funcionamento da proteína, o que nos leva a acreditar que essa mutação seja patogênica. Mas como não detectamos uma segunda alteração possivelmente patogênica, não podemos afirmar com segurança que essa variante é responsável pelo quadro de surdez nas duas pacientes. 
Identificamos também a variante E801L em heterozigose na propósita 37 que tem quadro clínico compatível com neuropatia auditiva. Essa alteração de aminoácidos foi o resultado de duas alterações 2401G>A e 2402A>T em cis. Segundo nossas análises, a variante E801L pode ser patogênica. Não foi encontrada uma segunda mutação exônica, mas identificamos uma mutação intrônica IVS3+46G>A (Tabela VI). A combinação da mutação E801L com a variante intrônica poderia explicar o quadro de surdez dessa paciente, mas, com as informações disponíveis no momento, é arriscado fazer tal afirmação.

A seguir faremos uma breve descrição das sete demais famílias em que consideramos que as mutações do gene $O T O F$ são a provável causa da surdez.

\section{IV.4.2.a. Família 1}

A propósita 1, encaminhada pelo Hospital das Clínicas da Faculdade de Medicina da Universidade de São Paulo, compareceu ao nosso atendimento aos 21 anos de idade. Ela nasceu de casamento consangüíneo. Apresentou perda auditiva bilateral progressiva desde os 12 anos de idade. Segundo a otorrinolaringologista Dra. Sulene Pirana, a paciente tem um quadro clínico compatível com neuropatia auditiva. Ela tem baixa estatura, apresenta dificuldade visuais no olho direito e teve menstruações irregulares até os 15 anos de idade. Foi estudado o cariótipo no laboratório da Dra. Angela M. Vianna Morgante, do Departamento de Genética e Biologia Evolutiva da Universidade São Paulo, cujo resultado foi normal (46, XX). Além disso, o DNA da propósita foi usado para hibridação em array- $C G H$, que é uma técnica que permite a triagem de ganhos e perdas de segmentos cromossômicos submicroscópicos. Essa técnica foi realizada pela equipe da Dra. Carla Rosenberg, professora visitante do Departamento de Genética e Biologia Evolutiva da Universidade de São Paulo. Não foi detectada nenhuma alteração na propósita.

O seqüenciamento do gene $O T O F$ identificou a variante $98 \mathrm{G}>\mathrm{A}(\mathrm{R} 33 \mathrm{Q})$ no exon 2 em heterozigose. Essa variante está no primeiro domínio C2 da otoferlina, mas esse domínio não é ativo na proteína. Segundo nossas análises (Tabela IX), essa mutação poderia ser benigna mas, na mesma propósita, identificamos uma segunda alteração E801L no exon 21, provavelmente patogênica, em heterozigose (Tabela VI). Como foram encontradas as duas mutações em heterozigose, concluímos que a causa de surdez poderia ser a combinação das mutações, R33Q e E801L, mas estudos 
populacionais de amostras de ouvintes estão em andamento para estudar a frequiência de ambas as alterações e inferir a natureza das mutações.

Não podemos estabelecer com precisão a causa dos outros sinais e sintomas. No entanto, a consangüinidade dos pais pode ter colocado em homozigose alelos desfavoráveis.

\section{IV.4.2.b. Família 6}

A família 6 foi encaminhada pela DERDIC, com dois afetados na irmandade. A família é libanesa. A propósita tinha 2 anos e seu irmão 9 anos de idade (Anexo II). Foi coletado também o material do avô materno igualmente surdo. A propósita (IV:1) e seu irmão (IV:3) são portadores de deficiência auditiva bilateral e profunda, desde o nascimento. As ondas do BERA e as EOAs do paciente IV:1 estão ausentes. O exame das EOAs foi feito aos quatro anos na propósita, idade em que as EOAs freqüentemente se perdem em pacientes com neuropatia auditiva (Sininger e Oba, 2001). É possível que a propósita poderia ter apresentado anteriormente um quadro compatível com neuropatia auditiva, mas não identificado a tempo pelos exames.

A clonagem do DNA do exon 25 da propósita (IV:1) seguida do seqüenciamento detectou uma mutação 2905-2923del19ins11 em heterozigose no gene OTOF (Figura 13). Já descrita na Espanha por Del Castillo e col. (2005a), essa mutação é considerada patogênica pois deleta 19 bases e insere 11 na mesma posição, o que leva a uma mudança no quadro de tradução da proteína. A mesma mutação, estudada por meio de eletroforese em gel de acrilamida a $6 \%$, foi encontrada em heterozigose no irmão (IV:3), na mãe (III:1) e no avó materno (II:4). Nos demais exons, conseguimos identificar duas mutações intrônicas IVS12+35T>C e IVS3014C>A na propósita. Com isso, não podemos afirmar com certeza que uma das variantes intrônicas é a segunda mutação nessa família, dado que é incomum que variantes intrônicas sejam patogênicas. Além disso, não podemos descartar a possibilidade de existência de deleções de exons inteiros que as técnicas por nós utilizadas não detectariam. No entanto, como a mutação 2905-2923del19ins11 segrega com a surdez na família, achamos que é provável que ela seja a causa e que haja uma segunda mutação ainda não detectada por razões metodológicas. 

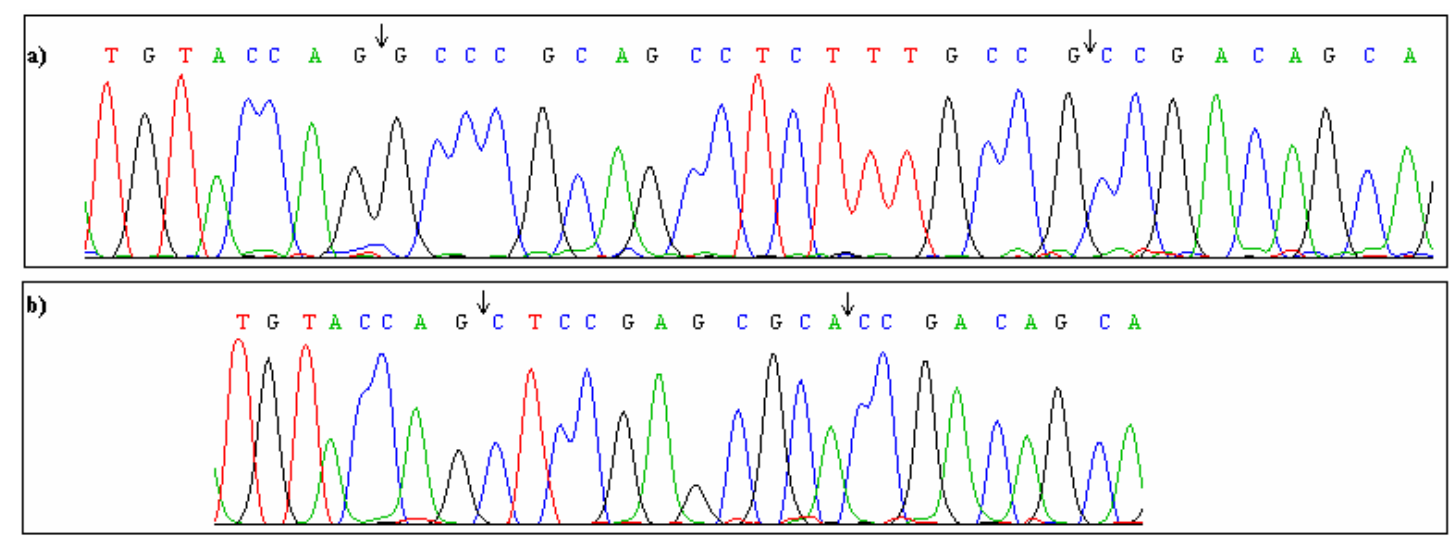

Figura 13. a) Resultado do seqüenciamento da fita sense do DNA de um indivíduo normal que não apresenta a mutação 2905-2923del19ins11 no exon 25. b) Resultado do seqüenciamento da fita sense de um dos alelos da propósita 6, após a clonagem do fragmento com a mutação 2905-2923 del19ins11. As setas indicam os limites da alteração.

\section{IV.4.2.c. Família 20}

A propósita da família 20 foi encaminhada pela DERDIC aos dois anos e sete meses de idade. A surdez foi confirmada entre 10 e 11 meses de idade pelo exame do BERA. A paciente tem deficiência auditiva profunda bilateral. As ondas do BERA estão ausentes em ambas as orelhas, com presença de microfonismo coclear na orelha direita e esquerda. As EOAs transientes estão presentes, o que sugeriu neuropatia auditiva. Ela tinha uma face peculiar, com frontal amplo. Foi realizado o exame de cariótipo no laboratório da Dra. Angela M. Vianna Morgante, que revelou resultado normal (46,XX).

O seqüenciamento dos exons do gene $O T O F$ identificou a mutação 15521567del16 no exon 15 em heterozigose. Separando os dois alelos por clonagem, conseguimos seqüenciar o alelo com a deleção de $16 \mathrm{pb}$ e o alelo normal (Figura 14). Essa deleção modifica o quadro de leitura e leva a um códon prematuro de parada da tradução no exon 16. Não foi detectada uma segunda mutação, porém, não podemos descartar a possibilidade de existência de deleções de exons inteiros que as técnicas por nós utilizadas não detectariam. Por isso, concluímos que a mutação 15521567del16 é provavelmente a causa de surdez e há uma segunda mutação ainda não detectada. 


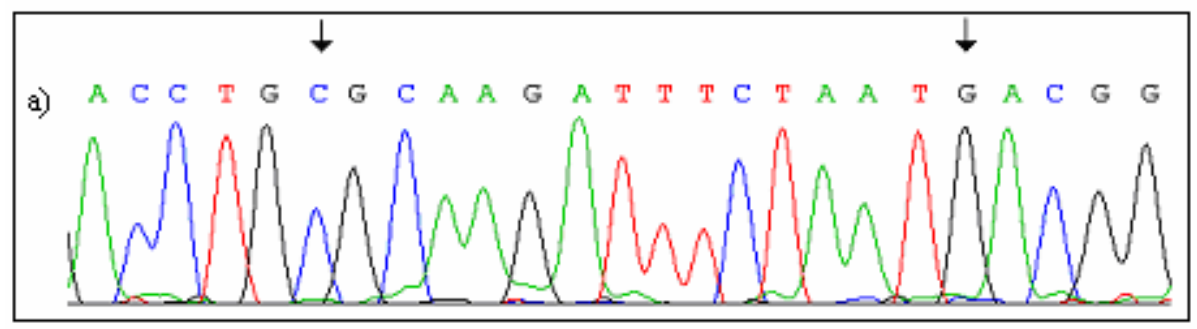

b)
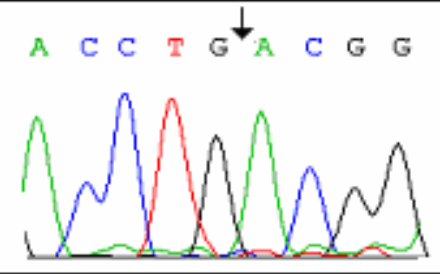

Figura 14. a) Resultado do seqüenciamento da fita sense do DNA de um indivíduo normal que não apresenta a mutação 1552-1567del16 no exon 15. b) Resultado do seqüenciamento da fita sense de um dos alelos da propósita 20, após a clonagem do fragmento com a mutação 1552-1567del16. As setas indicam o local da deleção.

\section{IV.4.2.d. Família 26}

A propósita, encaminhada pela DERDIC, compareceu ao nosso atendimento aos dois anos e dez meses de idade. Ela é filha de pais consangüíneos, primos em primeiro grau. A avaliação audiológica feita pela primeira vez aos dois anos de idade indicou perda auditiva bilateral profunda. A paciente 26 foi diagnosticada como portadora de neuropatia auditiva, confirmada pela presença das EOAs, ausência de ondas do BERA e presença do microfonismo coclear.

No seqüenciamento do gene OTOF foi encontrada a mutação 3400C>T (R1134X) no exon 28 em homozigose (Figura 15). Essa substituição leva à troca de arginina por um códon prematuro de parada da tradução. A mutação foi confirmada em heterozigose nos pais. Assim, concluímos que a perda auditiva apresentada pela paciente 26 é conseqüência da perda de função da otoferlina resultante da mutação R1134X encontrada em homozigose. 


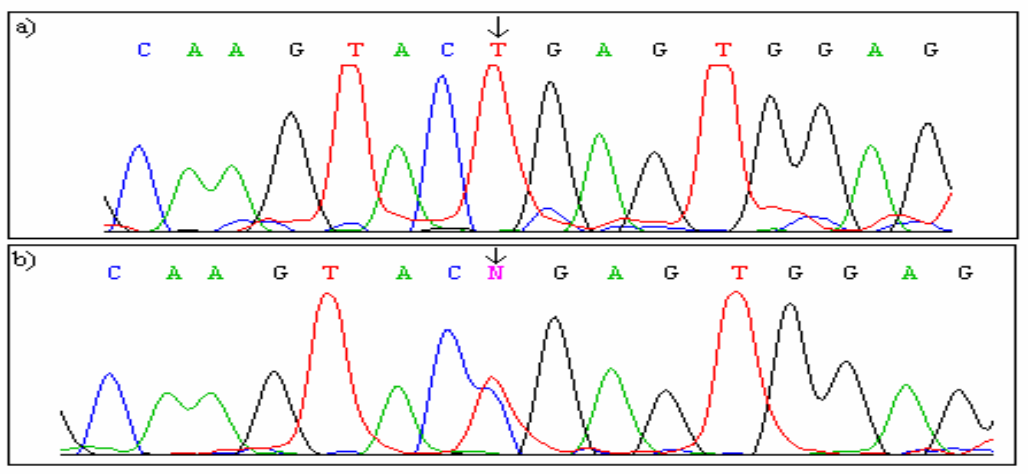

Figura 15. a) Resultado do seqüenciamento da fita sense do DNA da propósitoa apresentando a mutação $3400 \mathrm{C}>\mathrm{T}$ no exon 28 em homozigose. b) Resultado do seqüenciamento da fita sense do pai que apresenta a mutação $3400 \mathrm{C}>\mathrm{T}$ em heterozigose. A seta indica a posição da mutação.

\section{IV.4.2.e. Família 39}

O paciente 39, encaminhado pelo Dr. Decio Brunoni da Universidade Federal de São Paulo, compareceu ao nosso atendimento com dois anos e nove meses de idade. Ele apresentava deficiência auditiva profunda bilateral diagnosticada quando tinha um ano e cinco meses. A ausência de ondas do BERA e a presença das EOAs bilateralmente revelaram que o propósito tem um quadro audiológico compatível com neuropatia auditiva. Cinco meses depois, um novo teste das EOAs detectou uma diminuição nas EOAs. Com três anos e dois meses de idade, o propósito foi submetido à cirurgia de implante coclear.

Foi detectada em heterozigose a deleção 2348delG no exon 21 descrita previamente por Varga e col., 2006 (Figura 16). Além disso, identificamos a inserção 5800-5801insC no exon 46 do gene OTOF. Como todas as deleções e inserções de uma única base, essas mutações modificam o quadro de leitura da proteína. A deleção leva a um códon prematuro de parada da tradução do mesmo exon. É previsto que a inserção cause a adição de 120 aminócidos ao final da proteína. O seqüenciamento do DNA dos pais indicou que a deleção tem origem paterna, enquanto a inserção tem origem materna. Concluímos que a surdez do propósito 39 resulta das mutações 2348delG e 5800-5801insC. 

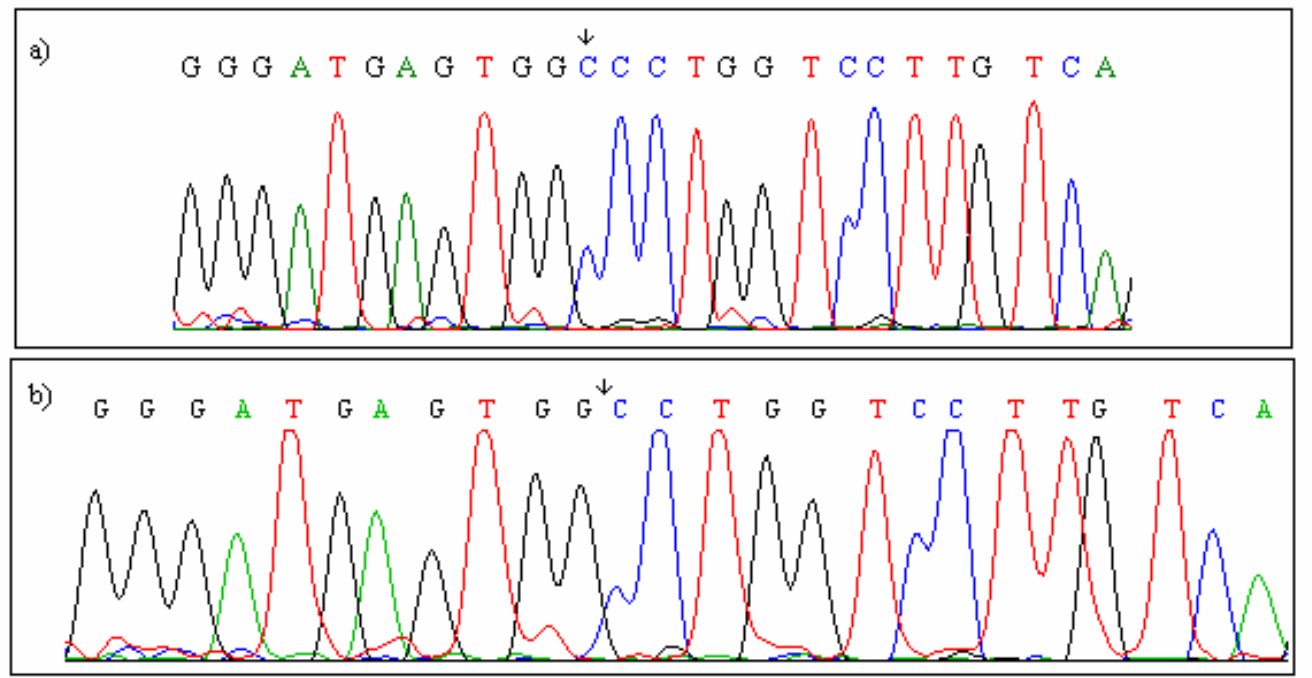

Figura 16. a) Resultado do seqüenciamento da fita anti-sense do DNA de um indivíduo normal que não apresenta a mutação $2348 \mathrm{delG}$ no exon 21 . b) Resultado do seqüenciamento da fita anti-sense de um dos alelos do propósito 39, após a clonagem do fragmento com a mutação 2348delG. As setas indicam o local da deleção.

\section{IV.4.2.f. Família 52}

A propósita 52 foi encaminhada pela DERDIC aos 7 anos de idade. $\mathrm{O}$ primeiro exame audiológico foi realizado aos 6 anos de idade. Segundo os otorrinolaringologistas, a paciente apresenta uma perda auditiva mais severa quando está febril. A alteração de ondas do BERA e a presença das EOAs bilateralmente revelaram que a propósita tem um quadro audiológico compatível com neuropatia auditiva.

Identificamos a mutação 1841G>A (G614E) no exon 17, em heterozigose na propósita. Pelas nossas análises, essa mutação é provavelmente patogênica (Tabela IX). Identificamos na mesma propósita uma segunda mutação 3239G>C (R1080P) no exon 27 e que é também provavelmente patogênica. Já foi descrito na literatura caso com mutação no gene $O T O F$ que apresentava perda auditiva profunda somente em situação de febre (Varga e col., 2006). A paciente descrita também tinha quadro de neuropatia auditiva principalmente na situação de febre. As mutações por nós detectadas podem ter efeito semelhante. A combinação das duas mutações provavelmente explica o quadro de neuropatia auditiva paciente 52 . 


\section{IV.4.2.g. Família 63}

A família 63 foi encaminhada pela DERDIC com duas crianças surdas, aos 4 e 5 anos de idade. O propósito (III:1) de 5 anos, apresenta perda auditiva estacionária profunda sensório-neural. Os exames do BERA do propósito e da sua irmã (III:2) são sugestivos de comprometimento neural com sinais de função coclear preservada bilateralmente (presença do microfonismo coclear). As EOAs estão presentes bilateralmente, indicando a presença de neuropatia auditiva.

O seqüenciamento dos exons do gene $O T O F$ no propósito revelou duas alterações 3751T $>\mathrm{G}$ (C1251G) e 5431 A>T (K1811X). A variante $\mathrm{C} 1251 \mathrm{G}$ foi considerada patogênica (vide item IV.4.2 p.55). A substituição, K1811X, troca a lisina por um códon prematuro de parada no exon 44 (Figura 17). Seqüenciamos o exon 44 do gene $O T O F$ nos pais e na irmã do propósito. O seqüenciamento do DNA do pai e da irmã mostrou a mutação 5431 A>T (K1811X) em heterozigose. Pretendemos confirmar a presença da segunda mutação C1251G na irmã, pois provavelmente a combinação de ambas as alterações é a causa da surdez nessa família.
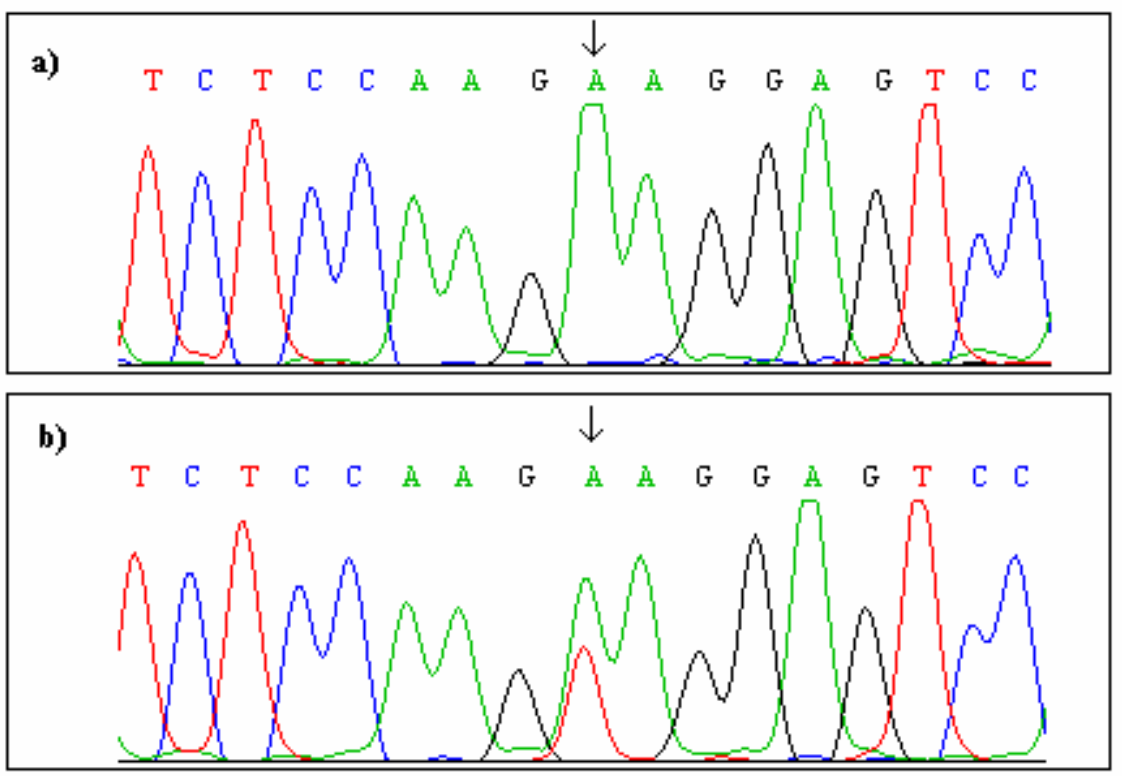

Figura 17. a) Resultado do seqüenciamento da fita sense do DNA de um indivíduo normal, que não apresenta a mutação $5431 \mathrm{~A}>\mathrm{T}$. b)Resultado do seqüenciamento da fita sense do DNA do propósito apresentando a mutação 5431A>T em heterozigose. A seta indica a posição da mutação.

Em resumo, o seqüenciamento dos 18 pacientes (11 com neuropatia auditiva e 11 das famílias compatíveis com ligação ao gene $O T O F$ dos quais 4 pertencem também ao grupo de neuropatia auditiva) identificou sete casos em que mutações do gene $O T O F$ são a provável causa da surdez. 
Dentre os 11 casos selecionados pela neuropatia auditiva, seis são provavelmente explicados por mutações no gene OTOF (Famílias 1, 20, 26, 39, 52 e 63). Nos cinco casos restantes, não foram identificadas mutações no gene OTOF. Por causa de problemas técnicos, faltou o seqüenciamento de dois exons em algums propósitos. Além disso, não foram pesquisadas deleções de exons inteiros e mutações nas regiões não traduzidas do gene $O T O F$. Por isso, não podemos concluir com certeza absoluta que a neuropatia auditiva não seja decorrente de mutações no gene OTOF nesses pacientes. Curiosamente, os resultados dos microssatélites nas famílias 33 e 37 são também compatíveis com ligação ao gene OTOF. Essa compatibilidade pode ser devida a segregação ao acaso dos cromossomos envolvidos. Mutações em outros genes, como $P J V K$ também relacionado à neuropatia auditiva e que está no mesmo cromossomo (2q31,1-q31,3), podem vir a explicar o quadro de neuropatia auditiva nas famílias 33 e 37.

Da amostra de 11 famílias selecionadas por estudo de ligação, somente uma delas (Família 6), além daquelas em que ocorria neuropatia auditiva (Famílias 26 e 63), revelou mutação certamente patogênica no gene $O T O F$. A compatibilidade de ligação ao gene $O T O F$ nas oito restantes poderia também ser atribuída ao acaso, ou talvez haja mutações como deleções de exons inteiros ou alterações em regiões não codificadoras por nós não estudadas. 
V. CONCLUSÕES 


\section{CONCLUSÕES}

Na nossa casuística de 343 indivíduos deficientes auditivos, a mutação Q829X no gene $O T O F$ não foi detectada em nenhum propósito. Portanto, não deve ser causa importante de surdez na nossa população, o que nos leva a conclusão de que do ponto de vista prático, não deve ser incluída na triagem genética de rotina de pesquisa de mutações na surdez, a não ser em casos selecionados.

Nos cinco casos portadores de alterações no tronco encefálico, não conseguimos identificar nenhuma mutação potencialmente patogênica. Porém, somente oito exons foram seqüenciados. Teoricamente, o local de lesão nesses pacientes está provavelmente no nervo auditivo enquanto o gene $O T O F$ se expressa nas células ciliadas internas. Não podemos excluir completamente a possibilidade de alterações no gene $O T O F$ nesses pacientes, pois nem todos os exons foram estudados.

Dos 52 casos familiais ou isolados de surdez sugestivos de herança autossômica recessiva (não associados ao gene GJB2 e GJB6), três são provavelmente explicados por mutações nesse gene $(5,8 \%)$.

Da amostra dos 11 propósitos selecionados por neuropatia auditiva, seis revelaram mutações potencialmente patogênicas. Concluímos que mutações no gene OTOF são causa freqüente de neuropatia auditiva na nossa população, classicamente atribuída a causas tóxicas e metabólicas, principalmente. As mutações do gene OTOF foram a causa de surdez em $2 \%$ dos casos da amostra total. Entre casos de neuropatia auditiva, elas estavam presentes mais de $50 \%$ dos casos.

Conseguimos identificar no total 58 alterações no gene $O T O F$, das quais onze são provavelmente patogênicas. Dentre as 47 não patogênicas, 21 não haviam sido anteriormente descritas. Dentre as 11 patogênicas, 9 nunca haviam sido publicadas.

Nossos resultados reforçam a idéia de que a neuropatia auditiva é um excelente critério de seleção de pacientes para estudo molecular do gene OTOF e que as causas genéticas podem explicar mais da metade dos casos. Além disso, reforçam a importância dos exames de emissões otoacústicas e de BERA no diagnóstico diferencial da surdez. 


\section{REFERÊNCIAS BIBLIGRÁFICAS}




\section{REFERÊNCIAS BIBLIGRÁFICAS}

Abreu-Silva RS. (2003). Pesquisa de mutações mitocondriais associadas à deficiência auditiva. Dissertação de Mestrado. Instituto de Biociências da USP. São Paulo.

Abreu-Silva RS, Lezirovitz K, Braga MC, Spinelli M, Pirana S, Della-Rosa VA, Otto PA, MingroniNetto RC. (2006). Prevalence of the A1555G (12S rRNA) and tRNA Ser(UCN) mitochondrial mutations in hearing-impaired Brazilian patients. Braz J Med Biol Res. 39(2):219-26.

Adato A, Raskin L, Petit C, Bonne-Tamir B. (2000). Deafness heterogeneity in a Druze isolate from the Middle East: novel $O T O F$ and PDS mutations, low prevalence of GJB2 35delG mutation and indication for a new DFNB locus. Eur J Hum Genet. Jun; 8(6):437-42.

Ahmad J, Khan SN, Khan SY, Ramzan K, Riazuddin S, Ahmed ZM, Wilcox ER, Friedman TB, Riazuddin S. (2005). DFNB48, a new nonsyndromic recessive deafness locus, maps to chromosome 15q12-q25.1. Hum Genet. Apr;116(5):407-12.

Ahmed ZM, Smith TN, Riazuddin S, Makishima T, Ghosh M, Bokhari S, Menon PS. Deshmukh D, Griffith AJ, Riazuddin S, Friedman TB, Wilcox ER. (2002). Nonsyndromic recessive deafness DFNB18 and Usher syndrome type IC are allelic mutations of USHIC. Hum Genet. Jun;110(6):527-31.

Ahmed ZM, Riazuddin S, Ahmad J, Bernstein SL, Guo Y, Sabar MF, Sieving P, Riazuddin S, Griffith AJ, Friedman TB, Belvantseva IA, Wilcox ER. (2003a). PCDH15 is expressed in the neurosensory epithelium of the eye and ear and mutant alleles are responsible for both USH1F and DFNB2. Hum Mol Genet. Dec 15;12(24):3215-23.

Ahmed ZM, Morell RJ, Riazuddin S, Gropman A, Shaukat S, Ahmad MM, Mohiddin SA, Fananapazir L, Caruso RC, Husnain T, Khan SN, Riazuddin S, Griffith AJ, Friedman TB, Wilcox ER. (2003b). Mutations of MYO6 Are Associated with Recessive Deafness, DFNB37. Am J Hum Genet 72(5):1315-22.

Ali G, Santos RL, John P, Wambangco MA, Lee K, Ahmad W, Leal S. (2006). The mapping of DFNB62, a new locus for autosomal recessive non-syndromic hearing impairment, to chromosome 12p13.2-p11.23. Clin. Genet.. May; 69(5):429-33.

Ansar M, Din MA, Arshad M, Sohail M, Faiyaz-Ul-Haque M, Haque S, Ahmad W, Leal SM (2003a). A novel autosomal recessive non-syndromic deafness locus (DFNB35) maps to 14q24.114q24.3 in large consanguineous kindred from Pakistan. Eur J Hum Genet 11(1):77-80.

Ansar M, Ramzan M, Pham TL, Yan K, Jamal SM, Haque S, Ahmad W, Leal SM. (2003b). Localization of a novel autosomal recessive non-syndromic hearing impairment locus (DFNB38) to 6q26-q27 in a consanguineous kindred from Pakistan. Hum Hered. 55(1):71-4.

Ansar M, Chahrour MH, Amin Ud Din M, Arshad M, Haque S, Phan TL, Yan K, Ahmad W, Leal SM. (2004). DFNB44, a novel autosomal recessive non-syndromic hearing impairment locus, maps to chromosome 7p14.1-q11.22. Hum Hered. 57(4):195-9.

Aslam M, Wajid, Chahrour MH, Ansar M, Haque S, Pham TL, Santos RP, Yan K, Ahmad W, Leal SM. (2005). A novel autosomal recessive nonsyndromic hearing impairment locus (DFNB42) maps to chromosome 3q13.31-q22.3. Am J Med Genet A.. Feb 15;133(1):18-22.

Azevedo MF. (2004). Triagem Auditiva Neonatal. In: Ferreira LP, Befi-Lopes DM, Limongi SCO. Tratado de Fonoaudiologia. $1^{\text {a }}$ ed. São Paulo: Roca Ltda. p.604-630.

Baldwin CT, Weiss S, Farrer LA, Destefano A, Adair R, Franklyn B, Kidd KK, Korostichevsky M \& Bonné-Tamir B. (1995). Linkage of congenital, recessive deafnes (DFNB4) to chromosome $7 \mathrm{q} 31$ and evidence for genetic heterogeneity in the Middle Eastern Druze population. Hum Mol Genet 4: 1637-1642. 
Batissoco AC. (2006). Mutações nos genes GJB2 e GJB6 em indivíduos com deficiência auditiva. Dissertação de Mestrado. Instituto de Biociências da USP. São Paulo.

Bassam BJ, Catano-Anolles G, Gresshoff PM. (1991). Fast and sensitive silver staining of DNA in polyacrilamide gels. Anal. Biochem. 196:80-83.

Berlin CI. (1999a). The efferent auditory system: basic science and clinical applications. San Diego: Singular;.p. 129.

Bess FH e Humes LE. (1988) Fundamentos de audiologia. $2^{\text {a }}$ ed. Porto Alegre: Artmed. p.65-105.

Bitner-Glindzicz. (2002). Hereditary deafness and phenotyping in humans. Br Med Bul.63:73-94. Review.

Bonfils P, Avan P, Londero Al. (1991). Progressive hereditary deafness with predominant inner hair cell loss. Am J Otol. 12:203-206.

Bonne-Tamir B, DeStefano AL, Briggs CE, Adair R, Franklyn B, Weiss S, Korostishevsky M, Frydman M, Baldwin CT, Farrer LA. (1996). Linkage of congenital recessive deafness (gene DFNB10) to chromosome 21q22.3. Am J Hum Genet. Jun;58(6):1254-9.

Bork JM, Peters LM, Riazuddin S, Bernstein SL, Ahmed ZM, Ness SL, Polomeno R, Ramesh A, Schloss M, Srisailpathy CR, Wayne S, Bellman S, Desmukh D, Ahmed Z, Khan SN, Kaloustian VM, Li XC, Lalwani A, Riazuddin S, Bitner-Glindzicz M, Nance WE, Liu XZ, Wistow G, Smith RJ, Griffith AJ, Wilcox ER, Friedman TB, Morell RJ. (2001). Usher syndrome 1D and nonsyndromic autosomal recessive deafness DFNB12 are caused by allelic mutations of the novel cadherin-like gene $\mathrm{CDH} 23$. Am J Hum Genet. Jan;68(1):26-37.

Braga MCC, Otto PA, Spinelli M. (1999). Recurrence Risks in Cases of Nonsyndromic Deafness. The Brazilian Journal of Dysmorphology and Speech-Hearing Disorders, v2, p. 33-40.

Campbell DA, McHale DP, Brown KA, Moynihan LM, Houseman M, Karbani G, Parry G, Janjua AH, Newton V, al-Gazali L, Markham AF, Lench NJ, Mueller RF. (1997). A new locus for nonsyndromal, autosomal recessive, sensorineural hearing loss (DFNB16) maps to human chromosome 15q21-q22. J Med Genet 34(12):1015-7.

Chaib H, Place C, Salem N, Chardenoux S, Vincent C, Weissenbach J, El-Zir E,Loiselet J, Petit C. (1996a). A gene responsible for a sensorineural nonsyndromic recessive deafness maps to chromosome 2p22-23. Hum Mol Genet 5(1):155-8.

Chaib H, Place C, Salem N, Dode C, Chardenoux S, Weissenbach J, el Zir E, Loiselet J, Petit C. (1996b). Mapping of DFNB12, a gene for a non-syndromal autosomal recessive deafness, to chromosome 10q21-22. Hum Mol Genet 5(7):1061-4.

Chen A, Wayne S, Bell A, Ramesh A, Srisailapathy CR, Scott DA, Sheffield VC, Van Hauwe P, Zbar RI, Ashley J, Lovett M, Van Camp G, Smith RJ. (1997). New gene for autosomal recessive non-syndromic hearing loss maps to either chromosome 3q or 19p. Am J Med Genet. Sep 5;71(4):467-71.

Chen W, Kahrizi K, Meyer NC, Riazalhosseini Y, Van Camp G, Najmabadi H, Smith RJ. (2005). Mutation of COL11A2 causes autosomal recessive non-syndromic hearing loss at the DFNB53 locus. J Med Genet. Oct;42(10):e61.

Davis H e Silverman SR. (1970). Auditory Test Hearing Aids. In Davis H, Silverman SR. Hearing and Deafness. Holt: Rinehart and Winston.

Dallos P. (1992). The active cochlea. J Neuroscience. 12 (12): 4574- 585. 
Delmaghani S, Aghaie A, Compain-Nouaille S, Ataie A, Lemainque A, Zeinali S, Lathrop M, Weil D, Petit C. (2003). DFNB40, a recessive form of sensorineural hearing loss, maps to chromosome 22q11.21-12.1. Eur J Hum Genet Oct;11(10):816-8.

Delmaghani S, del Castillo FJ, Michel V, Leibovici M, Aghaie A, Ron U, Van Laer L, Ben-Tal N, Van Camp G, Weil D, Langa F, Lathrop M, Avan P, Petit C.(2006). Mutations in the gene encoding pejvakin, a newly identified protein of the afferent auditory pathway, cause DFNB59 auditory neuropathy. Nat Genet. Jul;38(7):770-8.

Del Castillo I, Villamar M, Moreno-Pelayer MA, del Castillo FJ, Alvarez A, Telleria D, Menendez I, Moreno F. (2002). A deletion involving the connexin 30 gene in nonsyndromic hearing impairment. N Engl J Méd. 346(4):243-249.

Del Castillo I, Rodríguez-Ballesteros M, Moreno-Pelayo MA, Villamar M, Moreno F. (2005a). Novel mutations in the gene encoding otoferlin (OTOF) in Spanish subjects with non-syndromic profound hearing impairment. Livro de resumos do American Society of Human Genetics, Salt Lake City, Utah, abstract 1962.

Del Castillo FJ, Rodríguez-Ballesteros M, Alvares A, Hutchin T, Leonardi T, Oliveira CA, Azaiez H, Brownstein Z, Avenarius MR, Marlin S, Pandya A, Shahin H, Siemering KR, Weil D, Wuys W, Aguirre LA, Martín Y, Moreno-Pelayo MA, Vilamar M, Abraham KB, Dahl HHM, Kanaan M, Nance WE, Petit C, Smith RJH, Van Camp G, Sartorato EL, Murgia A, Moreno F, del Castillo I. (2005b). A novel deletion involving the connexin-30 gene, del(GJB6D13S1854), found in trans with mutations in the GJB2 gene (connexin-26) in subjects with DFNB1 non-syndromic hearing impairment. J Med Genetic. 42:588-594.

Dunkley C, Farnsworth A, Mason S, Dodd M, Gibbin K. (2003). Screening and follow up assessment in three cases of auditory neuropathy. Arch Dis Child. Jan;88(1):25-6.

Dib C, Faure S, Fizames C, Samson D, Drouot N, Vignal A, Millasseau P, Marc S, Hazan J, Seboun E, Lathrop M, Gyapay G, Morissette J, Weissenbach J. (1996). A comprehensive genetic map of the human genome based on 5,264 microsatellites. Nature. Mar 14;380(6570):152-4.

Ensembl. (2006). http://www.ensembl.org.

Estivill X, Govea N, Barcelo E, Badenas C, Romero E, Moral L, Scozzri R, D'Urbano L, Zeviani M, Torroni A. (1998). Familial progressive sensorineural deafness is mainly due to the mtDNA A1555G mutation and is enhanced by treatment of aminoglycosides. Am J Hum Genet. 62(1):27-35.

Fransen E, Van Camp G. (1999). The COCH gene: a frequent cause of hearing impairment and vestibular dysfunction? Br J Audiol. Oct;33(5):297-302.

Friedman TB, Liang Y, Weber JL, Hinnant JT, Barber TD, Winata S, Arhya IN, Asher JH Jr. (1995). A gene for congenital, recessive deafness DFNB3 maps to the pericentromeric region of chromosome 17. Nat Genet 9:86-91.

Fukushima K, Ramesh A, Srisailapathy CR, Ni L, Chen A, O'Neill M, Van Camp G, Coucke P, Smith $\mathrm{SD}$, Kenyon JB, et al. (1995a). Consanguineous nuclear families used to identify a new locus for recessive non-syndromic hearing loss on 14q. Hum Mol Genet 4: 1643-1648.

Fukushima K, Ramesh A, Srisailapathy CR, Ni L, Wayne S, O'Neill ME, Van Camp G, Coucke P, Jain $\mathrm{P}$, Wilcox ER, et al. (1995b). An autosomal recessive nonsyndromic form of sensorineural hearing loss maps to 3p-DFNB6. Genome Res 5(3):305-8.

Gallo-Teran J, Morales-Angulo C, Rodriguez-Ballesteros M, Moreno-Pelayo MA, del Castillo I, Moreno F. (2004). Evaluation of a family with sensorineural hearing loss due to the Q829X mutation in the OTOF gene. Acta Otorrinolaringol Esp. Mar;55(3):120-5. Review. Spanish..

Gasparini P, Estivill X, Volpini V, Totaro A, Castellvi-Bel S, Govea N, Mila M, Della Monica M, Ventruto V, De Benedetto M, Stanziale P, Zelante L, Mansfield ES, Sandkuijl L, Surrey S, 
Fortina P. (1997). Linkage of DFNB1 to non-syndromic neurosensory autosomal-recessive deafness in Mediterranean families. Eur J Hum Genet. Mar-Apr;5(2):83-8.

Goren A, Ram O, Amit M, Karen H, Lev-Maor G, Vig I, Pupko T, Ast G. (2006). Comparative Análisis Identifies Exonic Spicing Regulatory Sequences - The Complex Definition of Enhancers and Silencers. Mol Cell. Jun.22:769-781.

Green e col., 1998. "The Molecular Biology of Hearing and Deafness meeting Bethesda, October 8-11, 1998” (abstract 108) apud Van Camp \& Smith, 05/2003. Hereditary Hearing Loss Homepage (http://dnalab-www.uia.ac.be/dnalab/hhh/).

Greinwald JH Jr, Wayne S, Chen AH, Scott DA, Zbar RI, Kraft ML, Prasad S, Ramesh A, Coucke P, Srisailapathy CR, Lovett M, Van Camp G, Smith RJ. (1998). Localization of a novel gene for nonsyndromic hearing loss (DFNB17) to chromosome region 7q31. Am J Med Genet.78(2):107-13.

Guilford P, Ben Arab S, Blanchard S, Levilliers J, Weissenbach J, Belkahia A, Petit C. (1994a). A nonsyndrome form of neurosensory, recessive deafness maps to the pericentromeric region of chromsome 13q. Hum Mol Genet. 6 (1): 24-8.

Guilford P, Ayadi H, Blanchard S, Chaib H, Le Paslier D, Weissenbach J, Drira M, Petit C. (1994b). A human gene responsible for neurosensory, non-syndromic recessive deafness is a candidate homologue of the mouse sh-1 gene. Hum Mol Genet. 3(6):989-93.

Hassan MJ, Santos RL, Rafiq MA, Chahrour MH, Pham TL, Wajid M, Hijab N, Wambangco M, Lee K, Ansar M, Yan K, Ahmad W, Leal SM. (2005). A novel autosomal recessive nonsyndromic hearing impairment locus (DFNB47) maps to chromosome 2p25.1-p24.3. Hum Genet.Jan;118(5):605-10.

Hood LJ. (1998). Auditory neuropathy: what is it and what can we do about it? The hearing journal, 51(8):10-18.

Houseman MJ, Jackson AP, Al-Gazali LI, Badin RA, Roberts E, Mueller RF. (2001). A novel mutation in a family with non-syndromic sensorineural hearing loss that disrupts the newly characterised OTOF long isoforms. J Med Genet. Aug;38(8):E25.

Irshad S, Santos RL, Muhammad D, Lee K, McArthur N, Haque S, Ahmad W, Leal SM. (2005). Localization of a novel autosomal recessive non-syndromic hearing impairment locus DFNB55 to chromosome 4q12-q13.2. Clin Genet. Sep;68(3):262-7.

Jain PK, Fukushima K, Deshmukh D, Ramesh A, Thomas E, Lalwani AK, Kumar S,Plopis B, Skarka H, Srisailapathy CR, et al. (1995). A human recessive neurosensory nonsyndromic hearing impairment locus is potential homologue of murine deafness (dn) locus. Hum Mol Genet 4(12):2391-4.

Jain PK, Lalwani AK, Li XC, Singleton TL, Smith TN, Chen A, Deshmukh D, Verma IC, Smith RJ, Wilcox ER. (1998). A gene for recessive nonsyndromic sensorineural deafness (DFNB18) maps to the chromosomal region 11p14-p15.1 containing the Usher syndrome type $1 \mathrm{C}$ gene. Genomics 50(2):290-2.

Jewett D e Willinston JS. (1971). Auditory: evoked far fields averaged from scalp of humans. Brain. 94:681-696.

Judice TN, Nelson NC, Beisel CL, Delimont DC, Fritzsch B, Beisel KW. (2002). Cochlear whole mount in situ hybridization: identification of longitudinal and radial gradients. Brain Res Brain Res Protoc. Feb;9(1):65-76.

Kalatzis V, Petit C. (1998). The fundamental and Medical Impacts of recent Progress in research on Hereditary Hearing Loss. Hum Mol Genet. 7(10):1589-97.

Keats BJB e Berlin CI. (1999). Genomics and Hearing Impairment. Genome Research. 9(1):7-16. 
Kelsell DP, Dunlop J, Stevens HP, Lench NJ, Liang JN, Parry G, Mueller RF, Leigh IM. (1997). Connexin 26 mutations in hereditary non-syndromic sensorineural deafness. Nature. May $1 ; 387(6628): 80-3$

Kemp DT. (1978). Stimulated acoustic emissions from within the human auditory system. Journal of the Acoustical Society of America, v. 64, p. 1386-1978.

Kim TB, Isaacson B, Sivakumaran TA, Starr A, Keats BJB, Lesperance MM. (2004). A gene responsible for autosomal dominant auditory neuropathy (AUNA1) maps to 13q14-21. J. Med Genet. 41:872-876.

Kok YJ, Bom SJ, Brunt TM, Kemperman MH, van Beusekom E, van der Velde-Visser SD, Robertson NG, Morton CC, Huygen PL, Verhagen WI, Brunner HG, Cremers CW, Cremers FP. (1999). A Pro51Ser mutation in the $\mathrm{COCH}$ gene is associated with late onset autosomal dominant progressive sensorineural hearing loss with vestibular defects. Hum Mol Genet. Feb;8(2):3616

Kumar UA, Jayaram MM. (2006). Prevalence and audiological characteristics in individuals with auditory neuropathy/auditory dys-synchrony. Int J Audiol. Jun;45(6):360-6.

Kurc M. (1999) O amplificador coclear. Arq Fund Otorrinolaringol. 3 (2): 48-56.

Kurima K, Peters LM, Yang Y, Riazuddin S, Ahmed ZM, Naz S, Arnaud D, Drury S, Mo J, Makishima T, Ghosh M, Menon PS, Deshmukh D, Oddoux C, Ostrer H, Khan S, Riazuddin S, Deininger PL, Hampton LL, Sullivan SL, Battey JF Jr, Keats BJ, Wilcox ER, Friedman TB, Griffith AJ. (2002). Dominant and recessive deafness caused by mutations of a novel gene, TMC1, required for cochlear hair-cell function. Nat Genet. Mar;30(3):277-84.

Lewis DR. (2004). Emissões Otoacústicas: Aplicações Clínicas. In: Ferreira LP, Befi-Lopes DM, Limongi SCO.Tratado de Fonoaudiologia. $1^{\text {a }}$ ed. São Paulo: Roca Ltda. p.604-630.

Li XC, Everett LA, Lalwani AK, Desmukh D, Friedman TB, Green ED, Wilcox ER. (1998). A mutation in PDS causes non-syndromic recessive deafness. Nat Genet. Mar;18(3):215-7.

Liu XZ, Walsh J, Mburu P, Kendrick-Jones J, Cope MJ, Steel KP, Brown SD. (1997). Mutations in the myosin VIIA gene cause non-syndromic recessive deafness. Nat Genet. Jun;16(2):188-90.

Loundon N, Marcolla A, Roux I, Rouillon I, Denoyelle F, Feldmann D, Marlin S, Garabedian EN. (2005). Auditory neuropathy or endocochlear hearing loss? Otol Neurotol. Jul;26(4):748-54.

Madden C, Rutter M, Hilbert L, et al. (2002). Clinical and audiological features in auditory neuropathy. Arch Otolaryngol Head Neck Surg. 128:1026-1030.

Masmoudi S, Tlili A, Majava M, Ghorbel AM, Chardenoux S, Lemainque A, Zina ZB, Moala J, Mannikko M, Weil D, Lathrop M, Ala-Kokko L, Drira M, Petit C, Ayadi H. (2003). Mapping of a new autosomal recessive nonsyndromic hearing loss locus (DFNB32) to chromosome 1p13.3-22.1. Eur J Hum Genet. 11(2):185-8.

Mason JC, De Michele A, Stevens C, Ruth RA, Hashisaki GT. (2003). Cochlear implantation in patients with auditory neuropathy of varied etiologies. Laryngoscope. Jan;113(1):45-9.

Matas CG e Rondina C. (2004). Neuropatia auditiva. In: Ferreira LP, Befi-Lopes DM, Limongi SCO. Tratado de Fonoaudiologia. Roca (cap.55):704-712.

Mburu P, Mustapha M, Varela A, Weil D, El-Amraoui A, Holme RH, Rump A, Hardisty RE, Blanchard S, Coimbra RS, Perfettini I, Parkinson N, Mallon AM, Glenister P, Rogers MJ, Paige AJ, Moir L, Clay J, Rosenthal A, Liu XZ, Blanco G, Steel KP, Petit C, Brown SD. (2003). Defects in whirlin, a PDZ domain molecule involved in stereocilia elongation, cause deafness in the whirler mouse and families with DFNB31. Nat Genet. Aug;34(4):421-8. 
McGuirt WT, Smith RJ. (1999). Connexin 26 as a Cause of Hereditary Hearing Loss. Am J Audiology. $8: 1059-1066$

Medlej-Hashim M, Mustapha M, Chouery E, Weil D, Parronaud J, Salem N, Delague V, Loiselet J, Lathrop M, Petit C, Megarbane A. (2002). Non-syndromic recessive deafness in Jordan: mapping of a new locus to chromosome 9q34.3 and prevalence of DFNB1 mutations. Eur $J$ Hum Genet. 10(6):391-4.

Migliosi V, Modamio-Hoybjor S, Moreno-Pelayo MA, Rodriguez-Ballesteros M, Villamar M, Telleria D, Menendez I, Moreno F, Del Castillo I. (2002). Q829X, a novel mutation in the gene encoding otoferlin $(O T O F)$, is frequently found in Spanish patients with prelingual nonsyndromic hearing loss. J Med Genet. Jul;39(7):502-6.

Mir A, Ansar M, Chahrour MH, Pham TL, Wajid M, Haque S, Yan K, Ahmad W, Leal SM. (2005). Mapping of a novel autosomal recessive nonsyndromic deafness locus (DFNB46) to chromosome 18p11.32-p11.31. Am J Med Genet A. Feb 15;133(1):23-6.

Mirghomizadeh F, Pfister M, Apaydin F, Petit C, Kupka S, Pusch CM, Zenner HP, Blin N. (2002). Substitutions in the conserved C2C domain of otoferlin cause DFNB9, a form of nonsyndromic autosomal recessive deafness. Neurobiol Dis. Jul;10(2):157-64.

Mirghomizadeh F, Pfister M, Blin N, Pusch CM. (2003). Uncommon cytidine-homopolymer dimorphism in 5'-UTR of the human otoferlin gene. Int J Mol Med. Jan;11(1):63-4.

Möller AR, Jannetta P, Bennett M, Möller MB. (1981). Intracranially recorded responses from human auditory nerne: new insights into the origin of brainstem evoked potentials. Electroencephalography and Clinical Neurophysiology, v. 52, p. 18-27.

Morton N. (1991). Genetic Epidemiology of Hearing Impairment. Ann N. Y. Acad Sci. 1991; 630:1631.

Moynihan L, Houseman M, Newton V, Mueller R, Lench N. (1999). DFNB20: a novel locus for autosomal recessive, non-syndromal sensorineural hearing loss maps to chromosome 11q25qter. Eur J Hum Genet. Feb-Mar;7(2):243-6.

Mustapha M, Chardenoux S, Nieder A, Salem N, Weissenbach J, el-Zir E, Loiselet J, Petit C. (1998a). A sensorineural progressive autosomal recessive form of isolated deafness, DFNB13, maps to chromosome 7q34-q36. Eur J Hum Genet. May-Jun;6(3):245-50.

Mustapha M, Salem N, Weil D, el-Zir E, Loiselet J, Petit C. (1998b). Identification of a locus on chromosome 7q31, DFNB14, responsible for prelingual sensorineural non-syndromic deafness. Eur J Hum Genet. Nov-Dec;6(6):548-51.

Mustapha M, Weil D, Chardenoux S, Elias S, El-Zir E, Beckmann JS, Loiselet J, Petit C. (1999). An alpha-tectorin gene defect causes a newly identified autosomal recessive form of sensorineural pre-lingual non-syndromic deafness, DFNB21.Hum Mol Genet. Mar;8(3):409-12.

Mustapha M, Chouery E, Chardenoux S, Naboulsi M, Paronnaud J, Lemainque A, Megarbane A, Loiselet J, Weil D, Lathrop M, Petit C. (2002). DFNB31, a recessive form of sensorineural hearing loss, maps to chromosome 9q32-34. Eur J Hum Genet. Mar;10(3):210-2.

Netter FH. (1958). Nervous System, In: The Ciba Collection of Medical Illustrations. New York: CIBA;v.1p.39.

Naz S, Giguere CM, Kohrman DC, Mitchem KL, Riazuddin S, Morell RJ, Ramesh A, Srisailpathy S, Deshmukh D, Riazuddin S, Griffith AJ, Friedman TB, Smith RJ, Wilcox ER. (2002). Mutations in a novel gene, TMIE, are associated with hearing loss linked to the DFNB6 locus. Am J Hum Genet. Sep;71(3):632-6.

Naz S, Griffith AJ, Riazuddin S, Hampton LL, Battey JF Jr, Khan SN, Riazuddin S, Wilcox ER, Friedman TB. (2004). Mutations of ESPN cause autosomal recessive deafness and vestibular dysfunction. J Med Genet. Aug;41(8):591-5. 
Nuldemann AA, Costa EA, Seligman J, Ibañz RN. (1997). PAIR Perda Auditiva Induzida pelo

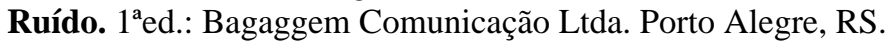

Oliveira P, Castro F, Ribeiro A. (2002). Surdez infantil. Rev Bras Otorrinolaringol. Maio-Jun 68(3):417-23.

Organização Mundial de Saúde. (2006). World Wide Web: www.who.int/pbd/deafness/facts/en/index.html

Ouyang XM, Xia XJ, Verpy E, Du LL, Pandya A, Petit C, Balkany T, Nance WE, Liu XZ. (2002). Mutations in the alternatively spliced exons of USH1C cause non-syndromic recessive deafness. Hum Genet. Jul;111(1):26-30.

Petit C. (1996). Genes Responsible for Human Hereditary Deafness: Symphony of a Thousand. Nat Genet. 14(4):385-91. Review.

Pujol R, Réclar-Enjalbert V e Pujol T. (01/2006). Promenade round the cochlea. World Wide Web URL:http://www.iurc.montp.inserm.fr/cric/audition/english/index.htm.

Pulleyn LJ, Jackson AP, Roberts E, Carridice A, Muxworthy C, Houseman M, Al-Gazali LI, Lench NJ, Markham AF, Mueller RF. (2000). A new locus for autosomal recessive non-syndromal sensorineural hearing impairment (DFNB27) on chromosome 2q23-q31. Eur J Hum Genet 8(12):991-3.

Ramzan K, Shaikh RS, Ahmad J, Khan SN, Riazuddin S, Ahmed ZM, Friedman TB, Wilcox ER, Riazuddin S. (2005). A new locus for nonsyndromic deafness DFNB49 maps to chromosome 5q12.3-q14.1.

Hum Genet. Jan;116(1-2):17-22.

Rance G, Beer DE, Cone-Wesson B, Shepherd RK, Dowell RC, King AM, Rickards FW, Clark GM. (1999). Clinical findings for a group of infants and young children with auditory neuropathy. Ear Hear. Jun;20(3):238-52.

Rapin I, Gravel J. "Auditory neuropathy": physiologic and pathologic evidence calls for more diagnostic specificity. (2003). Int J Pediatr Otorhinolaryngol. Jul;67(7):707-28.

Reynoso RA, Hendl S, Barteik ME, Curet CA, Nicemboin L, Moreno Barral J, Rodriguez Ballesteros M, Del Castillo I, Moreno F. (2004). Genetic study of hearing loss in families from Argentina. Rev Fac Cien Med Univ Nac Cordoba. 61(1):13-9.

Riazuddin S, Castelein CM, Ahmed ZM, Lalwani AK, Mastroianni MA, Naz S, Smith TN, Liburd NA, Friedman TB, Griffith AJ, Riazuddin S, Wilcox ER. (2000).Dominant modifier DFNM1 suppresses recessive deafness DFNB26. Nat Genet. 26(4):431-4.

Riazuddin S, Khan SN, Ahmed ZM, Ghosh M, Caution K, Nazli S, Kabra M, Zafar AU, Chen K, Naz S, Antonellis A, Pavan WJ, Green ED, Wilcox ER, Friedman PL, Morell RJ, Riazuddin S, Friedman TB. (2006). Mutations in TRIOBP, which encodes a putative cytoskeletalorganizing protein, are associated with nonsyndromic recessive deafness. Am J Hum Genet. Jan;78(1):137-43.

Rodriguez-Ballesteros M, del Castillo FJ, Martin Y, Moreno-Pelayo MA, Morera C, Prieto F, Marco J, Morant A, Gallo-Teran J, Morales-Angulo C, Navas C, Trinidad G, Tapia MC, Moreno F, del Castillo I. (2003). Auditory neuropathy in patients carrying mutations in the otoferlin gene (OTOF). Hum Mutat. Dec;22(6):451-6.

Robertson NG, Lu L, Heller S, Merchant SN, Eavey RD, McKenna M, Nadol JB Jr, Miyamoto RT, Linthicum FH Jr, Lubianca Neto JF, Hudspeth AJ, Seidman CE, Morton CC, Seidman JG. (1998). Mutations in a novel cochlear gene cause DFNA9, a human nonsyndromic deafness with vestibular dysfunction. Nat Genet. Nov;20(3):299-303. 
Rouillon I, Marcolla A, Roux I, Marlin S, Feldmann D, Couderc R, Jonard L, Petit C, Denoyelle F, Garabedian EN, Loundon N. (2006). Results of cochlear implantation in two children with mutations in the OTOF gene. Int J Pediatr Otorhinolaryngol. Apr;70(4):689-96.

Santos F, Pena SDJ, Epplen JT. (1993). Genetic and population study of a Y-Linked tetranucletide repeat DNA polymorphism with a simpl non-Isotopic technique. Hum Genet. 90:655-656.

Scott DA, Carmi R, Elbedour K, Yosefsberg S, Stone EM, Sheffield VC (1996). An autosomal recessive nonsyndromic-hearing-loss locus identified by DNA pooling using two inbred Bedouin kindreds. Am J Hum Genet. 59(2):385-91.

Scott DA, Kraft ML, Carmi R, Ramesh A, Elbedour K, Yairi Y, Srisailapathy CR, Rosengren SS, Markham AF, Mueller RF, Lench NJ, Van Camp G, Smith RJ, Sheffield VC. (1998). Identification of mutations in the connexin 26 gene that cause autosomal recessive nonsyndromic hearing loss. Hum Mutat. 11(5):387-94.

Scott HS, Kudoh J, Wattenhofer M, Shibuya K, Berry A, Chrast R, Guipponi M, Wang J, Kawasaki K, Asakawa S, Minoshima S, Younus F, Mehdi SQ, Radhakrishna U, Papasavvas MP, Gehrig C, Rossier C, Korostishevsky M, Gal A, Shimizu N, Bonne-Tamir B, Antonarakis SE. (2001). Insertion of beta-satellite repeats identifies a transmembrane protease causing both congenital and childhood onset autosomal recessive deafness. Nat Genet. Jan;27(1):59-63.

Shabbir MI, Ahmed ZM, Khan SY, Riazuddin S, Waryah AM, Khan SN, Camps RD, Ghosh M, Kabra M, Belyantseva IA, Friedman TB, Riazuddin S. (2006). Mutations of human TMHS cause recessively inherited non-syndromic hearing loss. J Med Genet. Aug;43(8):634-40.

Shaikh RS, Ramzan K, Nazli S, Sattar S, Khan SN, Riazuddin S, Ahmed ZM, Friedman TB, Riazuddin S. A new locus for nonsyndromic deafness DFNB51 maps to chromosome 11p13-p12. (2005). Am J Med Genet A. Nov 1;138(4):392-5.

Shahin H, Walsh T, Sobe T, Abu Sa'ed J, Abu Rayan A, Lynch ED, Lee MK, Avraham KB, King MC, Kanaan M. (2006). Mutations in a novel isoform of TRIOBP that encodes a filamentous-actin binding protein are responsible for DFNB28 recessive nonsyndromic hearing loss. Am J Hum Genet. Jan;78(1):144-52.

Sininger Y e Oba S. (2001). Patients with auditory neuropathy: who are they and what can they hear? In: Sininger Y, Starr A. Auditory neuropathy: a new perspective on hearing disorders. San Diego: Singular. cap.2,p.15-35.

Sundstrom R.A, Van Laer L, Van Camp G, and Smith R.J.H.. (1999). Autosomal Recessive Nonsyndromic Hearing Loss. Am J Med. Genet (Semin. Med. Genet.) 89:123-129.

Tang TP, McPherson B, Yuen KC, Wong LL, Lee JS. (2004). Auditory neuropathy/auditory dyssynchrony in school children with hearing loss: frequency of occurrence. Int J Pediatr Otorhinolaryngol. Feb;68(2):175-83.

Tariq A, Santos RL, Khan MN, Lee K, Hassan MJ, Ahmad W, Leal SM. (2006). Localization of a novel autosomal recessive nonsyndromic hearing impairment locus DFNB65 to chromosome 20q13.2-q13.32. J Mol Med. Jun;84(6):484-90.

Tekin M, Akcayoz D, Incesulu A. (2005). A novel missense mutation in a C2 domain of OTOF results in autosomal recessive auditory neuropathy. Am J Med Genet A. Sep 15;138(1):6-10.

Tlili A, Mannikko M, Charfedine I, Lahmar I, Benzina Z, Ben Amor M, Driss N, Ala-Kokko L, Drira M, Masmoudi S, Ayadi H. (2005). A novel autosomal recessive non-syndromic deafness locus, DFNB66, maps to chromosome 6p21.2-22.3 in a large Tunisian consanguineous family. Hum Hered.;60(3):123-8.

Van Camp G, Willens PJ, Smith RJ. (1997). Nonsyndromic Hearing Impairment: Unparalleled Heterogeneity. Am J Hum Genet. 60(4):758-64. 
Van Camp G e Smith R J H. (01/2006). Hereditary Hearing Loss Homepage. World Wide Web URL: www.uia.ac.be/dnalab/hhh/.

Van Laer L, McGuirt WT, Yang T, Smith RJ, Van Camp G. (1999). Autosomal dominant nonsyndromic hearing impairment. Am J Med Genet. Sep 24;89(3):167-74. Review.

Varga R, Kelley PM, Keats BJ, Starr A, Leal SM, Cohn E, Kimberling WJ. (2003). Non-syndromic recessive auditory neuropathy is the result of mutations in the otoferlin (OTOF) gene. J Med Genet. Jan;40(1):45-50

Varga R, Avenarius MR, Kelley PM, Keats BJ, Berlin CI, Hood LJ, Morlet TG, Brashears SM, Starr A, Cohn ES, Smith RJ, Kimberling WJ. (2006). OTOF mutations revealed by genetic analysis of hearing loss families including a potential temperature sensitive auditory neuropathy allele. J Med Genet. Jul;43(7):576-81.

Verpy E, Masmoudi S, Zwaenepoel I, Leibovici M, Hutchin TP, Del Castillo I, Nouaille S, Blanchard S, Laine S, Popot JL, Moreno F, Mueller RF, Petit C. (2001). Mutations in a new gene encoding a protein of the hair bundle cause non-syndromic deafness at the DFNB16 locus. Nat Genet. Nov;29(3):345-9.

Veske A, Oehlmann R, Younus F, Mohyuddin A, Muller-Myhsok B, Mehdi SQ, Gal A (1996). Autosomal recessive non-syndromic deafness locus (DFNB8) maps on chromosome 21q22 in a large consanguineous kindred from Pakistan. Hum Mol Genet 5(1):165-8.

Wajid M, Abbasi AA, Ansar M, Pham TL, Yan K, Haque S, Ahmad W, Leal SM. (2003). DFNB39, a recessive form of sensorineural hearing impairment, maps to chromosome 7q11.22-q21.12. Eur J Hum Genet. Oct;11(10):812-5.

Walsh TD, Shahin H, Morrow J, King M-C, Lynch E, Avraham K, Kanaan M (2000). DFNB28, a novel locus for prelingual nonsyndromic autosomal recessive hearing loss maps to 22q13 in a large consanguineous Palestinian kindred. 50th Annual Meeting of The American Society of Human Genetics Program Nr: 2059. (http://www.faseb.org/genetics/ashg00/f2059.htm).

Walsh T, Walsh V, Vreugde S, Hertzano R, Shahin H, Haika S, Lee MK, Kanaan M, King MC, Avraham KB. (2002). From flies' eyes to our ears: mutations in a human class III myosin cause progressive nonsyndromic hearing loss DFNB30. Proc Natl Acad Sci U S A. May 28;99(11):7518-23.

Wang A, Liang Y, Fridell RA, Probst FJ, Wilcox ER, Touchman JW, Morton CC, Morell RJ, NobenTrauth K, Camper SA, Friedman TB. (1998). Association of unconventional myosin MYO15 mutations with human nonsyndromic deafness DFNB3. Science. May 29;280(5368):1447-51.

Wang Q, Gu R, Han D, Yang W. (2003). Familial auditory neuropathy. Laryngoscope. Sep;113(9):1623-9.

Wang Q, Li R, Zhao H, Peters JL, Liu Q, Yang L, Han D. (2005) Clinical and molecular characterization of a chinese patient with auditory neuropathy associated with mitochondrial 12S rRNA T1095C mutation. Am J Hum Genet. (133A):27-30.

Wang QJ, Li QZ, Rao SQ, Lee K, Huang XS, Yang WY, Zhai SQ, Guo WW, Guo YF, Yu N, Zhao YL, Yuan H, Guan J, Leal SM, Han DY, Shen Y. (2006). AUNX1, a novel locus responsible for X linked recessive auditory and peripheral neuropathy, maps to Xq23-27.3. J Med Genet. Jul;43(7):e33.

Weil D, Kussel P, Blanchard S, Levy G, Levi-Acobas F, Drira M, Ayadi H, Petit C. (1997). The autosomal recessive isolated deafness, DFNB2, and the Usher 1B syndrome are allelic defects of the myosin-VIIA gene. Nat Genet. Jun;16(2):191-3.

Wilcox ER, Burton QL, Naz S, Riazuddin S, Smith TN, Ploplis B, Belyantseva I, Ben-Yosef T, Liburd NA, Morell RJ, Kachar B, Wu DK, Griffith AJ, Riazuddin S, Friedman TB. (2001). Mutations 
in the gene encoding tight junction claudin-14 cause autosomal recessive deafness DFNB29. Cell 104(1):165-72.

Willems PJ. (2000). Mechanism of Disease: Genetic Causes of Hearing Loss. $N$ Engl J Med. 342(15)1101-1109.

Yasunaga S, Grati M, Cohen-Salmon M, El-Amraoui A, Mustapha M, Salem N, El-Zir E, Loiselet J, Petit C. (1999). A mutation in OTOF, encoding otoferlin, a FER-1-like protein, causes DFNB9, a nonsyndromic form of deafness. Nat Genet. Apr;21(4):363-9.

Yasunaga S, Grati M, Chardenoux S, Smith TN, Friedman TB, Lalwani AK, Wilcox ER, Petit C. (2000). OTOF encodes multiple long and short isoforms: genetic evidence that the long ones underlie recessive deafness DFNB9. Am J Hum Genet. Sep;67(3):591-600.

Yasunaga S, Petit C. (2000b). Physical map of the region surrounding the otoferlin locus on chettachromosome 2p22-p23. Genomics. May 15;66(1):110-2.

Zwaenepoel I, Mustapha M, Leibovici M, Verpy E, Goodyear R, Liu XZ, Nouaille S, Nance WE, Kanaan M, Avraham KB, Tekaia F, Loiselet J, Lathrop M, Richardson G, Petit C (2002).Otoancorin, an inner ear protein restricted to the interface between the apical surface of sensory epithelia and their overlying acellular gels, is defective in autosomal recessive deafness DFNB22. PNAS 99(9):6240-5. 


\section{ANEXOS}


Anexo I. Cópia da ficha de anamnese utilizada na entrevista durante aconselhamento genético dos pacientes.

\section{ESTUDO GENÉTICO-CLÍNICO DOS CASOS DE SURDEZ PARA USO EM \\ ACONSELHAMENTO GENÉTICO}

DADOS PESSOAIS:

DATA: CASO $\mathrm{N}^{\circ}$ :

NOME:

NASC. IDADE SEXO: $M($ ) $F(~)$

NATURAL: -OCUPAÇÃO

ESCOLARIDADE:-

$\mathrm{B}($ ) $\mathrm{P}($ ) $\mathrm{N}($ )

PAI:

IDADE: NATURAL:

OCUP.: ESCOL

MÃE:

IDADE: NATURAL:

OCUP. ESCOL

ENDEREÇO

TELEFONE:

ORIGEM DO PACIENTE:

MOTIVO DA CONSULTA:

HISTÓRICO FAMILIAL:

CONSANGÜINIDADE PARENTAL: ( )NÃO ～( )SIM

GRAU:

OUTROS CASOS DE SURDEZ NA FAMÍLIA: ( )NÃO ( )SIM

CASOS DE DOENÇAS GENÉTICAS NA FAMÍLIA: ( )NÃO （ )SIM

CONSULENTE JÁ TEVE ABORTOS: ( )NÃO （ )SIM 
HEREDOGRAMA:

CARACTERIZAÇÃO DO TIPO DE SURDEZ:

()BILATERAL ()UNILATERAL ()?

( )ESTACIONÁRIA ( )PROGRESSIVA ( )?

( )LEVE (27-40 DB) ( )MODERADA (40-65 DB) ( )GRAVE (65-95 DB)

( )PROFUNDA (> 95 DB)

( )CONDUTIVA ( )NEUROSSENSORIAL ()MISTA ( )?

ETIOLOGIA: ( )CONGÊNITA ( )PÓS-NATAL IDADE DE INÍCIO:-

ÉPOCA EM QUE PERCEBERAM O PROBLEMA:

ÉPOCA EM QUE FOI FEITO O DIAGNÓSTICO DE SURDEZ:

( )ZUMBIDO ( )TONTURA 
GESTAÇÃO:

( )SEM INTERCORRÊNCIAS

( )COM INTERCORRÊNCIAS

( )FEZ PRÉ-NATAL

INFECÇÕES MATERNAS: ( )NÃO （ )SIM

( )CMV ( )RUBÉOLA

( )TOXOPLASMOSE ( )SÍFILIS

( )HERPES

( )OUTRAS DOENÇAS OU SINTOMAS

USO DE DROGAS PELA MÃE: ( )NÃO ( )SIM QUAIS?:

RAIO X NA GESTAÇÃO: ( )NÃO （ )SIM

OBSERVAÇÕES:

PERÍODO PERINATAL:

( )SEM INTERCORRÊNCIAS ( )COM INTERCORRÊNCIAS

PARTO: ()NORMAL ( )CESÁREA MOTIVO:

( )FORCEPS

CRONOLOGIA: ( )TERMO ( )PRÉ-TERMO ( )PÓS-TERMO

PESO AO NASCER

COMPRIMENTO AO NASCER:

BOAS CONDIÇÕES DE VITALIDADE: ( )NÃO ( )SIM

( )ANOXIA ( )CIANOSE ( )ICTERÍCIA

( )INCOMPATIBILIDADE DE Rh ( )FOTOTERAPIA ( )INCUBADORA

( )FEBRE ALTA ( )DEFEITOS FÍSICOS

SAIU DO HOSPITAL COM A MÃE: ( )NÃO ( )SIM

OBSERVAÇÕES: 
DESENVOLVIMENTO NEUROPSICOMOTOR:

DNPM: ( ) NORMAL ()COM ATRASO

BEBÊ ()FIRME ()MOLE

SUSTENTOU PESCOÇO:-

SENTOU COM APOIO:-

SENTOU SEM APOIO:

ENGATINHOU:

ANDOU:

PRIMEIRAS PALAVRAS:

( )ANTIBIÓTICOS AMINOGLICOSÍDEOS ()USO DE OUTRAS DROGAS OTOTÓXICAS

( )INFECÇÕES DE OUVIDO ( )DIABETES MELITO

()MENINGITE ()SARAMPO ()CAXUMBA

( )MENINGOENCEFALITES ( )INFECÇÃO DAS VIAS AÉREAS SUPERIORES

( )EXPOSIÇÃO CONSTANTE A RUÍDOS

OUTRAS DOENÇAS, INTERNAÇÕES, CIRURGIAS:-

EXAMES REALIZADOS:

HIPÓTESE DIAGNÓSTICA:

( )HEREDITÁRIA ( )ADQUIRIDA ( )?

()ISOLADA ()SINDRÔMICA ()?

PAIS PRETENDEM TER MAIS FILHOS: ( )NÃO ( )SIM

FIZERAM ( )LAQUEADURA ( )VASECTOMIA

DIAGNÓSTICO:

CONDUTA: 
This document was created with Win2PDF available at http://www.win2pdf.com.

The unregistered version of Win2PDF is for evaluation or non-commercial use only. This page will not be added after purchasing Win2PDF. 
Anexo II. Genealogias das 64 famílias selecionadas

Legenda das genealogias

$\square$ Homem ouvinte

Mulher ouvinte

- Homen surdo

Mulher surda

$\diamond$ Sexo desconhecido

$\varnothing \square$ Falecidos

$\widehat{O}$ Gêmeas monozigóticas

¿ Gêmeos dizigóticos

प Retardo Mental

Consangüíneos

\# Divorciados

$\triangle$ Aborto

['] Adoção

入 Propósito

Mapa genético da região 2 p22-23, onde se localiza o gene OTOF

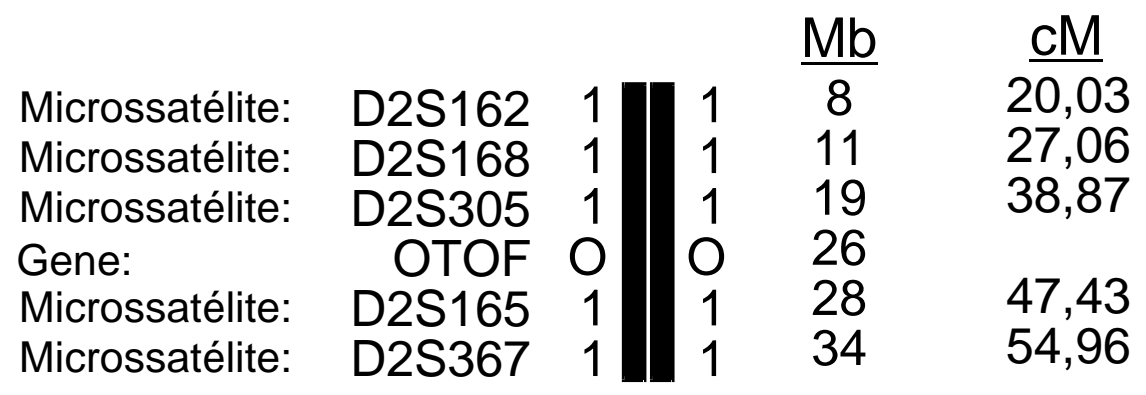

Os números ao lado das barras correspondem a números dados aos diferentes fragmentos detectados na análise de microssatélites.

O indica a posição do gene OTOF 
Família 1

Neuropatia Auditiva

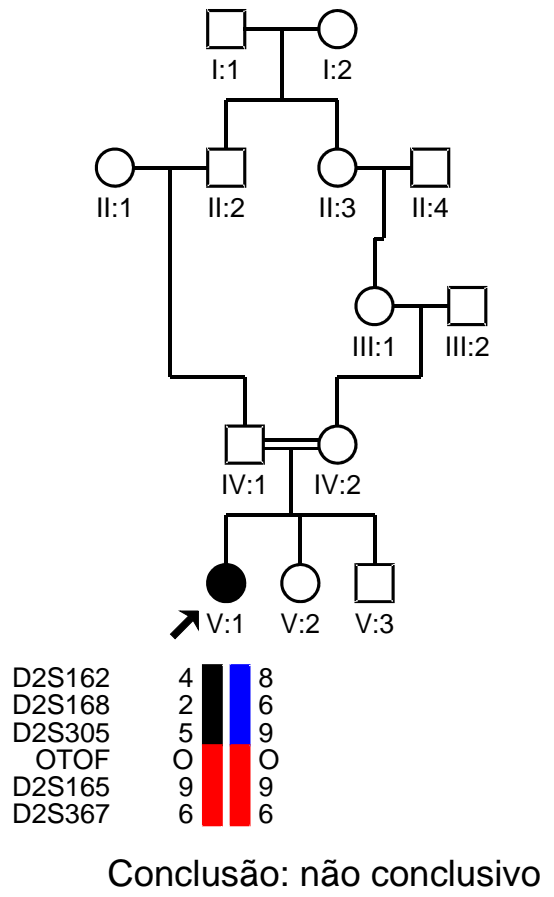

Família 3

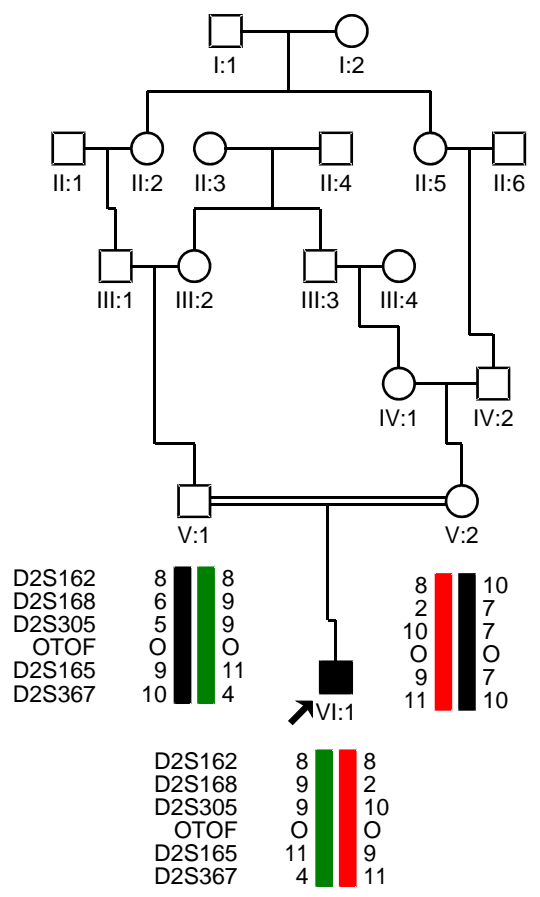

Conclusão: provavelmente não ligado ao gene OTOF

\section{Família 2}

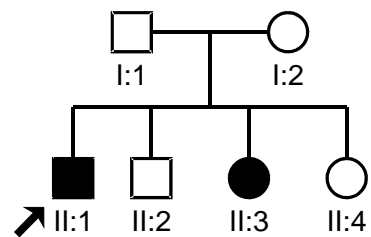

D2S162

D2S168

D2S305

OTOF

D2S165

D2S367

\section{Família 4}

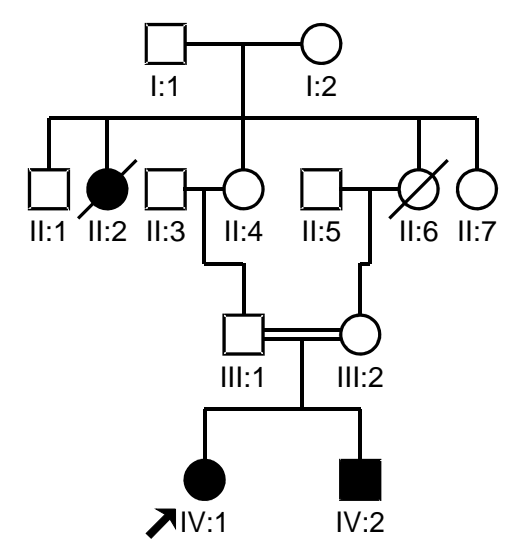

D2S162
D2S168
D2S305
OTOF
D2S165
D2S367

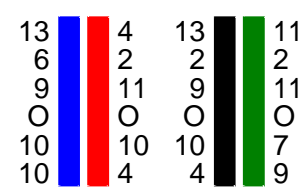

Conclusão: provavelmente não ligado ao gene OTOF 


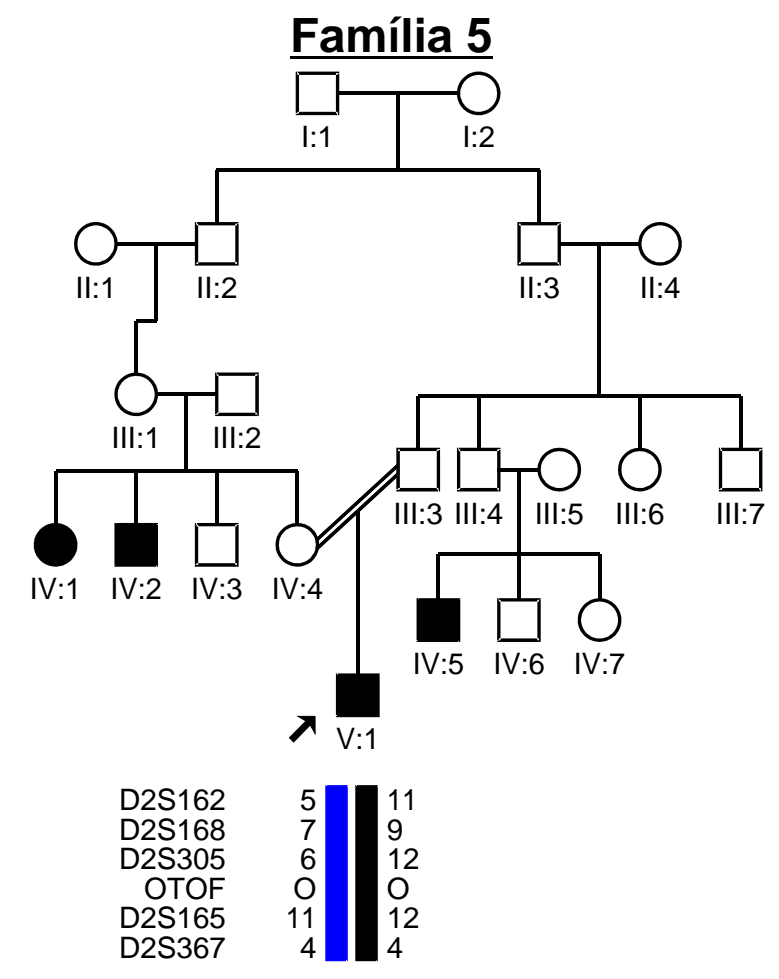

Conclusão: provavelmente não ligado ao gene OTOF

Família 7

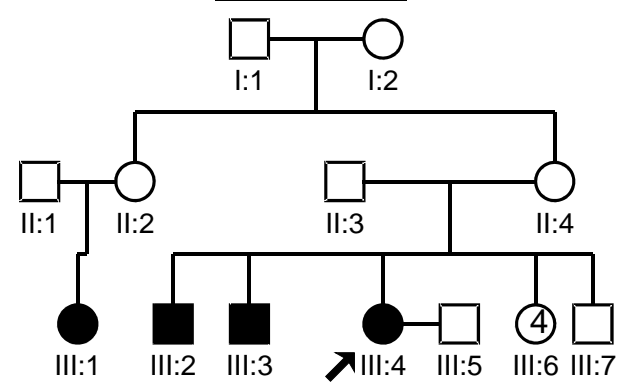

\begin{tabular}{rr|lr|l} 
D2S162 & 8 & 11 & 8 & 11 \\
D2S168 & 3 & 7 & 3 & 7 \\
D2S305 & 3 & 8 & 3 & 8 \\
OTOF & 0 \\
O & 0 \\
D2S165 & 6 & 6 & 6 & 0 \\
D2S367 & 10 & 11 & 10 & 8 \\
\hline
\end{tabular}

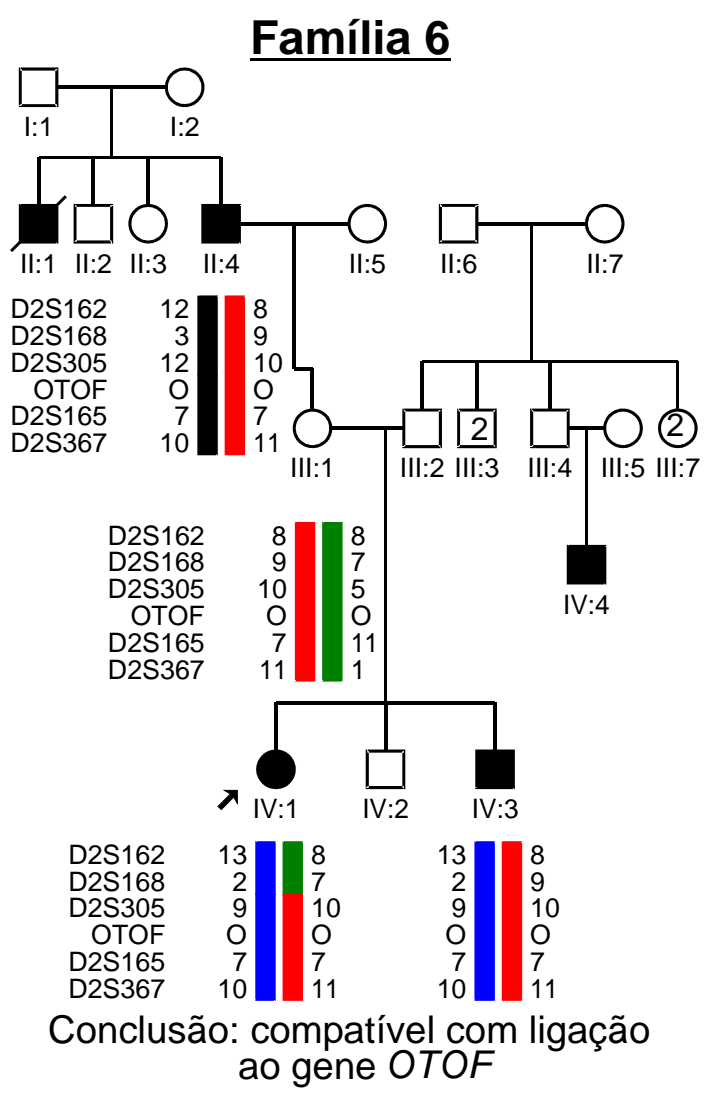

\section{Família 8}

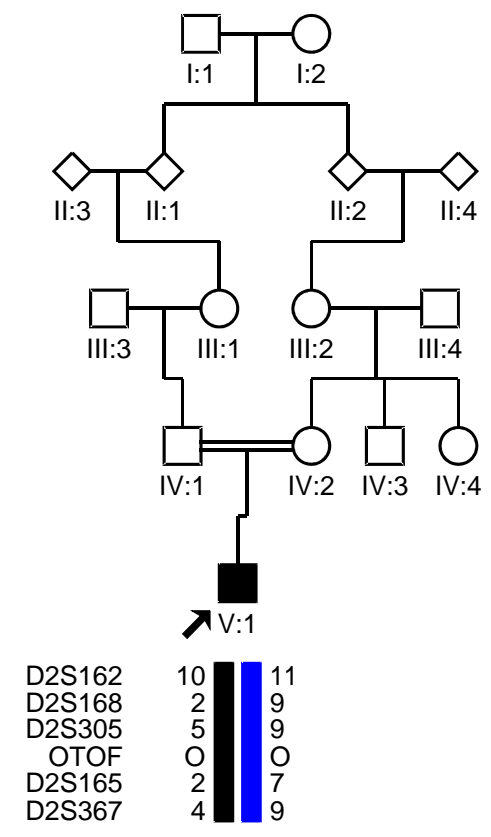

Conclusão: compatível com ligação ao gene OTOF
Conclusão: provavelmente não ligado ao gene OTOF 


\section{Família 9}

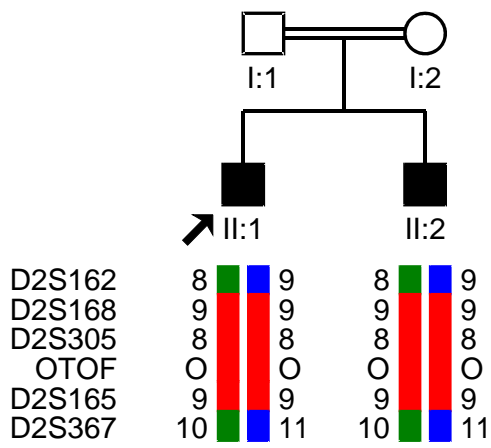

Conclusão: compatível com ligação ao gene OTOF

\section{Família 11}

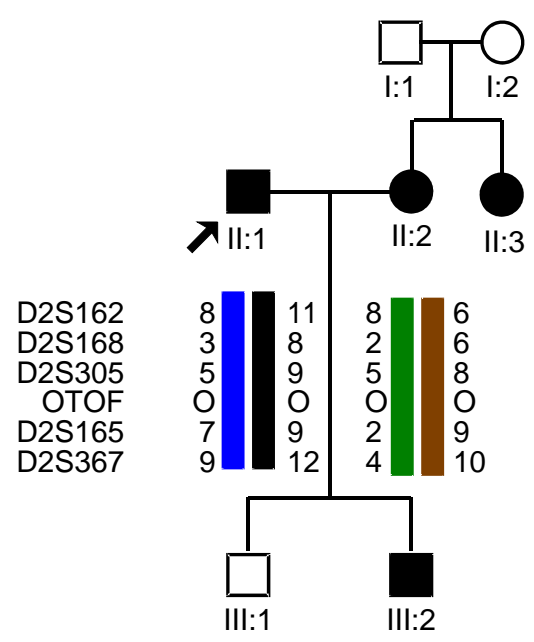

Conclusão: não conclusivo
Família 10

Alteração do tronco encefálico

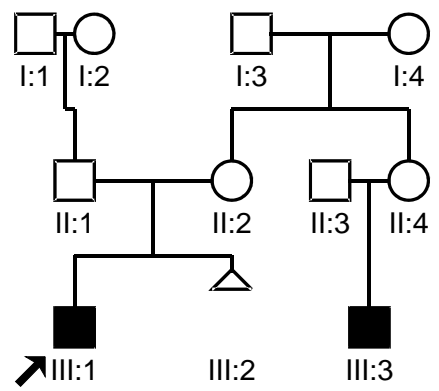

D2S162

D2S168

D2S305

OTOF

D2S165

D2S367

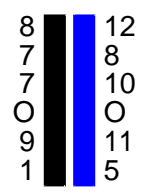

Conclusão: não conclusivo

\section{Família $12 \quad$ Família 13}
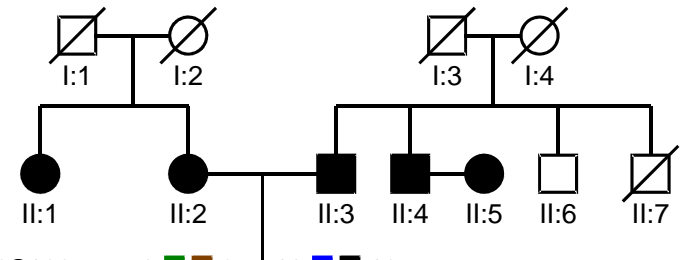

D2S162

D2S168

D2S305

D2S165

D2S367

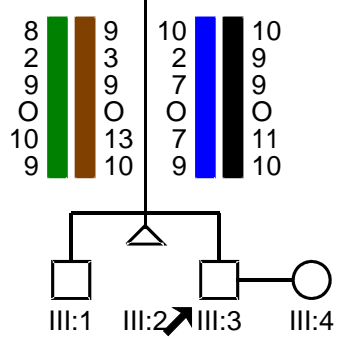




\section{Família 14}

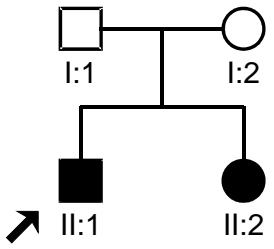

$\left.\begin{array}{rr}\text { D2S162 } & 3 \\ \text { D2S168 } & 6 \\ \text { D2S305 } & 5 \\ \text { OTOF } & 0 \\ \text { D2S165 } & 2 \\ \text { D2S367 } & 9\end{array} \quad \begin{array}{rr}8 & 6 \\ 8 & 4 \\ 9 & 7 \\ 0 & 0 \\ 9 & 10 \\ 9 & 9\end{array}\right]$

Conclusão: provavelmente não ligado ao gene OTOF

\section{Família 16}

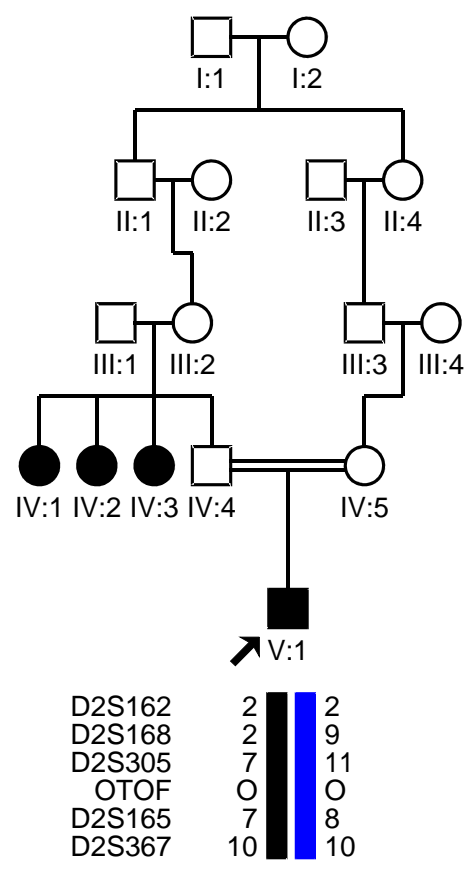

Conclusão: provavelmente não ligado ao gene OTOF

\section{Família 15}
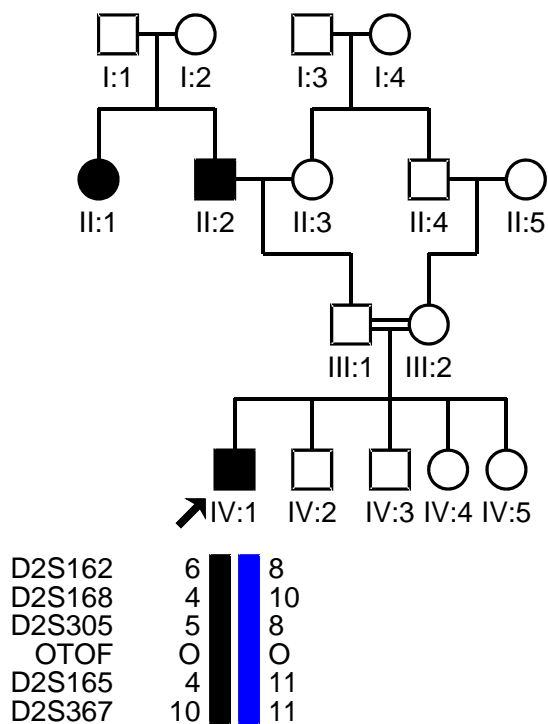

Conclusão: provavelmente não ligado ao gene OTOF

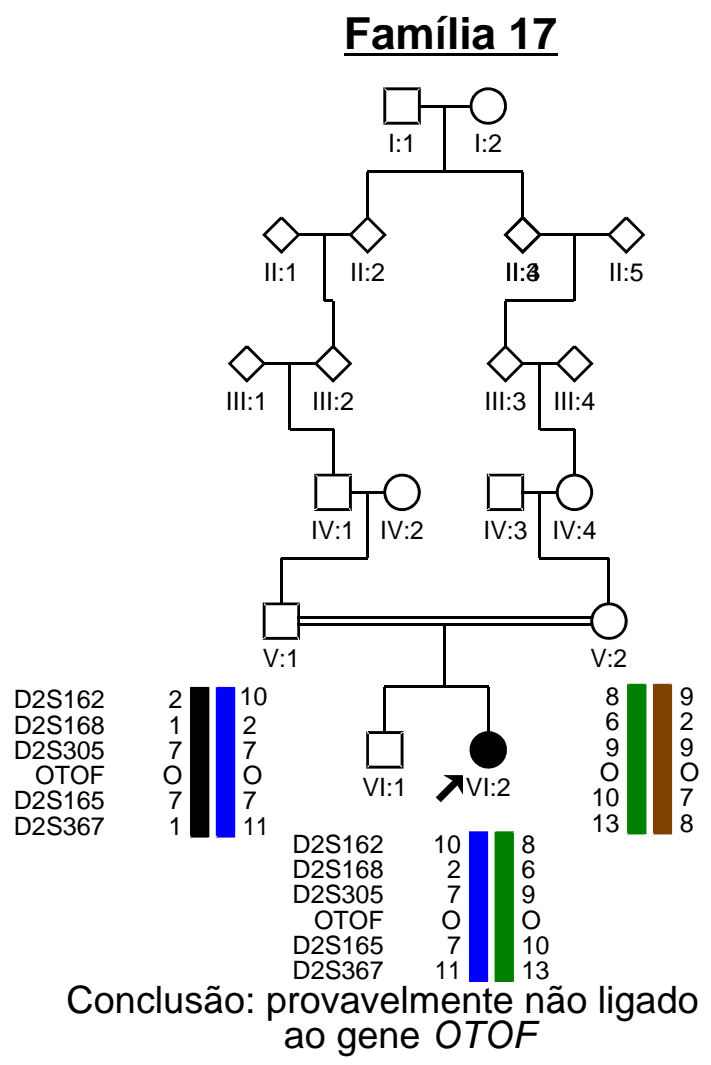




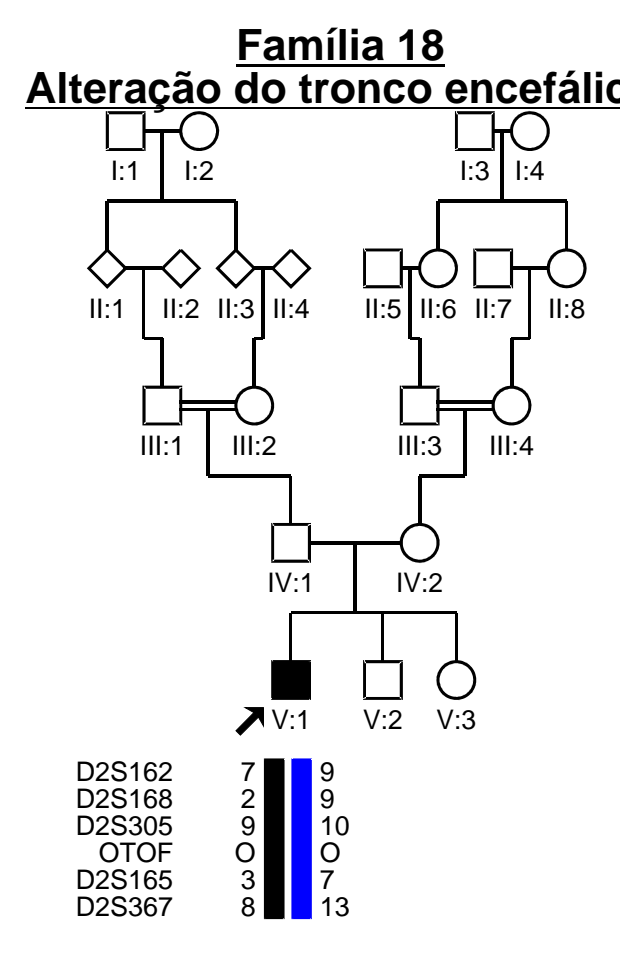

Conclusão: não conclusivo
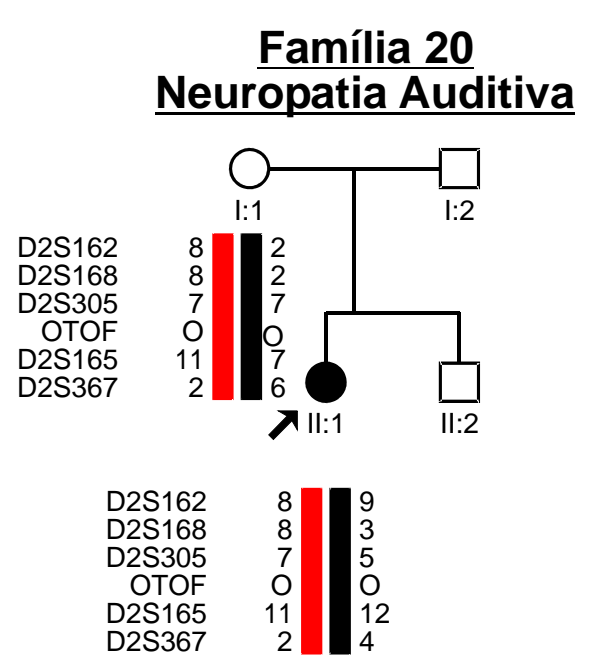

Conclusão: não conclusivo

\section{Família 19 \\ Alteração do tronco encefálico}
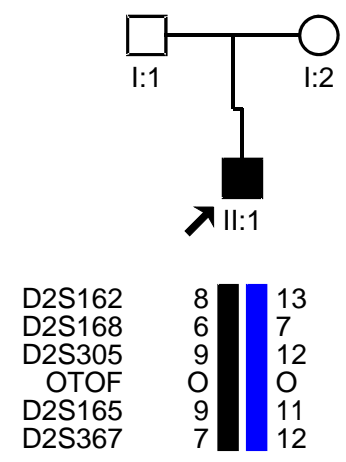

Conclusão: não conclusivo

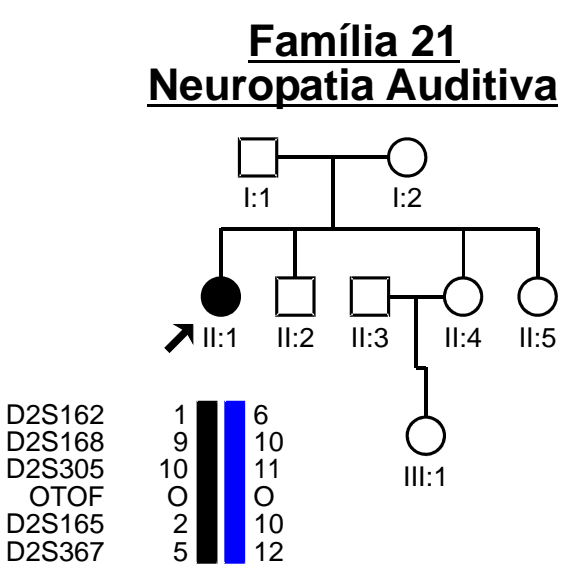




\section{Família 22}

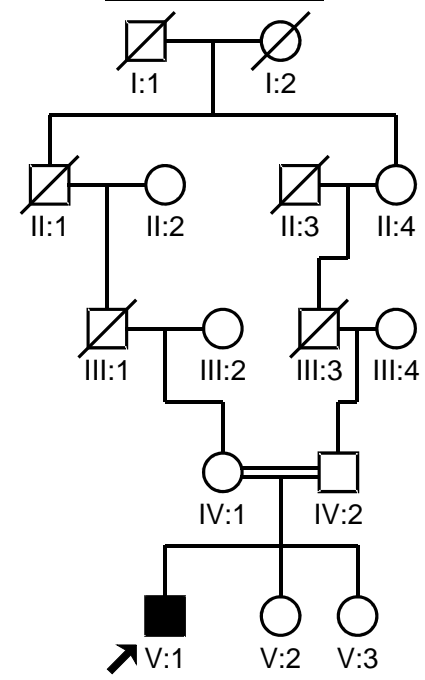

D2S162
D2S168
D2S305
OTOF
D2S165
D2S 367

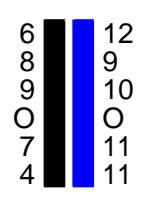

Conclusão: provavelmente não ligado ao gene OTOF

\section{Família 24}

Alteração do tronco encefálico
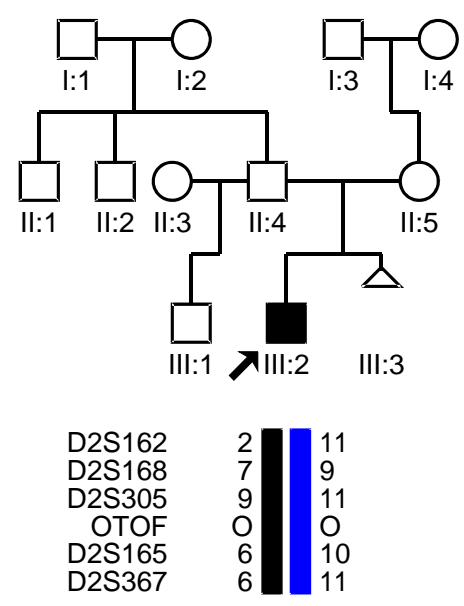

Conclusão: não conclusivo

\section{Família 23}
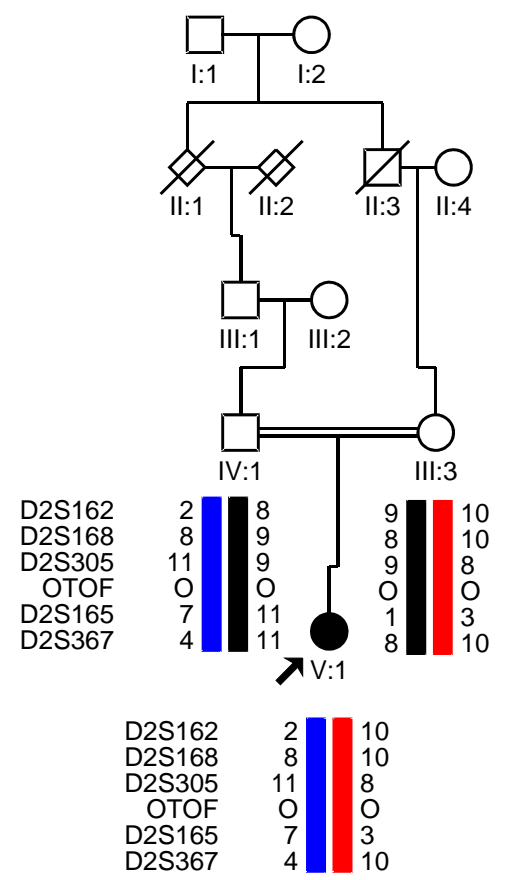

Conclusão: provavelmente não ligado ao gene OTOF

\section{Família 25}

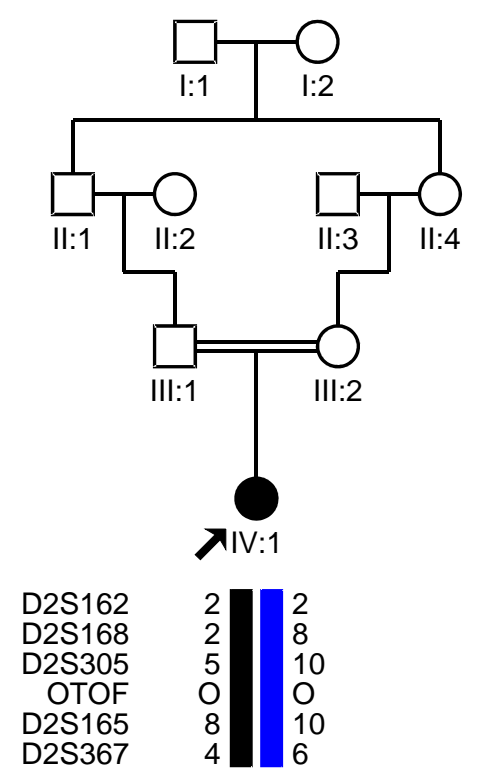

Conclusão: provavelmente não ligado ao gene OTOF 


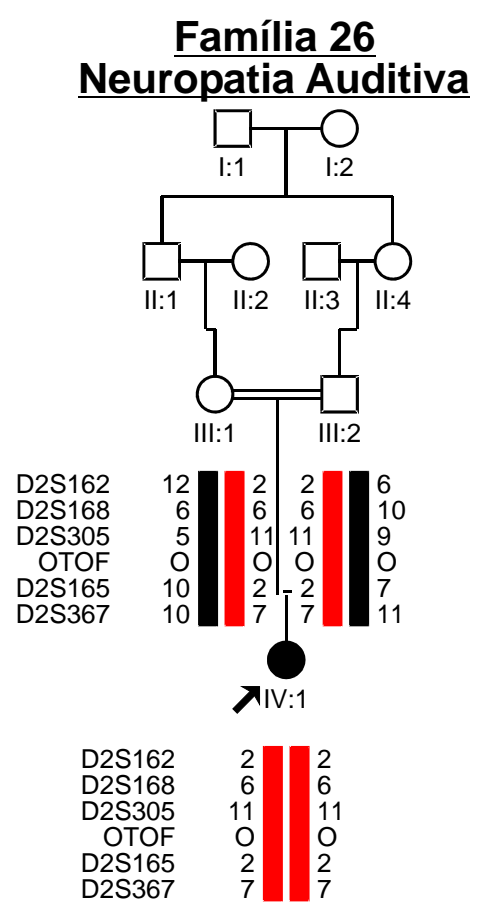

Conclusão: compatível com ligação ao gene OTOF

Família 28

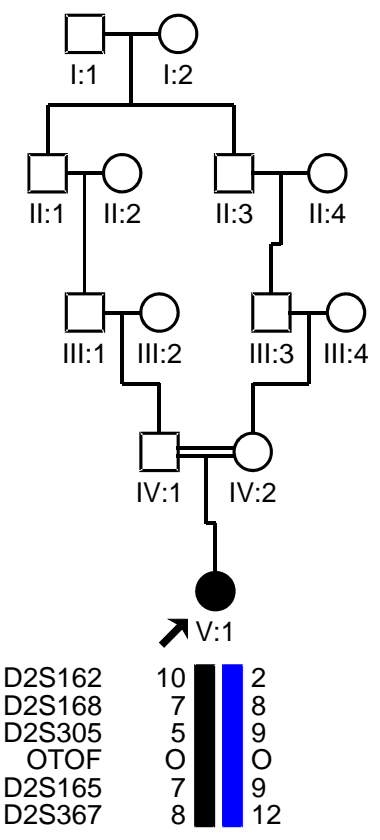

Conclusão: provavelmente não ligado ao gene OTOF

\section{Família 27}

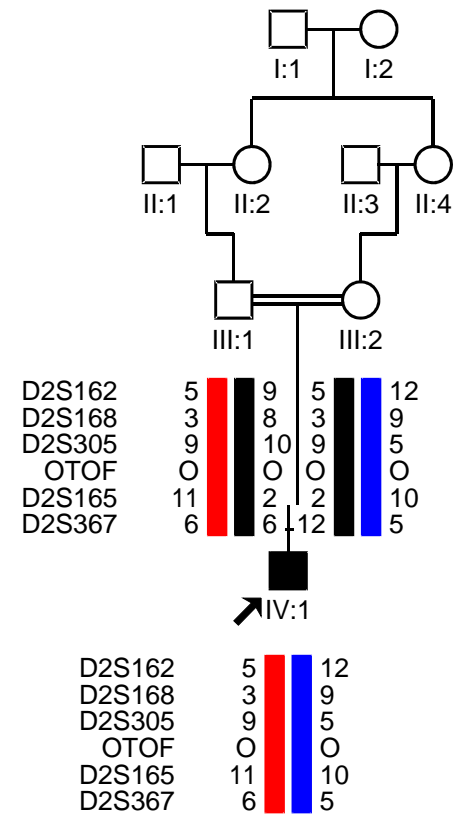

Conclusão: provavelmente não ligado ao gene OTOF

\section{Família 29}

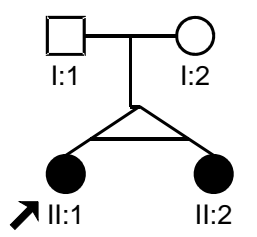

D2S162

D2S168

D2S305

OTOF

D2S165

D2S367

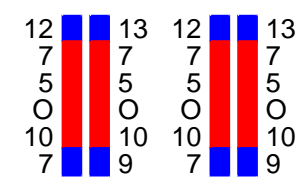

Conclusão: compatível com ligação ao gene OTOF 


\section{Família 30}

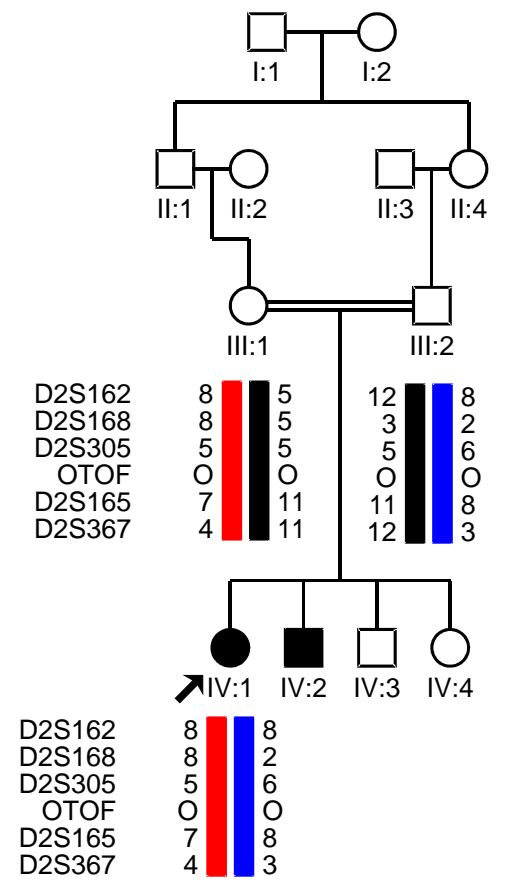

Conclusão: provavelmente não ligado ao gene OTOF

\section{Família 32}

Alteração do tronco encefálico

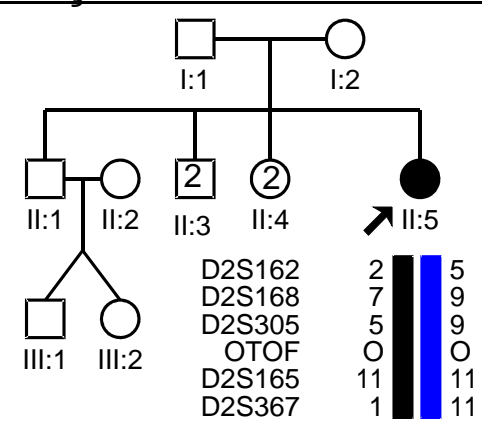

Conclusão: não conclusivo

\section{Família 31}

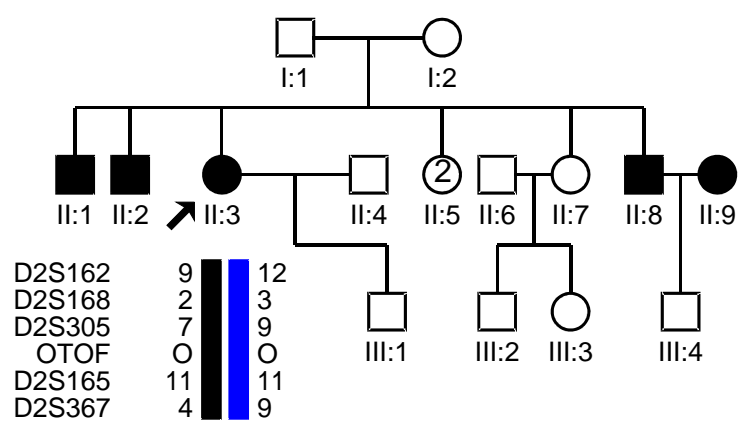

Conclusão: não conclusivo

Família 33

Neuropatia Auditiva

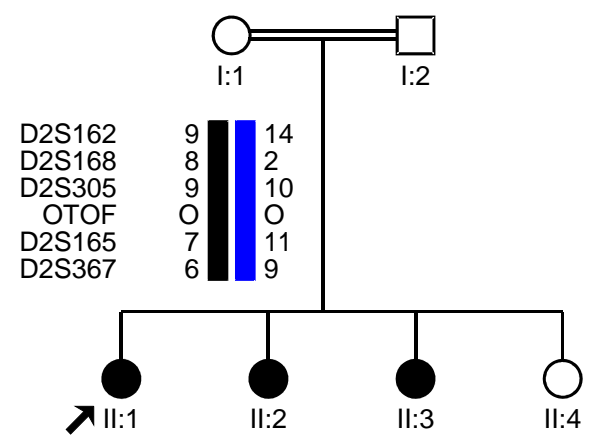

D2S162

D2S168

D2S305

OTOF

D2S165

D2S367
Conclusão: compatível com ligação ao gene OTOF 
Família 34

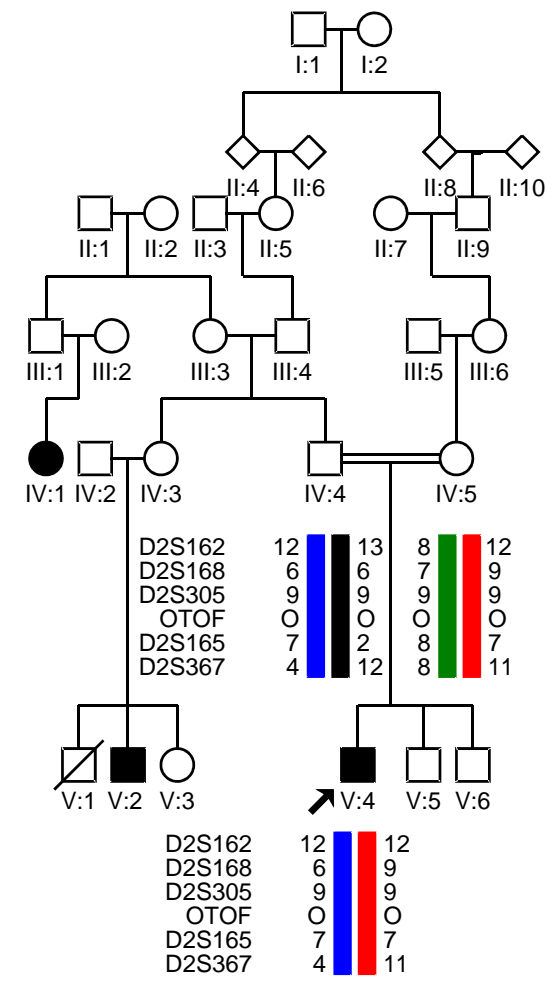

Conclusão: provavelmente não ligado ao gene OTOF

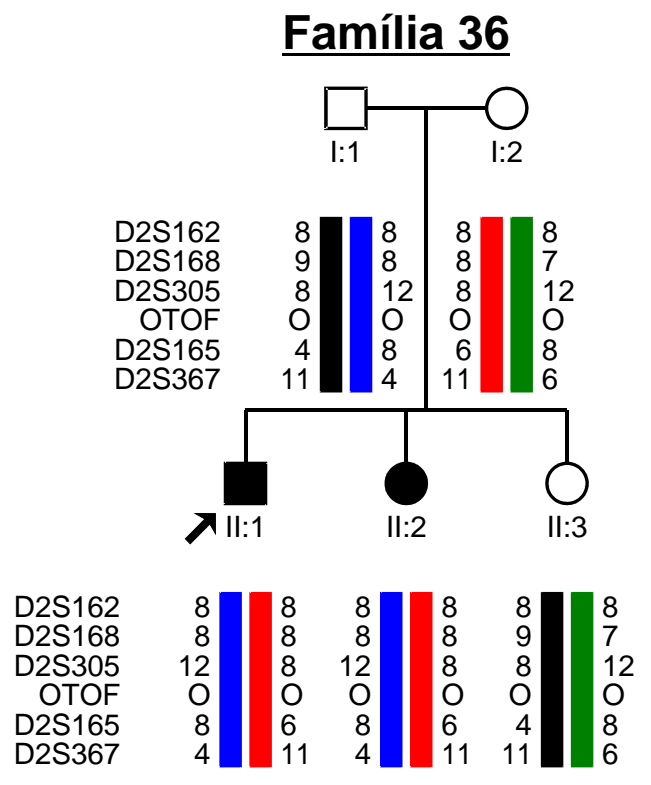

Conclusão: compatível com ligação ao gene OTOF

\section{Família 35}

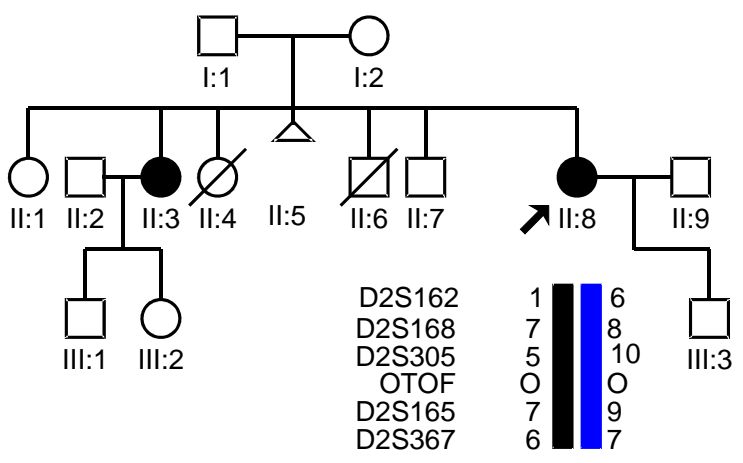

Conclusão: não conclusivo

Família 37

Neuropatia Auditiva
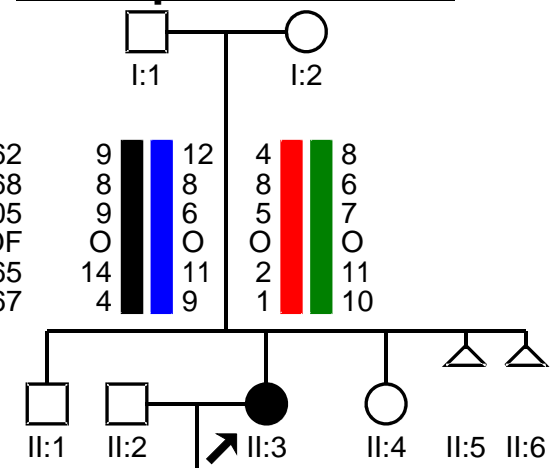

D2S162

D2S168

D2S305

OTOF

D2S165

D2S367

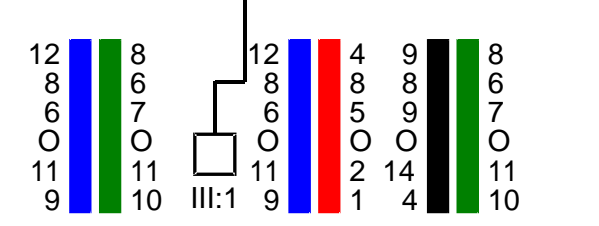

Conclusão: compatível com ligação ao gene OTOF 


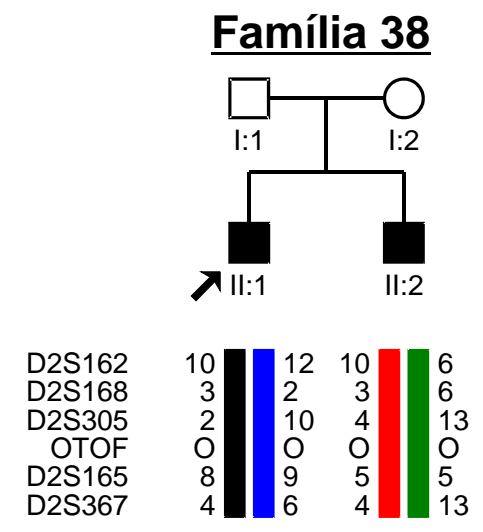

Conclusão: provavelmente não ligado ao gene OTOF

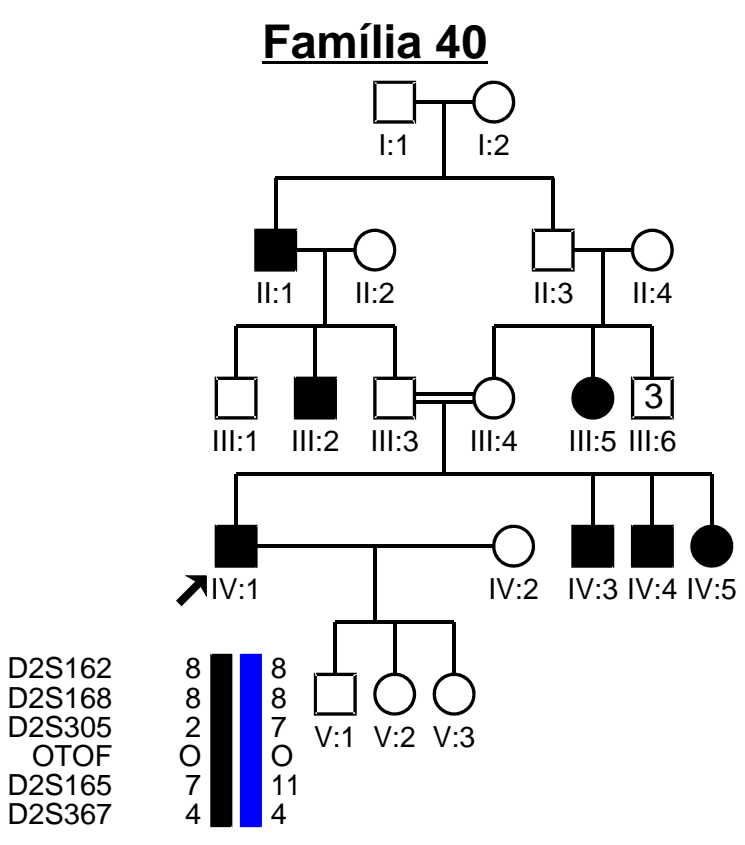

Conclusão: provavelmente não ligado ao gene OTOF

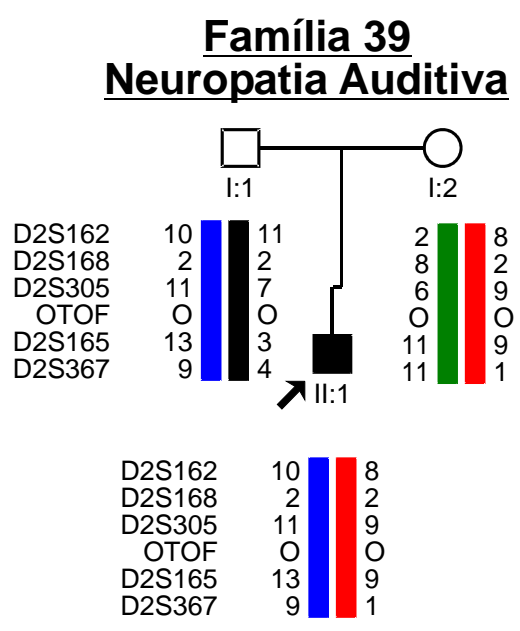

Conclusão: não conclusivo

\section{Família 41}
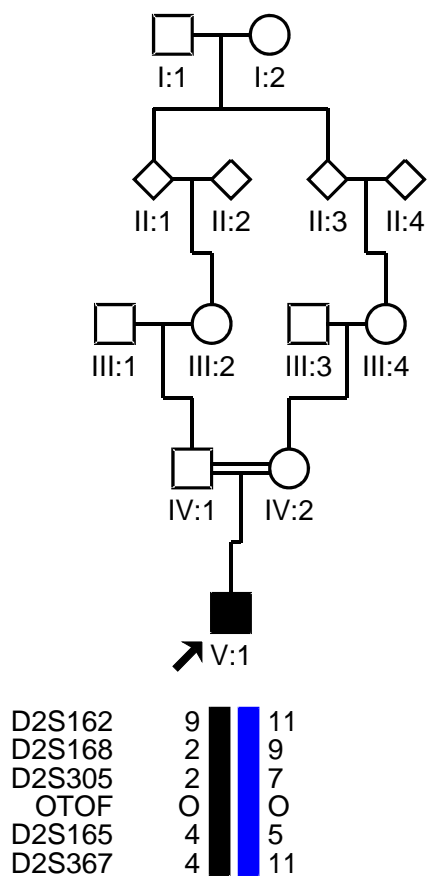

Conclusão: provavelmente não ligado ao gene OTOF 


\section{Família 42}
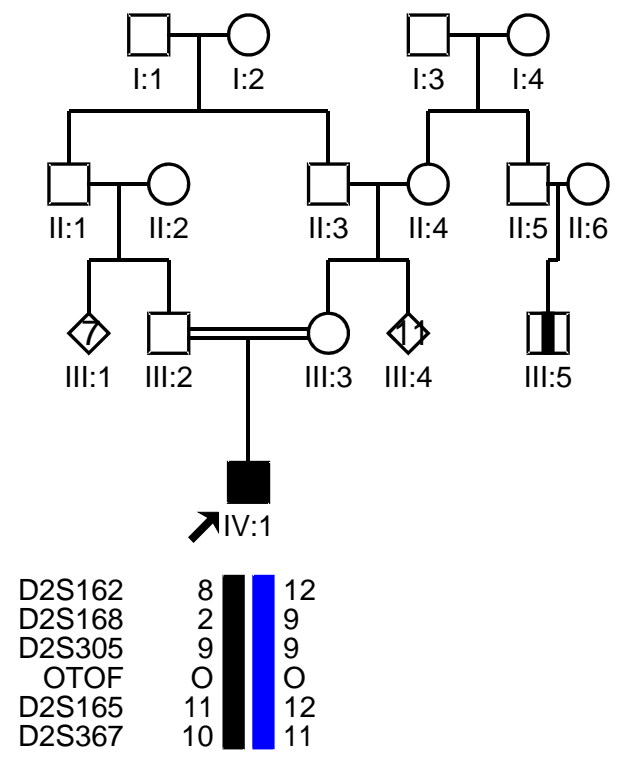

Conclusão: provavelmente não ligado ao gene OTOF

\section{Família 44}

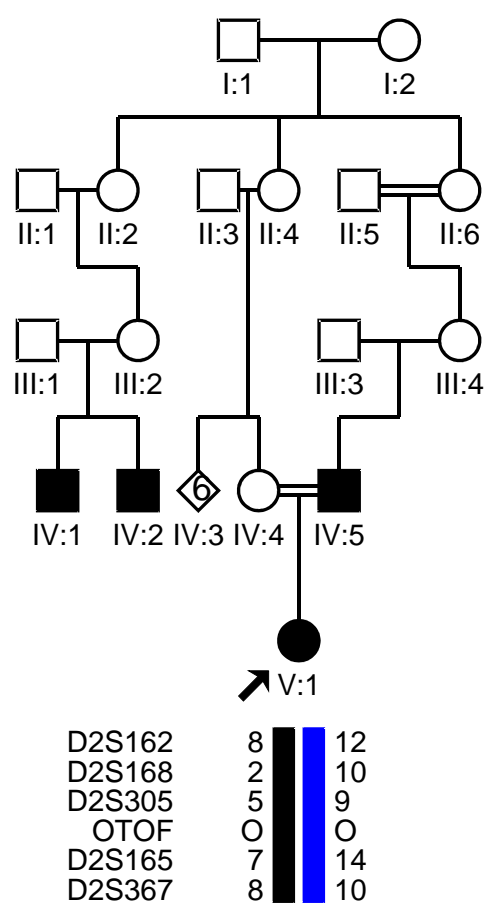

Conclusão: provavelmente não ligado ao gene OTOF

\section{Família 43}

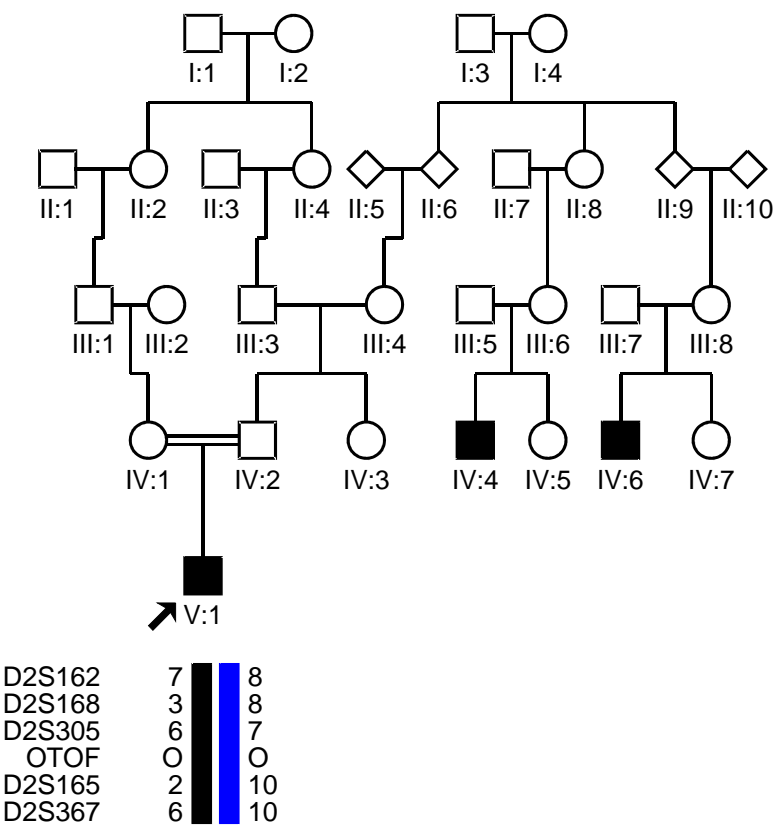

Conclusão: provavelmente não ligado ao gene OTOF

Família 45

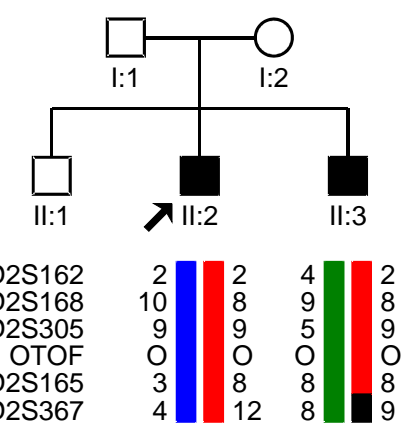

Conclusão: provavelmente não ligado ao gene OTOF 
Família 46

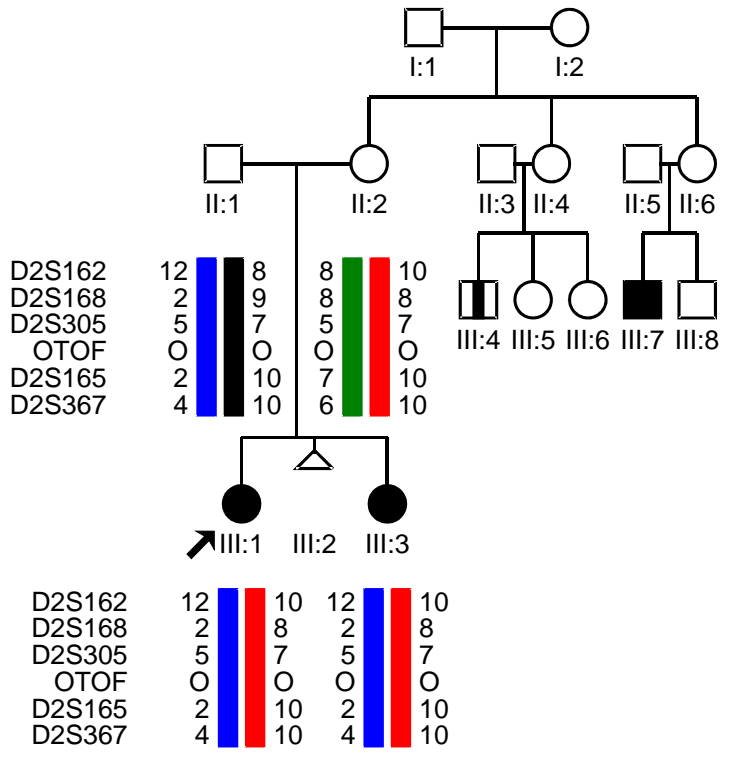

Conclusão: compatível com ligação ao gene OTOF

\section{Família 48}

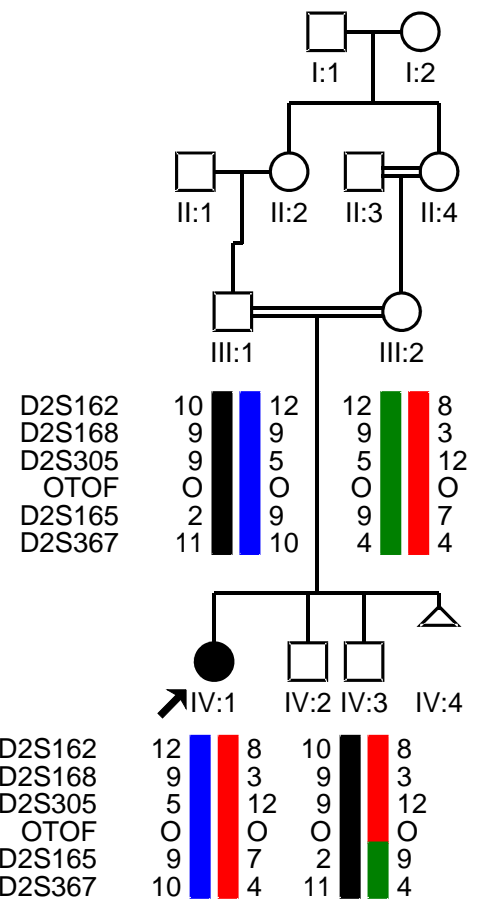

Conclusão: provavelmente não ligado ao gene OTOF
Família 47

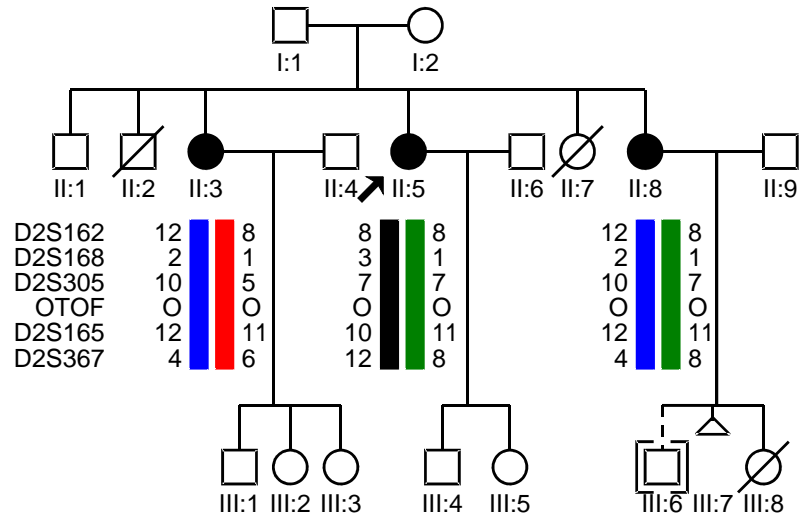

Conclusão: provavelmente não ligado ao gene OTOF

\section{Família 49}

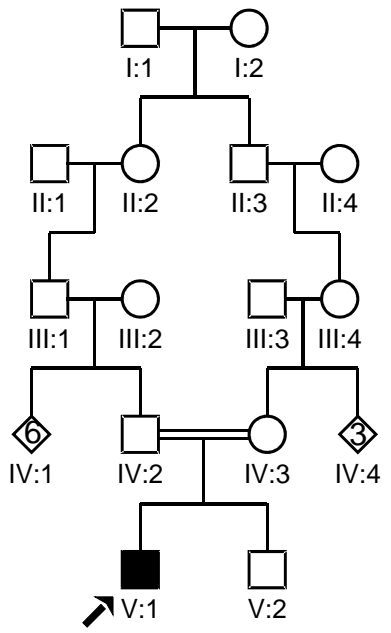

\begin{tabular}{rl|l} 
D2S162 & 8 & 4 \\
D2S168 & 1 \\
D2S305 & 9 \\
OTOF & 0 \\
D2S165 & 7 \\
D2S367 & 4 & 8 \\
11
\end{tabular}

Conclusão: provavelmente não ligado ao gene OTOF 


\section{Família 50}

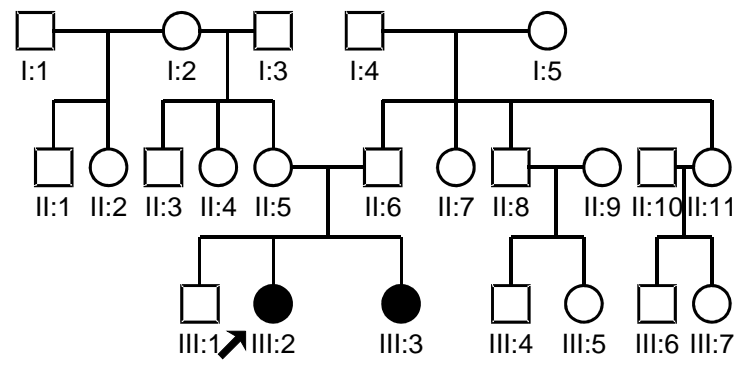

\begin{tabular}{rl|lr|l} 
D2S162 & 8 & 9 & 1 & 7 \\
D2S168 & 7 & 9 & 7 & 9 \\
D2S305 & 4 \\
OTOF & 0 & 5 & 9 & 5 \\
D2S165 & 9 & 0 & 0 \\
D2S367 & 4 & 10 & 9 & 9 \\
10 & 10
\end{tabular}

Conclusão: provavelmente não ligado ao gene OTOF

Família 52

Neuropatia Auditiva

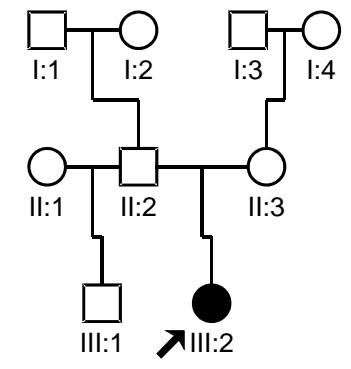

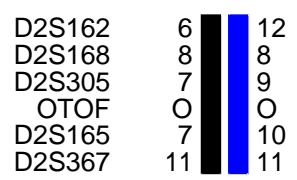

Conclusão: não conclusivo
Família 51

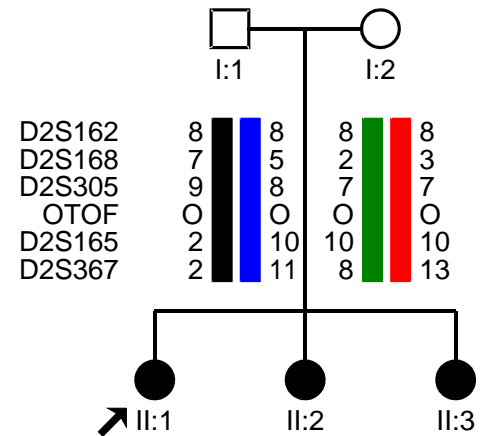

D2S162

D2S168

D2S305

OTOF

D2S165

D2S367

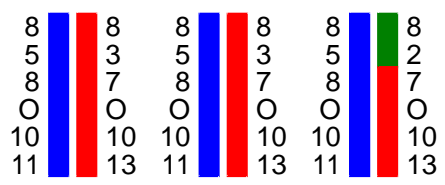

Conclusão: compatível com ligação ao gene OTOF

\section{Família 53}

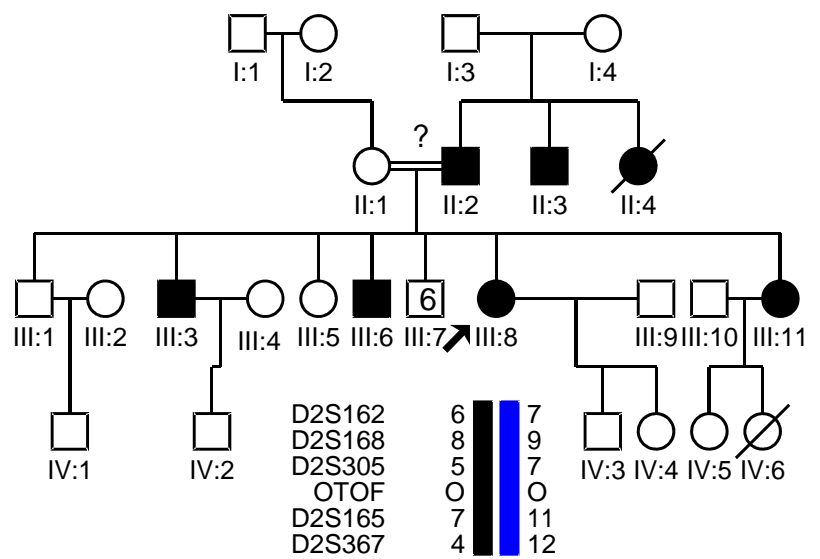


Família 54

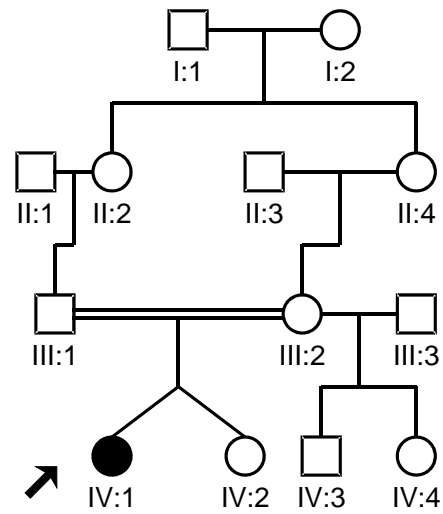

D2S162
D2S168
D2S305
OTOF
D2S165
D2S 367

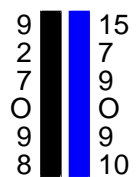

Família 55

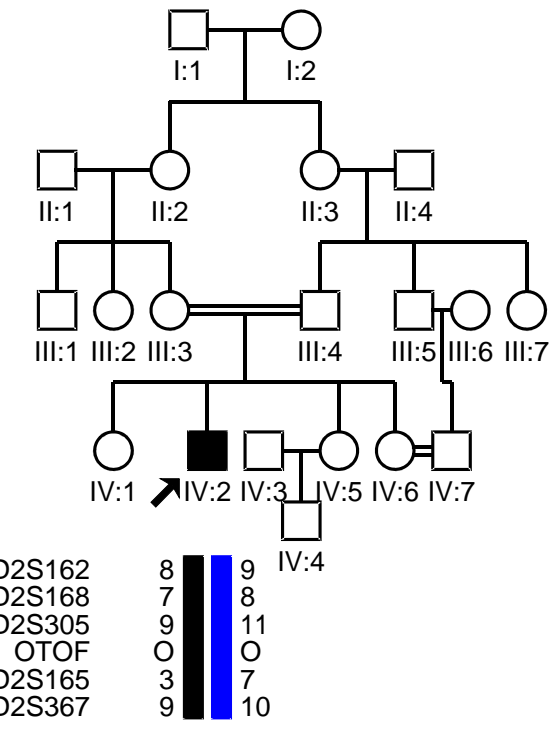

Conclusão: provavelmente não ligado ao gene OTOF

Conclusão: provavelmente não ligado ao gene OTOF

\section{Família 56}

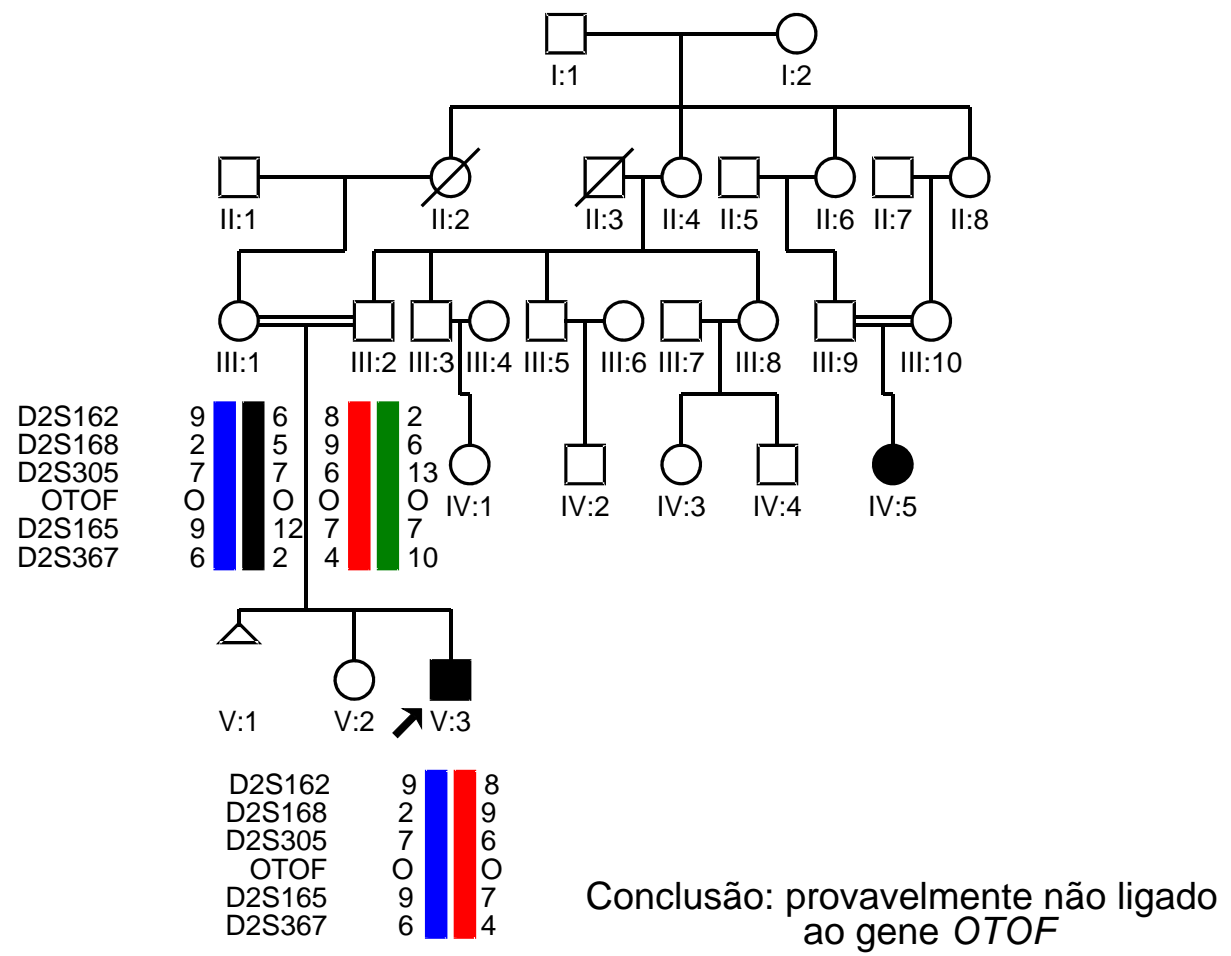


Família 57

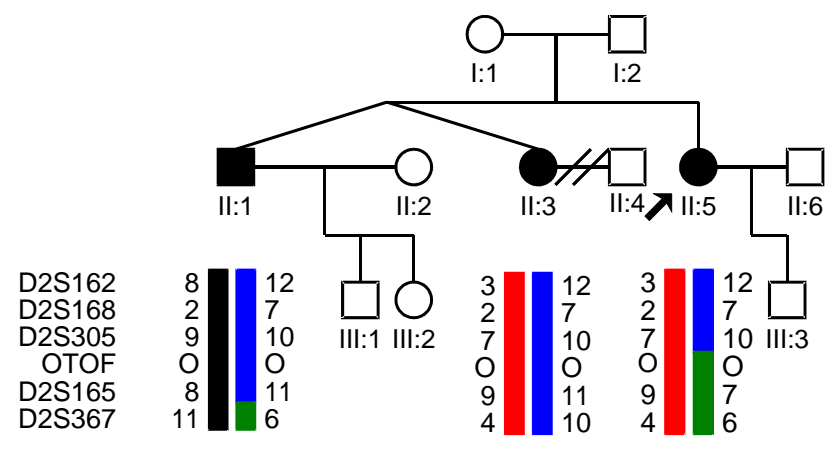

Conclusão: provavelmente não ligado ao gene OTOF

Família 59

Neuropatia Auditiva

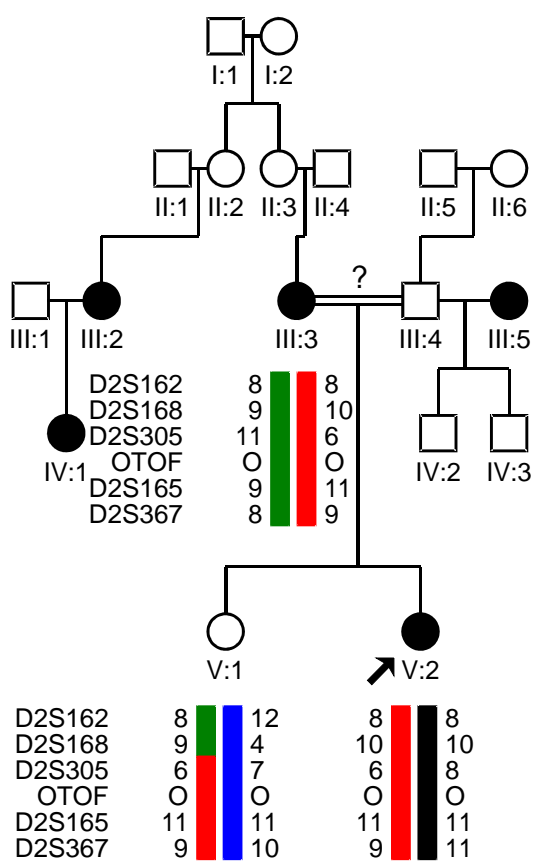

Conclusão: não conclusivo
Família 58

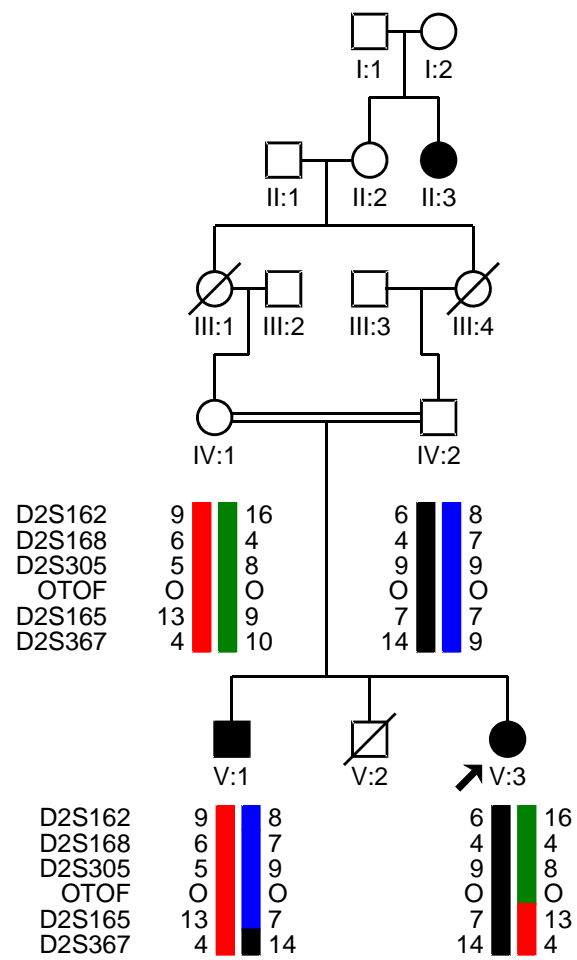

Conclusão: provavelmente não ligado ao gene OTOF

\section{Família 60}

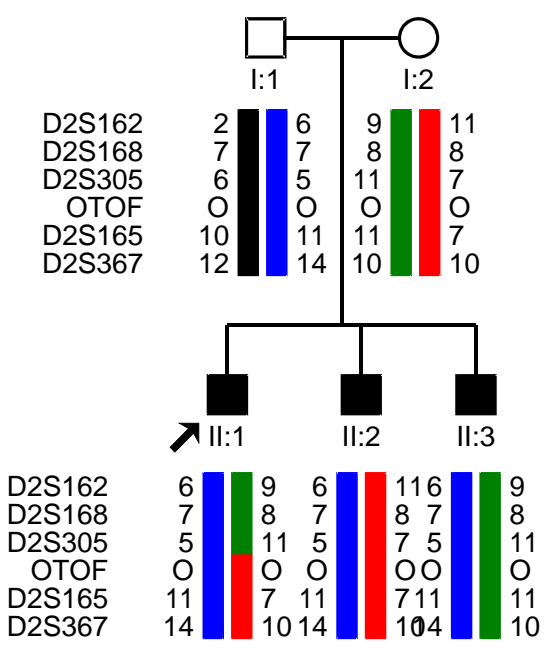

Conclusão: provavelmente não ligado ao gene OTOF 
Família 61
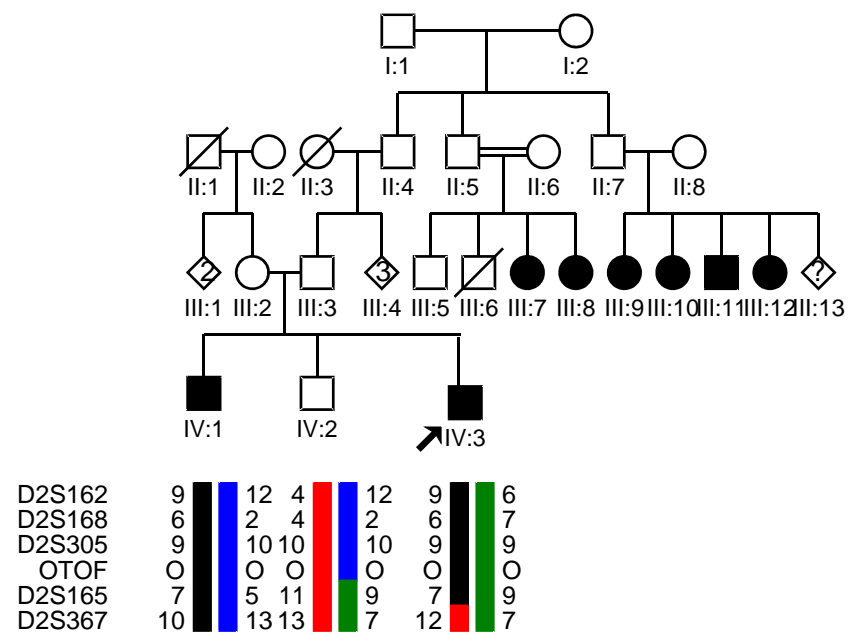

Conclusão: provavelmente não ligado ao gene OTOF

Família 63

Neuropatia Auditiva
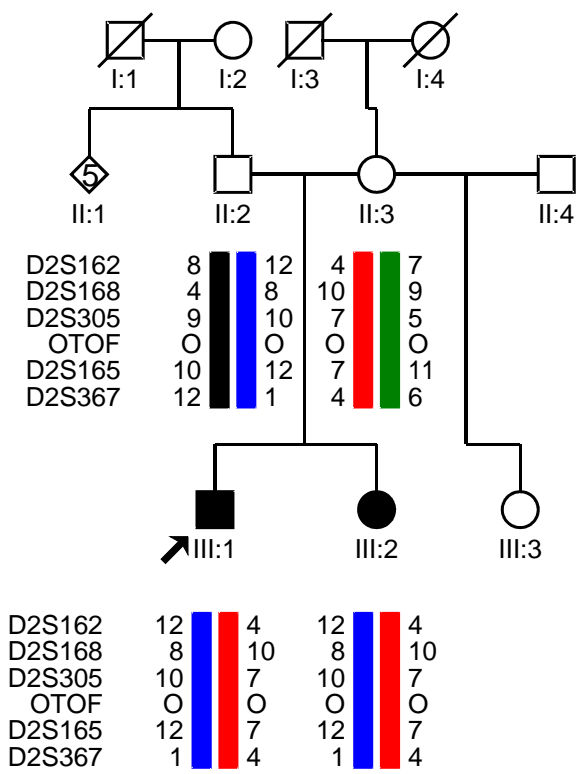

Conclusão: compatível com ligação ao gene OTOF

\section{Família 62}

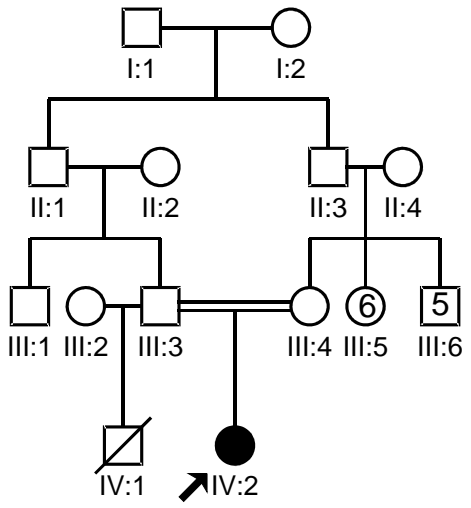

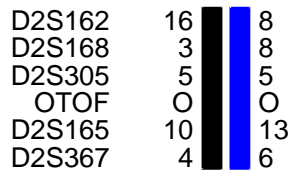

Conclusão: provavelmente não ligado ao gene OTOF

Família 64 Neuropatia Auditiva
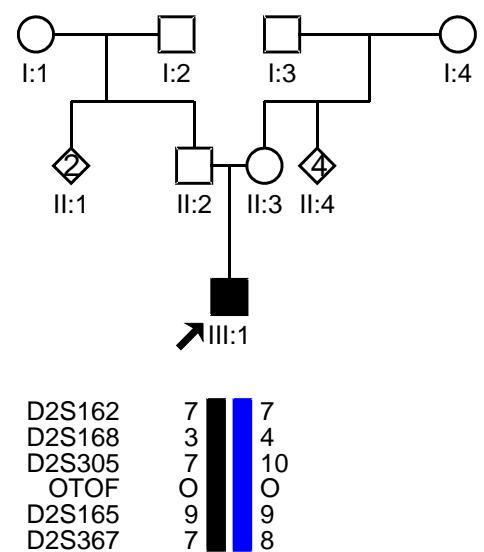

Conclusão: não conclusivo 
This document was created with Win2PDF available at http://www.win2pdf.com.

The unregistered version of Win2PDF is for evaluation or non-commercial use only. This page will not be added after purchasing Win2PDF. 